\title{
Preservation of muscle microcirculation in ischemia/reperfusion and transplantation
}

Citation for published version (APA):

Bastiaanse, J. (2006). Preservation of muscle microcirculation in ischemia/reperfusion and transplantation. [Doctoral Thesis, Maastricht University]. D\&L Graphics. https://doi.org/10.26481/dis.20060602jb

Document status and date:

Published: 01/01/2006

DOI:

10.26481/dis.20060602jb

Document Version:

Publisher's PDF, also known as Version of record

\section{Please check the document version of this publication:}

- A submitted manuscript is the version of the article upon submission and before peer-review. There can be important differences between the submitted version and the official published version of record.

People interested in the research are advised to contact the author for the final version of the publication, or visit the DOI to the publisher's website.

- The final author version and the galley proof are versions of the publication after peer review.

- The final published version features the final layout of the paper including the volume, issue and page numbers.

Link to publication

\footnotetext{
General rights rights.

- You may freely distribute the URL identifying the publication in the public portal. please follow below link for the End User Agreement:

www.umlib.nl/taverne-license

Take down policy

If you believe that this document breaches copyright please contact us at:

repository@maastrichtuniversity.nl

providing details and we will investigate your claim.
}

Copyright and moral rights for the publications made accessible in the public portal are retained by the authors and/or other copyright owners and it is a condition of accessing publications that users recognise and abide by the legal requirements associated with these

- Users may download and print one copy of any publication from the public portal for the purpose of private study or research.

- You may not further distribute the material or use it for any profit-making activity or commercial gain

If the publication is distributed under the terms of Article $25 \mathrm{fa}$ of the Dutch Copyright Act, indicated by the "Taverne" license above, 


\section{PRESERVATION OF MUSCLE MICROCIRCULATION in ischemia/reperfusion and transplantation}


Ter nagedachtenis aan mijn vader 


\title{
Preservation of muscle microcirculation in ischemia/reperfusion and transplantation
}

\author{
PROEFSCHRIFT \\ ter verkrijging van de graad van doctor \\ aan de Universiteit Maastricht, \\ op gezag van de Rector Magnificus, \\ Prof. mr. G.P.M.F. Mols \\ volgens het besluit van het College van Decanen, \\ in het openbaar te verdedigen \\ op vrijdag 2 juni 2006 om 12.00 uur
}

\author{
door \\ Jacqueline Bastiaanse \\ geboren op 20 maart 1971 \\ te Weert
}




\section{Promotores:}

Prof. dr. M. Kon (UMC Utrecht)

Prof. dr. W.D. Boeckx

Prof. dr. D.W. Slaaf

\section{Copromotor:}

Dr. M.G.A. oude Egbrink

\section{Beoordelingscommissie:}

Prof. dr. P.J.E.H.M. Kitslaar (voorzitter)

Prof. dr. M.P. van Dieijen-Visser

Prof. dr. G. Kootstra

Prof. dr. dr. N. Pallua (UK Aachen)

Prof. dr. G.J. Tangelder (VUMC Amsterdam)

\section{Ontwerp en Layout:}

D\&L Graphics

www.dlgraphics.nl

\section{Druk:}

SchrijenLippertzHuntjens

\section{Uitgeverij:}

D\&L Graphics

ISBN-10: 90-8590-015-8

ISBN-13: 978-90-8590-015-3

Financial support for publication of this thesis by AB Medical PRS BV, Baxter BV. Tramedico BV and Tricolast NV is gratefully acknowledged. 


\section{ConTEnTS}

\section{Chapter 1}

Introduction

\section{Chapter 2}

Transplantation and tissue preservation

\section{Chapter 3}

Effect of HTK on the microcirculation in the rat cremaster muscle during warm ischemia and reperfusion

\section{Chapter 4}

Effect of hypothermia and HTK on the microcirculation

in the rat cremaster muscle after ischemia

\section{Chapter 5}

Do preservation solutions protect rat cremaster microcirculation during ischemia and reperfusion?

\section{Chapter 6}

Preservation of rat cremaster muscle microcirculation

after prolonged cold storage and transplantation

\section{Chapter 7}

General discussion

\section{Chapter 8}

Summary

\section{Chapter 9}

Samenvatting

Dankwoord 



\section{CHAPTER 1 Introduction}

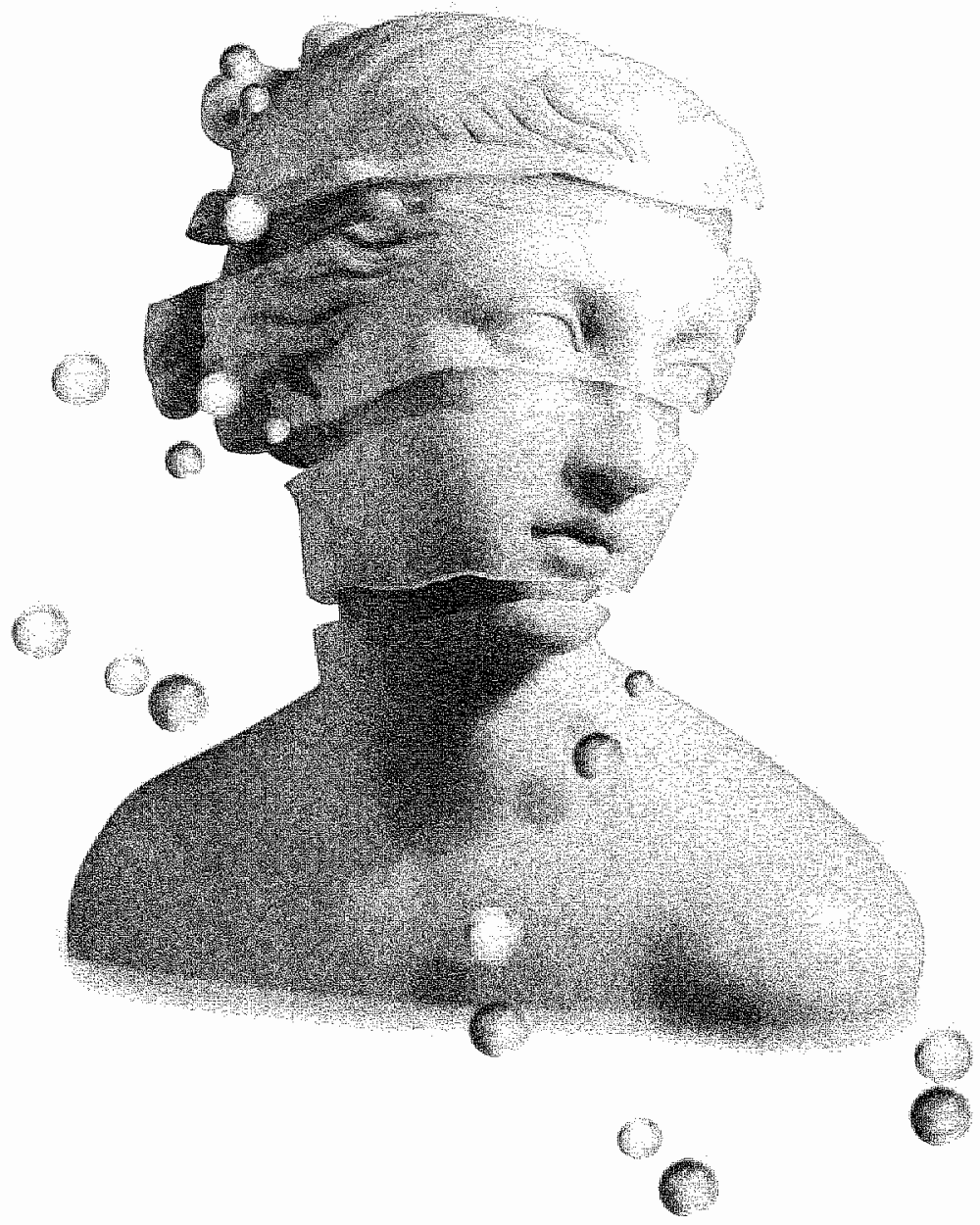




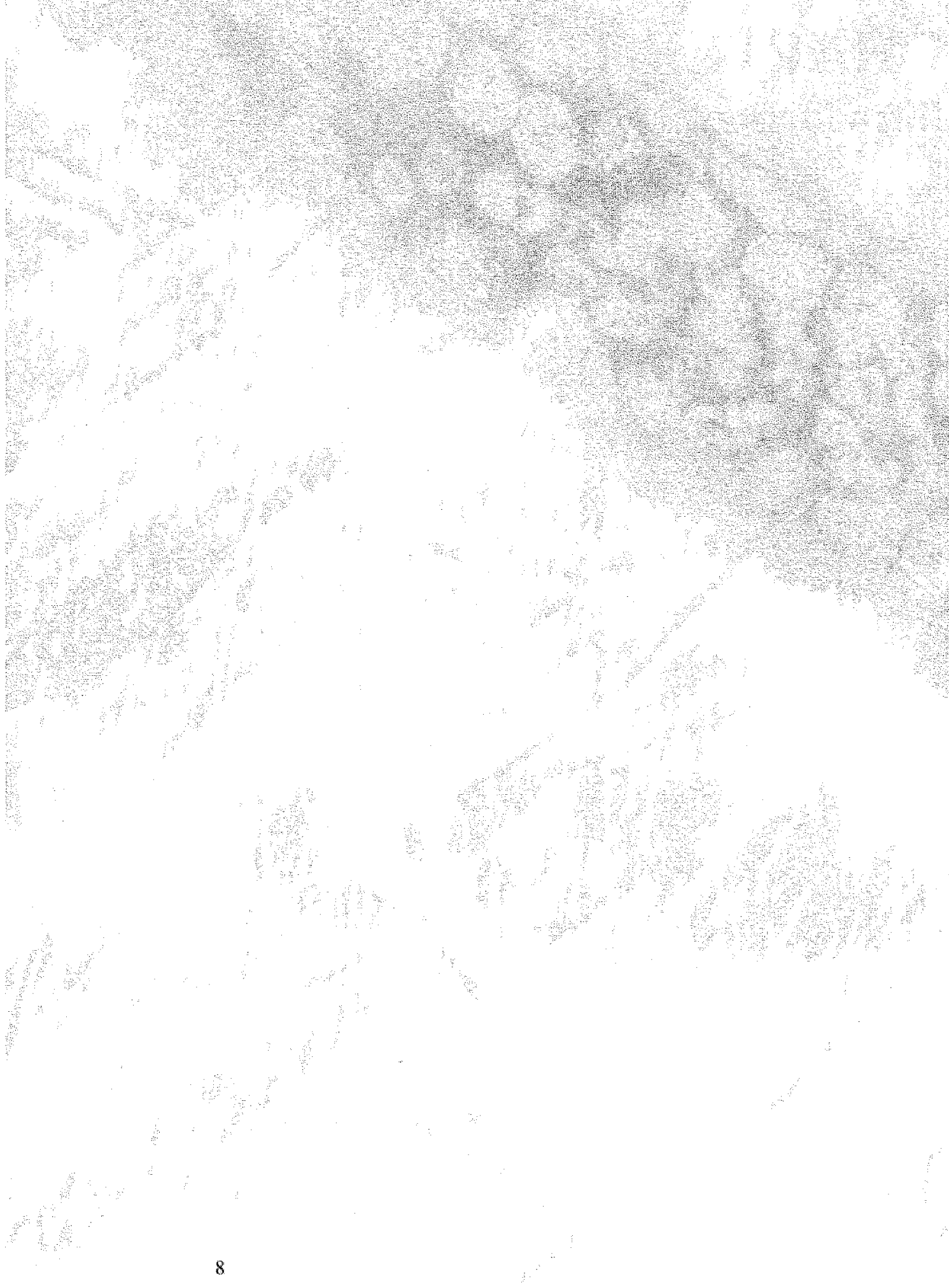


In reconstructive surgery, free flap transplantation has become a standard procedure for reconstruction of major defects such as massive burns, tumor resection, traumatic injuries, or congenital anomalies. Survival rate of these flaps is high $(95-98 \%))^{1-3}$ However, reconstruction of complex tissue defects often results in loss of its function. ${ }^{4,5}$ In addition, the morbidity of the donor site can be substantial. ${ }^{6}$ The results may be improved by replacing missing tissue with analogue cadaver tissue (identical tissue), so-called composite-tissue allografts (CTAs). ${ }^{7}$ CTAs are composed of various tissues such as skin, bone, muscle, fat, cartilage, nerves and blood vessels. CTAs would provide surgeons with homologous tissue without any donor-site limitation or morbidity in the recipient. Experimental data show that CTAs can become clinical reality. Hand and larynx transplantations have been performed clinically. ${ }^{8}$ Under appropriate immunosuppression, long-term survival of allografts has been achieved with good functional results. ${ }^{9,10}$ In spite of progress in operative technique and immunosuppresion, development of strategies to preserve tissues over longer periods has not been extended. In case of long ischemic intervals, grafts should be protected against deleterious effects of ischemia and reperfusion (see chapter 2 ).

Hypothermia and more specifically surface cooling, is currently the most important preservation method for storing solid organs in the ischemic periods during transplantation, because it decreases cellular metabolism and acidification. " Hypothermia was also shown to be beneficial for skeletal muscle. ${ }^{12}$ Morphology, metabolism and survival rate have been used as indicators of preservation. ${ }^{13-15}$ The use of preservation solutions for allograft preservation may improve the effects of cold storage. The morphological and biochemical effects of various preservation solutions have been investigated by several groups. ${ }^{16,17}$ of all CTA tissues, muscle tissue is most sensitive to ischemia. ${ }^{18}$ Muscle appears tolerant of ischemia for up to 3 hours: irreversible muscle cell damage starts after 3 hours of ischemia and is nearly complete at 6 hours. 18 In previous studies in our lab, contractility of isolated rat skeletal muscles was assessed after a period of cold storage at 4 and $10^{\circ} \mathrm{C}$ in various preservation solutions. It was found that contractility of isolated rat muscles was best preserved in Histidine-Tryptophan-KetoglutarateBretschneider solution (HTK) at $4^{\circ} \mathrm{C} .{ }^{19}$ Only a slight reduction in muscle function was found after 16 hours of cold storage in HTK with addition of antioxidants and 2,3-butanedione monoxime (BDM), which reduces intracellular calcium levels. ${ }^{20}$ The preservation strategy was based on diffusion $^{20}$ and, therefore, this preservation strategy might be limited to 
relatively small muscles onlly. ${ }^{19}$ In larger (human) muscles, cold storage by immersion in a preservation solution at $4^{\circ} \mathrm{C}$ may not be sufficient, because diffusion distances may be too large. Perfusion of the muscle with the preservation solution may improve its preservation during isolation, because diffusion distances are reduced dramatically and also because the vascular compartment may then be protected. After all, survival of transplanted tissue requires not only cellular protection, but also preservation of the vascular bed.

To enable development of optimal preservation methods for CTAs it is important to know the effect of coolling, as well as the effects of immersion of muscle tissue in and/or perfusion of muscle tissue with a preservation solution on the microvascular consequences of ischemia and reperfusion. Therefore, it was the general aim of the research described in this thesis to contribute to the development of a preservation strategy for muscle tissue, with special attention for preservation of the (micro)vascular compartment. In previous studies effects of colld storage and preservation solutions on contractility of muscle function were investigated. ${ }^{19}$ Effects on the microcirculation, however, were not assessed. Therefore, in the present study, the effects of (a) pre-ischemic perfusion with a preservation solution and (b) cooling on the microvascular consequences of ischemia and reperfusion or transplantation were examined in vivo in the rat cremaster muscle (Fig. 1). This muscle can be isolated on its vascular pedicle ${ }^{21}$ and
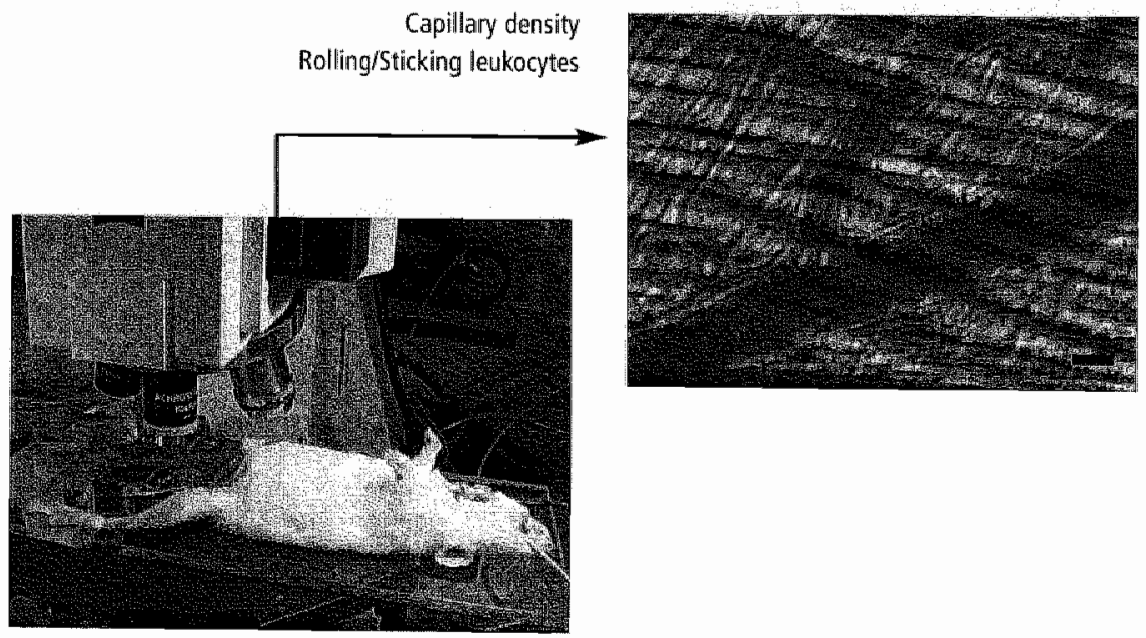

Fig. 1.1

Intravital microscopic setup used to visualize the cremaster muscle microcirculation in anesthetized rats. The microscopic images allow quantification of leukocyte-vessel wall interactions and capillary density in real-time. Bar indicates $20 \mu \mathrm{m}$. 
perfused with a preservation solution. ${ }^{22}$ In addition, the thin cremaster muscle of young rats allows clear visualization of microvessels and quantification of various microvascular parameters. The model was used to simulate clinical conditions of transplantation. . $^{23-25}$ Ischemia can be induced by placing a vascular clamp on the femoral artery (after isolation of the pedicle). ${ }^{22}$ Furthermore, the cremaster muscle can be harvested, stored in a preservation solution, and microsurgically transplanted.

As an introduction to the experimental chapters, chapter 2 of this thesis provides an overview of the literature on transplantation, ischemia/ reperfusion injury, preservations solutions, and relevant methods from microcirculation research.

Chapter 3 describes the effects on the microcirculation of pre-ischemic perfusion with the preservation solution HTK followed by 4 hours of warm ischemia and subsequent reperfusion in the rat cremaster model.

Because the period of 4 hours of warm ischemia seemed too short to assess the beneficial effects, if any, of the preservation solution HTK on the rat cremaster microcirculation, the ischemic period was extended to 6 hours in the study described in chapter 4 . In this study, the effects of cooling on ischemia/reperfusion injury were investigated as well.

In chapter 5, the effects of pre-ischemic perfusion with Celsior solution were compared with those of HTK, in order to assess the effects of the presence of radical scavengers in the preservation solution on preservation of the microvasculature. We hypothesized that the relatively high concentration of radical scavengers in the preservation solution Celsior would improve the results of HTK in preserving muscle tissue during ischemia and reperfusion.

In the last part of our study, described in chapter 6, we developed a transplantation model of the rat cremaster muscle, and determined the microvascular consequences of transplantation after direct transplantation and after a prolonged period of 8 or 24 hours of cold storage in HTK solution.

The thesis ends with a general discussion in chapter 7. 


\section{REFERENCES}

1. Kerrigan CL, Stotland MA. Ischemia reperfusion injury: a review. Microstugeny: $1993 ; 14: 165-75$.

2. Genden EM, Rinaldo A, Suarez C. Wei WI, Bradley PJ, Ferlito A. Complications of free flap transfers for head and neck reconstruction following cancer resection. Oral Oncol 2004:40:979-84.

3. Chien W, Varvares MA, Hadlock T, Cheney M, Deschler DG. Effects of aspirit and low-dose heparin in head and neck reconstruction using microvascular free flaps. Larymgoscope. 2005:115:973-6.

4. Chen CH. Lin GT, Fu YC, Wu CFi, Shieh TY, Huang IY, Shen YS, Chen CM. Comparison of deltopectoralis flap and free radial forearm flap in reconstruction after oral cancer ablation. Oral Oncol. 2005;41:602-6.

5. Lewin JS, Barringer DA, May AH, Gillenwater AM, Amold KA, Roberts DB, Yu P. Functional outcomes after circumferential pharyngoesophageal reconstruction. Laryngoscope. 2005;115:1266-71.

6. Lipa JE, Novak CB, Binlıammer PA. Patient-reported donor-site morbidity following anterolateral thigh free flaps. J Reconstr Microsurg. 2005;21:365-70.

7. Llull R. An open proposal for clinical composite tissue allotransplantation. Thansplamt Proc. 1998:30:2692-6; discussion 2697-703.

8. Petit F, Minns AB, Dubernard JM, Hettiaratchy S, Lee WP. Composite tissue allotransplantation and reconstructive surgery: first clinical applications. Am Surg. 2003;237:19-25.

9. Cendales L, Hardy MA. Immunologic considerations in composite tissue transplantation: overview. Microsurgery. 2000;20:412-9.

10. Siemionow M, Ortak T, Izycki D, Oke R, Cunningham B, Prajapati R, Zins JE. Induction of tolerance in composite-tissue allografts. Transplantation, 2002;74:1211-7.

11. Belzer FO, Southard JH. Principles of solid-organ preservation by cold storage. Transplantation. 1988:45:673-6.

12. Brunelli GA, Brunelli GR. Tissue changes at different periods of ischemia. Int Angiol. 1995:14:253-63.

13. Sumimoto R, Dohi K, Urushihara T, Jamieson NV, Ito H, Sumimoto K, Fukuda Y. An examination of the effects of solutions containing histidine and lactobionate for heart, pancreas, and liver preservation in the rat. Transphanation. 1992:53:1206-10.

14. Kwon KY, Park CK. Cho CH, Cho WH, Chang ES. Ultrastructural evaluation of preservation and reperfusion effects of low potassium dextran glucose solution in canine allograft lungs. Transplant Proc. 2000;32:2439-41.

15. Li XL, Man K, Liu YF, Lee TK, Tsui SH, Lau CK, Lo CM, Fan ST, Insulin in University of Wisconsin solution exacerbates the ischemic injury and decreases the graft survival rate in rat liver transplantation. Transplantation. 2003;76:44-9. 
16. Defino VD, Gray DW, Leow CK, Shimizu S. Ferguson DJ, Moris PI. A comparison of fou solutions for cold storage of panceatic islets. Tratsplanarion. 1993;56:132530.

17. Nardo B, Beltempo P, Bertelli R, Montalti R, Vwarell M, Urbani L, Masetti M, Di Naro $A$ Filipponi F, Mosca F, Phna $A$, Cavallari $A$. Comparison of Celsior and University of Wisconsin solutions in cold preservation of liver from octogenarian dionors Transplani Proc. 2004:36:5234.

18. Blaisdell FW. The pathophysiology of skeletal muscle ischemia and the reperfusion syndrome: a rewiew Cardiowasc Surg. 2002; 10:620-30.

19. varn der Hejden EP, Kroese AB, Stremel RW, Bar PR, Kon M. Werker PM. Contractile properties of rat skeletal muscles following storage at 4 degrees $\mathrm{C}$. Chin Sci (Lond). $1999: 97: 45-57$.

20. van der Hejjden EP, Kroese AB, Werker PM, de With MC, de Smet M, Kon M, Bar DP. Improving the preservation of isolated rat skeletal muscles stored for 16 hours at 4 degrees C. Transplantation. 2000;69:1310-22.

21. Anderson GL. Acland RD, Siemionow M. MCCabe SJ. Vascular isolation of the rat. cremaster muscle. Microwasc Res. $1988,36: 56-63$.

22. Franken RJ, Werker PM, Peter FW, Overgoor ML, Wang WZ, Anderson GL, Schuschke DA, Banis JC, Jr, Kon M, Barker JH. Microcirculatory changes following different temperature washouts in a free tlap model. Microsurgery, 1999:19:214-22.

23. Siemionow M, Wang WZ, Anderson G, Firrell J. Leakocyte-endothelial interaction and capillary perfusion in ischemia/reperfusion of the rat cremaster muscle. Mrovacinc Endothelum Lymplatics. 1991;7:183-97.

24. Wang WZ, Anderson G, Maldonado C, Barker J. Attenuation of vasospasm and capilary no-reflow by ischenic preconditioning in skeletal muscle. Microsargery. $1996 ; 17: 324-9$.

25. Alper M, Ozek C, Erden O, Denk M, Colen LB, Prewit R. Effects of University of Wisconsin and Iactated Ringer's solutions to ischemia-reperfusion injury in isolated cremaster flap. Mrowsugery. 2002,22:69-73. 
. 


\section{CHAPTER 2 Transplantation and tissue preservation}

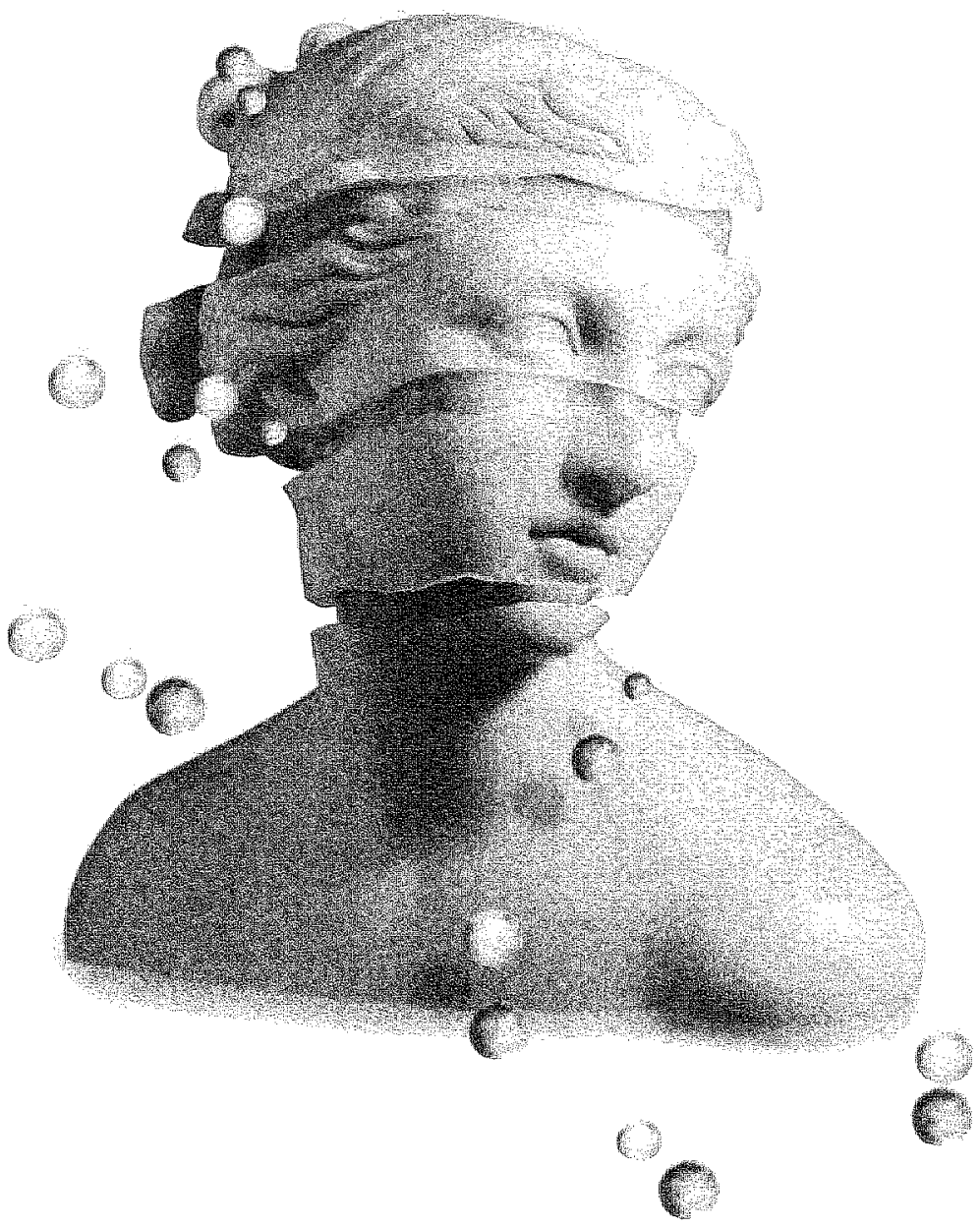





\subsection{INTRODUCTION}

In the twentieth century microsurgery was developed by combining techniques of vascular surgery with an operating microscope, development of fine instruments, fine suture material and new operative strategy and techniques; it was a culmination of achievements in vascular surgery. In 1902, Alexis Carrel developed the vascular anastomosis technique, ' which today is stil» applied with only minor modifications. This provided the foundation for clinical transplantation and cardiovascular surgery. At that time, shape and size of small blood vessels $(<3 \mathrm{~mm})$ was a great problem. Trauma to blood vessel walls in any form, including suturing, precipitated the clotting process. Furthermore, organ or tissue preservation was another problem. How could organs or tissues be kept viable while operating on the vessels serving them? ${ }^{2}$

In 1908, Carrel (and Guthrie) devised methods for transplantation of whole organs. In addition, Carrel (and Lindbergh) pioneered many preservation techniques. For example, organs were perfused with normothermic, oxygenated serum at supraphysiological volumes and exhibited viability for several days ${ }^{2}$ During the First World War most vascular injuries were still managed by ligation, which often resulted in amputation. Results improved with establishment of antibiotics in clinical. surgery. However, small vessels $(<3 \mathrm{~mm})$ were still beyond the scope of routine practice. In 1960, vascular surgeon Jules Jacobson performed the first anastomosis in vessels of $3 \mathrm{~mm}$ or smaller. ${ }^{3}$ Daniel and Taylor performed the first series of free tissue transfers. ${ }^{4}$

Owing to the development of microsurgery, plastic surgeons were no longer limited to local pedicled flaps for the reconstruction of complex defects. 5

Microvascular transplantation, also known as free flap or free tissue transfer, involves transplanting of nonessential donor tissue from one part of the body to another to restore form or function. The transplanted tissue must have a single blood supply with an artery and a draining vein that are both adequate to sustain circulation. The free flap is anastomosed to recipient vessels in or near the area to be reconstructed and blood flow is re-established. Free flaps are used in the reconstruction of complex wounds where compound tissue loss has occurred, in the reconstruction of congenital deficiencies or chronic wounds, in tumor ablation reconstruction, and in the reconstruction after trauma.

Microvascular surgical procedures, including free tissue transfers, involve an inherent period of ischemia during surgery. ${ }^{6}$ When the flap is isolated on its vascular pedicle (flap elevation, flap harvesting), ischemia 
begins whenever the surgeon transects the vascular pedicle. Flap inset and vascular anastomoses are performed during the ischemic period. Flap loss almost never becomes evident in this period. ${ }^{6}$ In most cases, normothermic ischemia is tolerated well. Under normal conditions, the ischemic period lasts from 1.5-3 hours. In complex cases or in complications, the ischemic period may be longer. ${ }^{6}$

When anastomoses are completed and microvascular clamps removed, the period of flap reperfusion starts. Restoration of blood flow will reverse the transient derangement of the ischemic period. However, although restoration of blood flow is necessary for tissue survival, the tissue may get damaged when it is reperfused with oxygenated blood (see $\$ 2.3$ ). ${ }^{7}$ During the past decade, experimental studies have provided convincing evidence that dysfunction of the microcirculation plays a pivotal role in manifestation of tissue injury in ischemia-reperfusion and free flap transfer. ${ }^{8}$ Microcirculatory derangements are characterized by capillary perfusion failure and inflammation associated leukocyte recruitment. ${ }^{9}$ The study of mechanisms of injury requires experimental in vivo models.

At present, survival rate of free flaps in clinical practice is $95-98 \% .^{10,11}$ Functional outcome of reconstruction of complex defects, however, is suboptimal. ${ }^{12-15}$ In addition, morbidity of the donor site can be substantial. ${ }^{16}$ These results may be improved by replacing missing tissue with analogue cadaver tissue, the so-called composite tissue allografts (CTAs). ${ }^{17}$ CTAs can be composed of various tissues such as skin, bone, muscle, fat, cartilage, nerve and blood vessels. CTAs would provide surgeons with homologous tissue without any donor-site limitation or morbidity in the recipient. Experimental data indicate that CTAs can become clinical reality. ${ }^{17,18}$ Hand and larynx transplantations have been performed clinically. ${ }^{19-21}$ In these situations, prolonged ischemic periods occur. Under appropriate immunosuppression, long-term survival of allografts has been achieved with good functional results. ${ }^{22}$ In spite of progress in operative technique and immunosuppresion, devellopment of preservation strategies for CTAs has not been extended. In case of long ischemic intervals, grafts should be protected against deleterious effects of ischemia and reperfusion. There is, at present, no better preservation strategy for CTAs than surface cooling. In a limited number of studies the effect of preservation solutions on allograft preservation has been investigated using morphological and biochemical changes as markers. ${ }^{23-27}$ In other studies effects of cold storage and preservation solutions on muscle function were investigated. ${ }^{28}$ Effects on the microcirculation, however, 
were not assessed. Because histological techniques will not reveal impaired function of the microcirculation ${ }^{29}$ and seem less sensitive for detection of ischemia/reperfusion injury, effects of various preservation strategies should preferably be investigated with techniques that allow functional assessment of this part of the circulation such as intravital microscopy.

In this chapter, literature on tissue (free flap) transplantation will be reviewed, including information on currently used preservation strategies. In addition, current knowledge on mechanisms causing the effects of ischemia and reperfusion is summarized, with special attention for consequences at the level of the microcirculation and for experimental models in which these consequences can be examined.

\subsection{TRANSPLANTATION AND PRESERVATION}

\subsubsection{Organ transplantation}

The Scottish surgeon John Hunter (1728-1793) is known as the father of experimental surgery. Several of his experimental procedures involved transplantation. ${ }^{30,31}$ The first well-documented report of successful free autografts of skin was in 1804 by Baronio. ${ }^{32,33}$ In 1822, Bunger reported successful use of a free full-thickness human skin autograft. ${ }^{32,34}$ In $\| 886$, Thiersch described the resurfacing of wounds with large sheets of splitthickness skin. ${ }^{32}$ From 1925 to 1945 , corneal transplantation emerged as a widespread and generally accepted practice. ${ }^{35}$ Although important developments in the second half of the $19^{\text {th }}$ century (such as use of general anesthetics and antiseptic surgery) were important in progress of transplantation, organ replacement is a development of the $20^{\text {th }}$ century. Transplantation of vascularized organs became possible when techniques for vascular anastomosis were developed. Ullmann reported the first longfunctioning renal transplant in 1902. ${ }^{36}$ Between 1902 and 1912, Carrel and Guthrie performed large series of animal transplantation experiments. 1,37,38 With the introduction of immunosuppression in clinical practice, the brief history of clinical transplantation began. In 1954, Murray performed the first kidney-transplantation with long-term function ${ }^{39}$ and in 1967 the first human liver transplantation was performed by Starzl. ${ }^{40}$ The first successful heart transplantation was performed in 1967 by Barnard. ${ }^{41.42}$ In contrast to cardiac allografts, clinical lung transplantations proved much more difficult ${ }^{43}$ and were not successfully performed until the $1980 \mathrm{~s}^{44}$

At present organ transplantation has a high success rate that increases each year. One-year graft survival for kidney, liver, and heart is now 
approaching $85 \%$ or more. ${ }^{45}$ This impressive survival rate can be attributed to increasing experience of transplant centers, transplant surgeons and physicians, better selection of donors and recipients, and more effective immunosuppressive drugs. Improved methods for preserving cadaveric organs have also contributed to these favorable results. ${ }^{46}$

Along with improved capability of transplanting tissues and organs, interest in preservation and storage of living tissues developed. Organ preservation allows time to arrange a transplantation procedure and to optimize conditions. Current methods of organ preservation are based on suppression of metabolism by hypothermia and on systems that support active metabolism. To make organs tolerant to hypothermia, blood is removed and replaced with an appropriate hypothermic preservation solution. Composition of the preservative appears to be a critical determinant of tolerance of the organ to hypothermic storage. Although the ideal cold-storage medium is not yet available, organ storage has been improved significantly during the past two decades. Belzer and Collins madle landmark developments in organ preservation in the late $1960 \mathrm{~s} .{ }^{47-49}$ In 1967, Belzer and colleagues showed that three-day kidney preservation was possible by continuous machine perfusion at $10^{\circ} \mathrm{C}$ with a perfusate derived from plasma. ${ }^{47}$ At temperatures of 0 to $4^{\circ} \mathrm{C}$, tissues remain viable in absence of circulation ten or more times longer than at normal body temperature. The simple method of hypothermia proved useful in preserving skin, cornea, kidney, liver, heart, and pancreas. Flushing an organ with a cold perfusate, usually a balanced electrolyte solution, was widely used for rapid cooling, within seconds, to temperatures that were achieved only after a number of minutes with surface cooling. 50

\subsubsection{Free tissue transfer}

As in organ transplantation, microsurgical procedures involving transfer of free tissues necessitate an inherent period of ischemia for the transferred tissue. ${ }^{6}$ However, in contrast to organ transplantation, free tissue or free flap transfer is normally not attended by long periods of ischemia. In clinical practice, no preservation technique is used. Duration of tissue ischemia is considered to be one of the most important factors that determine survival of free tissue transfers. Under normal conditions of elective surgery, and even emergency surgery, the period of unavoidable ischemia lasts 1.5 to 3 hours. For most tissues (skin, muscle, bone, nerve) involved in reconstructive efforts, this period of normothermic ischemia is well tolerated. Numerous studies have shown skeletal muscle to be the least tolerant to ischemia of all extremity tissues. ${ }^{51}$ In more complex 
situations, or in case of complications with thrombosis in repared vessels, the initial ischemic period may be significantly prolonged and a secondary period of ischemia can arise. If ischemic times are extended to the point that normal tolerance is exceeded, necrosis will occur.

Free flaps are centered over the vascular pedicle and therefore the entire transferred tissue is well vascularized. Because the distal portion of a local or pedicled flap is located distal to the vascular territory of the pedicle, complications arise from partial muscle or cutaneous necrosis at the distal part of the flap. Distal necrosis results in dehiscence often followed by fistula formation. ${ }^{52}$

Failure rates of free flaps are reported between $2 \%$ and $8 \%$ with a reexploration rate between $6 \%$ and $14 \% .{ }^{53,54}$ Using free flaps with larger caliber, long pedicles quote lower failure rates (as low as $1 \%$ ).

The donor site has fewer associated complications because it is usually undiseased and is subjected to one procedure instead of two (resection and reconstruction at the recipient site, particularly in case of tumor resection). However, postoperative recovery and rehabilitation associated with the donor site of free tissue transfer may result in poor patient outcome. Pedicled flaps have limited donor site morbidity and require minimal postoperative wound care. The most common complications are partial split-thickness skin graft loss and sensory defects. ${ }^{52}$

\subsubsection{Composite Tissue Allografts}

By definition, a composite tissue allograft (CTA) may consist of any combination of skin, subcutaneous tissue, nerve, blood vessels, muscle, and bone (obtained from cadaveric donor). It could serve as ideal replacement for missing tissues after traumatic loss, tumor resection, or congenital absence by supplying near-identical parts for reconstruction. When the wound has been severely scarred or irradiated, these allografts have the additional advantage of primary vascularization over conventional avascular allografts or even skin autografts. ${ }^{55}$

From a surgical point of view, harvesting tissues from a cadaveric donor has several advantages. First, tissue allotransplantation meets the pre-eminent objective of any tissue reconstruction, to replace "like with like". For example, a thumb would be reconstructed with a thumb, not a toe. Second, donor site morbidity is avoided; this saves the surgeon from the dilemma of healthy tissue destruction, a drawback of any reconstruction using autologous tissues. Thus, CTA transplantation is advantageous for two important reasons: improvement of the result of tissue reconstruction and reduction of donor site harvesting. It allows the surgeon to achieve an 
optimal physical, functional, esthetic, and psychological result. However, these advantages of CTAs must be balanced against the need for indefinite immunosuppressive treatment, which has potentially serious side effects. ${ }^{20}$

CTA transplantation adheres to trends of solid organ transplantation: harvesting from cadaveric donors, immunologic incompatibility between donor and recipient, and life-long immunosuppression of the recipient. An efficient, yet non-toxic immunosuppressive treatment has always been the limiting factor of organ transplantation. Unlike solid organ allografts, composite tissue allografts, such as hand, are histologically heterogeneous and are composed of tissues that express varying degrees of antigenicity. Among these tissues are skin and muscle, which are highly antigenic. Other immunocompetent components such as bone marrow and lymph nodes are also target of very severe rejection. ${ }^{56}$ Many relevant studies have been conducted on animals, and in 1997 a team from Louisville demonstrated that an immunosuppressive tritherapy of tacrolimus, mycophenolate mofetill and prednisone could prevent rejection of an entire limb allograft without major toxicity in a preclinical model (adult swine) for up to 90 days. 57

In 1988 and 1989 , a team directed by Guimberteau was the first to perform two clinical allotransplantations. They transplanted the digital flexor tendon apparatus harvested from a nonrelated living donor and from a cadaveric donor. The grafts were revascularized onto the recipient's ulnar vessels with satisfactory functional results. ${ }^{58}$

Between 1988 and 1998, Mackinnon performed peripheral nerve allotransplantations in 7 patients following upper limb or lower limb trauma. ${ }^{59} \mathrm{Grafts}$ were harvested from limbs of cadaver donors and preserved for 7 days in a cold preservation solution (University of Wisconsin) at $5^{\circ} \mathrm{C}$ until implantation. Immunosuppression was stopped 6 months after transplantation, when regeneration across the allograft was evident. This allograft transplantation was successful in 6 patients, with return of motor function and sensation in the affected limb. Despite specific conditions that are not applicable to other tissues (nonvascularization of the grafts, prolonged preservation before transplantation, and withdrawal of immunosuppressive treatment), successful nerve allografting protocols have direct applicability to CTA transplantations.

Since September 1998, several hand transplantations have been performed around the world; ${ }^{60-63}$ four of these were bilateral. Grafts of the first four unilateral allografts were stored at $4^{\circ} \mathrm{C}$ for 6 to 12 hours (cold ischemia time), preceded by perfusion of the brachial artery with University of Wisconsin preservation solution for organ transplants. In 
Lyon and Louisville, patients experienced a few episodes of moderate rejection several weeks or months after the operation. They were diagnosed by erythema on the hand allografts and confirmed with skin biopsies. Rejection was controlled in all cases with an increase in prednisone dosage and topical steroids. After 10 months, patients were able to perform simple tasks of every day life. Good thumb-index and lateral pinch allowed them to perform prehensile activities under visual control to compensate for the lack of sensibility. However, nerve regeneration did not result in reinnervation of the intrinsic muscles or satisfactory distal sensitivity. ${ }^{64}$ Other applications of CTAs in functional reparative surgery are vascularized larynx allografts performed in 1998 by Strome, ${ }^{65}$ and vascularized femoral and knee allotransplants performed by Hoffmann et al. ${ }^{66}$

Early results of CTA transplantation proved that such transplantations are technically feasible, with graft survival depending on high-level and indefinite immunosuppression. However, potential side effects of chronic immunosuppression currently limit widespread application of CTAs in reconstructive surgery. In the long term, tolerance induction through a preconditioning regimen of the recipient offers great promise by avoiding indefinite immunosuppression. ${ }^{67}$ Such strategies could make CTA transplantation a safer and more widespread procedure. Beside rejection of the transplanted tissue, ischemia/reperfusion injury may also lead to tissue damage. Of all tissues present in CTAs, muscle tissue is most sensitive to ischemia/reperfusion injury. ${ }^{51}$ Before CTAs can be applied more frequently in clinical practice, a preservation strategy for CTAs (particularly for muscular tissue) needs to be developed and evaluated.

\subsection{ISCHEMIA REPERFUSION INJURY (I/R INJURY)}

Transplantation of an organ or (composite) tissue involves an obligatory period of ischemia during surgery, preservation, and revascularization. During this ischemic period blood supply to the tissue is interrupted, which initiates a sequence of cellular and biochemical events that can lead to cellular dysfunction and ultimately to cell death. Although restoration of blood flow and oxygenation of the tissue is a prerequisite for recovery of ischemic tissue, reperfusion itself may also result in an enhancement of tissue injury. This paradoxal situation results from a series of reactions in which reactive oxygen metabolites produced by endothelial cells, leukocytes, and other cells appear to be eminently involved. ${ }^{7}$ 
During the ischemic period, cellular metabolism is converted to anaerobic pathways; lactate accumulates and tissue $\mathrm{pH}$ drops. Cellular ATP content diminishes, which inhibits ionic pump activity and impairs membrane transport functions, and disturbs calcium hemostasis. As a result, intracellular calcium concentration will rise, which triggers activation of several enzymes and accumulation of inflammatory mediators. ${ }^{6}$ In the microcirculation, a deficient cell energy reserve can induce swelling of capillary endothelial cells, which increases resistance to capillary blood flow during the immediate post-ischemic reperfusion phase. This is considered to be one of the potential causes of post-ischemic "capillary no-reflow". 68

Tolerance of tissues for ischemia varies with the nature of the tissue. Skeletal muscle appears to be relatively sensitive to ischemia, because of its active metabolism. Tissues like fat and skin are less sensitive. ${ }^{51}$ These differences in sensitivity are particularly important in transplantation of free flaps or CTAs that include muscle tissue. A myocutaneous flap is for example less tolerant to an ischemic period than a skin flap. ${ }^{6}$ The duration of the ischemic period determines the severity of tissue damage. ${ }^{69}$ Belkin and colleagues ${ }^{70}$ have shown that significant muscle injury occurred after 3 hours of ischemia, while after 6 hours only $3 \%$ of control functional activity remained. In another study, Labbe and co-workers ${ }^{71}$ noted that the extent of necrosis in muscle tissue increased with ischemia duration: 2,30 and $90 \%$ after 3,4 and 6 hours of ischemia, respectively. It was also observed that muscle necrosis was more severe in the central part of the muscle.

While reperfusion of jeopardized ischemic tissue is necessary to restore oxygenation, it also initiates a cascade of events that further exacerbates cell damage and tissue injury. While quality and quantity of tissue injury may vary between tissues, it is generally accepted that microvascular dysfunction is a key component of this pathologic process. ${ }^{7}$ The cellular element within the microcirculation that appears to be most affected is the endothelial cell. This cell, at the interface between blood and tissue, experiences an oxidant stress during reperfusion that is initiated by biochemical and molecular changes occurring during ischemia. Both endothelial xanthine oxidase and nicotinamide diphosphonucleotide (NADPH) systems are involved in the increased production of reactive oxygen species (ROS). ${ }^{6}$ These ROS mediate microvascular responses to ischemia and reperfusion (I/R) by stimulating the formation of inflammatory mediators and increasing synthesis and expression of endothelial adhesion molecules for leukocytes, and by inactivating the 
endothelial cell-derived antiadhesive agent nitric oxide (NO). These responses promote activation of leukocytes and their subsequent adhesion to endothelial cells. ${ }^{7}$

Leukocytes are thought to play an important role in the manifestation of microvascular and tissue injury. The degree of tissue damage during I/R strongly correlates with the number of recruited leukocytes. ${ }^{72}$ Migration of leukocytes was described as a three-step process (Fig. 2.1). ${ }^{73}$ First, leukocytes roll along the endothelial cell surface, which is mediated by adhesion molecules of the selectin family. ${ }^{74}$ If the proinflammatory stimulus is sufficient, leukocytes may become activated by chemokines and firmly adherent (stationary adhesion) to venular endothelium. Firm attachment of leukocytes to the vessel wall is required for subsequent diapedesis. Adhesion is mediated by molecules of the integrin family expressed on leukocytes and Ig-like adhesion molecules expressed on endothelium. ${ }^{75,76}$ Adherent leukocytes may then diapedese into the perivascular space. Migrated leukocytes induce parenchymal cell injury via release of ROS and proteolytic enzymes. They can also exacerbate ischemic injury by disrupting the microvascular barrier during diapedesis.

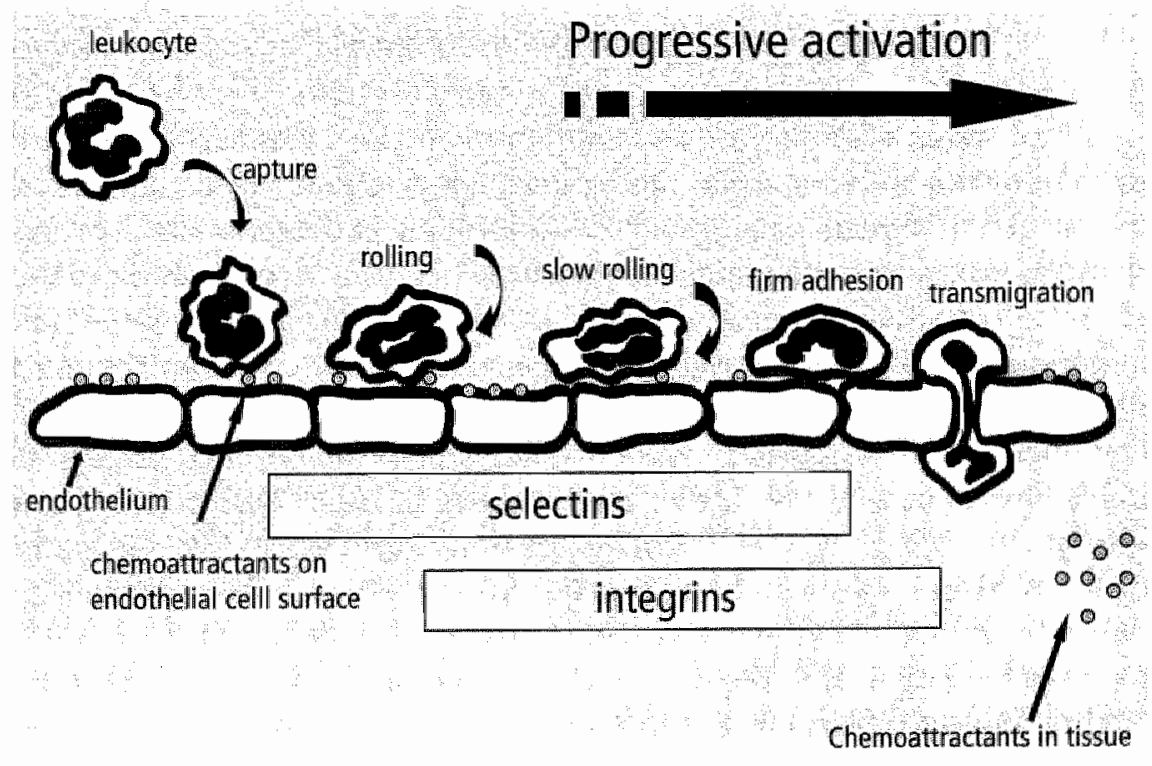

Fig. 2.1

Leukocyte recruitment is a multi-step event that is initiated by selectins, resulting in a rolling interaction. Leukocyte rolling is a prerequisite to firm adhesion and migration mediated by integrins and members of the Ig superfamily. Expression and or activation of these adhesion molecules occurs via chemoattractants released from the local enwiromment. 
As a consequence, microvascular permeability increases, transcapillary fluid filtration enhances, and edema results. Increase in interstitial tissue pressure may compress capillaries, thereby hampering microvascular perfusion and promoting the no-reflow phenomenon (Fig 2,2). ${ }^{51,77-79}$

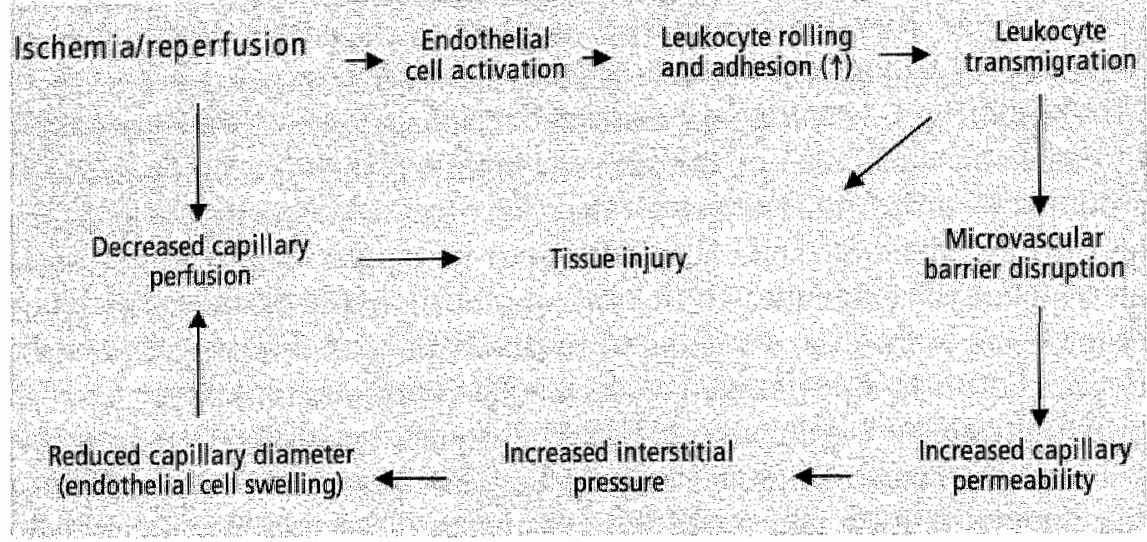

Fig. 2.2

Mechanisms proposed to explain the role of leukocyte-endothelial interactions and reduced capillary perfusion in the development of post-ischemic tissue injury in skeletal muscle.

Prevention of leukocyte accumulation in postischemic tissues by depletion with anti-neutrophil serum or leukocyte filters results in marked attenuation of reperfusion injury. ${ }^{80}$ Pharmacologic interventions addressing generation or release of oxidants, interaction between adhesion molecules, or action of proinflammatory mediators have attenuated leukocyte adherence and leukocyte-mediated tissue injury in experimental models. ${ }^{80-83}$ In spite of the success of blockade of leukocyte adhesion to endothelium in reducing tissue injury in such animal models, results of clinical trials of neutrophil adhesion blockade in I/R disorders have been disappointing. ${ }^{84}$ However, recent successes using integrin antagonists in diseases like psoriasis and inflammatory bowel disease demonstrate the clinical potential of antiadhesive therapy directed at leukocyte integrins. ${ }^{85}$ Other potentially interesting approaches to prevent I/R induced leukocyte infiltration and subsequent tissue damage, include administration of nitric oxide donors and ischemic/heat shock preconditioning. ${ }^{86-91}$ Beside leukocytes, other cells or factors may also contribute to development of $I / R$ injury; examples are an increased recruitment of blood platelets to the microcirculation and local coagulation.92-94 
Tissue preservation is a necessary component of transplantation, because an organ or CTA must be transported to the recipient's hospital. Most organs can be shared between donor and recipient hospitals within 24 to 36 hours. Currently, methods are sufficient to preserve kidney, liver, and pancreas for this length of time. However, methods to effectively preserve lung and heart for more than 4 to 6 hours have not yet been developed. ${ }^{50}$ Preservation of CTAs, with inevitable exposure to ischemia and reperfusion, may also lead to tissue damage. Before CTAs can be applied more frequently in clinical practice, a preservation strategy needs to be developed, in particular for the muscular component of CTAs. ${ }^{51}$

The ultimate aim of tissue and organ preservation is to provide a recipient with a viable graft, which will exhibit primary function. Hereto, damaging effects of ischemia and reperfusion have to be minimized, both in microcirculation and in tissue. Success of organ preservation methods depends on temperature during storage and on use of an appropriate preservation solution. At present, most organs are stored at low temperature (hypothermia). Although the ideal temperature is not yet known, it is commonly accepted that a temperature of about $4^{\circ} \mathrm{C}$ is suitable for most organs. The appropriate preservative must create a physiological environment that maintains viability of tissue during the hypothermic period of ischemia. To this purpose, the solution must counteract the tendency for cells to swell in the cold, provide an optimal $\mathrm{pH}$, an appropriate concentration of electrolytes, and osmotically active agents. Moreover, the solution must be well distributed throughout the tissue. Hence, the ideal preservation solution provides metabolites, substrates, and agents that enhance recovery of the organ on reperfusion, and suppresses unwanted reactions and breakdown of critically important metabolites. ${ }^{95}$ The biochemical factors (and their concentrations) necessary for high-quality, long-term organ preservation are not fully known; further research in this field is necessary. Combination of hypothermia and an optimal preservation fluid will help to minimize injury, when tissue is reperfused with blood at the end of the transplantation procedure. At present, there is no satisfactory answer to the question whether a universal preservative can be used or whether individual organs require a specific preservation method.

In organ harvesting, organs are usually cooled before they are removed. The cold preservation solution flushes blood from the organ and cools the 
organ to the preservation temperature $\left(0\right.$ to $5^{\circ} \mathrm{C}$ ). The organ (or tissue) is stored in preservation solution and kept at these low temperatures (simple cold storage). Perfusion storage involves continuous infusion of a cold preservation fluid through the vasculature of the harvested organ. ${ }^{96}$ Machine perfusion is used in some centers for preservation of kidneys.96-98

\subsubsection{Hypothermia}

Hypothermia is at present the most important preservation method for organs, because it reduces metabolism. However, hypothermia may be a risk factor as well. ${ }^{99,100}$ Hypothermia induces a decrease in the activity of membrane-bound ion pumps (particularly the Na-K ATPase pump) and a decrease in the rate of turnover of ATP. When ion-pump activity is suppressed for long periods, membrane potential is lost and chloride diffuses down its concentration gradient. Furthermore, colloids in the cell exert a colloidal osmotic pressure that pulls water into the cell. The result is cell swelling, organelle swelling, a disruption of architecture of the cell (cytoskeleton), and dilution of the intracellular milieu. ${ }^{46,101}$ Cell swelling can be tolerated for short periods, but eventually it causes irreversible damage. Organs can be well preserved for relatively long periods with preservation solutions that suppress cell swelling. ${ }^{101}$ However, even if cell swelling is prevented, organs and tissues stored at hypothermia eventually lose viability. Because anaerobic metabolism continues at a slow rate, metabolic end-products like lactate and hypoxanthine accumulate. On reperfusion, these by-products contribute to generation of oxygen free radicals, which are directly damaging to tissue and act to induce an acute inflammatory response (see $\$ 2.3$ ). In addition, intracellular acidosis results in lysosomal instability and altered mitochondrial function. ${ }^{102}$ Direct deleterious effects of hypothermia include physical alterations in cellular membranes and calcium influx into parenchymal and endothelial cells, leading to tissue damage. ${ }^{101}$

Machine perfusion of an organ at body temperature (normothermic perfusion) ${ }^{103}$ is now proposed as promising alternative. ${ }^{101}$ Normothermic perfusion immediately after retrieval of an organ allows regeneration of ATP levels and clearance of metabolites, which minimizes accumulation of stubstrates for free radical production upon reperfusion. Animal experiments on liver and kidney transplantation, as well as results from human renal transplantations are promising (for review see ${ }^{101}$ ). They suggest that storage times may be extended well beyond the current limits when this method would be applied clinically. 


\subsubsection{Preservation solutions}

In principle, preservation solutions provide a physical and biochemical environment that maintains viability of structural components of tissue during hypothermic metabolic arrest, and minimize effects of reperfusion injury. ${ }^{95}$ Preservation solutions can be divided into two categories based on the concentration of $\mathrm{Na}^{+}$and $\mathrm{K}^{+}$ions. Preservation fluids which mimic the interior cellular ionic milieu are called the intracellular type. They have a $\mathrm{Na}^{+}$concentration less than $70 \mathrm{mmol} / \mathrm{L}$ and a $\mathrm{K}^{+}$concentration tanging between 30 and $125 \mathrm{mmol} / \mathrm{L}$. Preservatives with ionic concentrations similar to extracellular fluid are termed the extracellular type; their $\mathrm{Na}^{+}$ concentration is higher than $70 \mathrm{mmol} / \mathrm{L}$, while $\mathrm{K}^{+}$concentration ranges between 5 and $30 \mathrm{mmol} / \mathrm{L}$. Examples of intracellular preservation fluids are HTK-Bretschneider solution (HTK), University of Wisconsin solution (UW), Roe solution, Collins solution, and intracellular Stanford solution. Extracellular type fluids include Celsior solution, Krebs solution, and St. Thomas Hospital solution. Several clinical studies report superior results with intracellular solutions over the extracellular type. ${ }^{104}$ In line with this, intracellular solutions UW and HTK proved to be superior to extracellular solutions for preservation of skeletal muscle function in an experimental study. ${ }^{28}$ A range of chemical compounds could potentially be added to preservation solutions to minimize deleterious effects of hypothermia and $\mathrm{I} / \mathrm{R}$, and to prolong preservation times. Promising in this respect are free radical scavengers, lazaroids, anti-apoptosis agents and calcium channel blockers. ${ }^{101}$

Below, a selection of currently used preservation solutions and their characteristics is presented in more detail.

\section{Collins/Euro-Collins solution}

Many preservation solutions were developed along with research efforts to find appropriate cardioplegic solutions. G.M. Collins ${ }^{105}$ developed one of the first solutions for kidney preservation. Basic principle of this Collins solution is the philosophy of "intracellular electrolyte composition". It contains a strong phosphate buffer, and glucose is used as a carrier for the osmotic load to reach a hypertonic condition of $420 \mathrm{mOsmol}$. This may be the major disadvantage, because even under hypothermic conditions glucose is broken down at \east to the level of lactate, which results in doubling of intracellular substrate molecules followed by cell swelling. ${ }^{99}$ The Eurotransplant Organization modified the Collins solution by leaving out magnesium without negative effect on preservation results. This EuroCollins solution was cheap but not simple in use, because sterilization of 
the glucose-containing fluid had to be done separately from the electrolyte part and mixing before use was necessary. Euro-Collins solution was standard in Europe for about 15 years. ${ }^{99}$

\section{University of Wisconsin solution}

University of Wisconsin solution (UW) is an intracellular type preservation solution. Its development introduced three new philosophies: a) osmotic concentration is no longer maintained by metabolically active glucose; it is rather achieved by administration of metabolically inert substrates like lactobinat and raffinose; b) much attention is paid to additional administration of colloid carrier hydroxyethylstarch (HES); c) addition of oxygen radical scavengers, glutathion, allopurinol, and adenosin. ${ }^{106}$ This solution has proven to guarantee extremely long cold ischemia tolerance, 72 hours in kidneys ${ }^{107}$ and certainly 48 hours in livers. ${ }^{108}$ At the moment, UW is considered the standard preservation solution for livers, kidneys, and pancreases. Attempts to use UW for heart preservation, however, were not convincing. ${ }^{99}$ Disadvantages of UW are its high viscosity and its high price; in addition, the radical scavenger glutathion cannot be detected in the solution by chemical analysis. ${ }^{99}$

\section{Histidin-Tryptophan-Ketoglutarate Solution (HTK)}

HTK is an intracellular type preservation solution with a low potassium concentration. It was introduced by H.J. Bretschneider, who was interested in developing a physiologic cardioplegic solution. ${ }^{109}$ Basic philosophy is the introduction of a very potent buffer system, histidin, along with two substrates tryptophan and ketoglutarate. As opposed to UW, HTK solution has a very low viscosity and according to Bretschneider, high volumes at a low flow rate should be applied to guarantee "equilibration." HTK has been tested in clinical trials and its effects were compared with those of UW. In clinical transplantation of liver, kidney, and pancreas, HTK and UW appeared to have similar safety and efficacy profiles. ${ }^{110,111}$ In a multi-center randomized prospective trial, HTK and UW had similar efficacy at the endpoint of delayed graft function. ${ }^{12-114}$

\section{Celsior}

The extracellular preservation solution Celsior, created by PasteurMerieux, is a high sodium, low potassium solution, that is unique in this respect. It is based on a mixture of the impermeant inert osmotic carrier philosophy of UW solution, using lactobionat and mannitol, and the strong buffer philosophy of HTK solution, using $30 \mathrm{mmol}$ of histidin 
buffer. In addition, Celsior also contains oxygen radical scavengers. Celsior has been found to be effective in heart, lung, kidney, small bowel, and liver preservation in experimental and clinical studies. ${ }^{115-117}$

\section{Perfluorocarbons}

Perfluorocarbons (PFC) are hydrocarbon molecules in which all or most of hydrogen atoms have been replaced with fluorine. ${ }^{118}$ These chemicals have a high solubility for the respiratory gases and, in emulsified form, are present in oxygen-transporting plasma substitutes now undergoing clinical trials. PFC-based solution has been examined as an oxygen carrier for blood substitutes, myocardial protection, ventilatory support, cell culture, ${ }^{119}$ and organ preservation before transplantation. ${ }^{118,120}$ PFC was first used for organ preservation as a component of the two-layer method (TLM), where pancreatic grafts are placed in a chamber containing both fully oxygenated PFC and UW solution. ${ }^{120,121}$ During the preservation period, the tissue is oxygenated through PFC and substrates are supplied by the UW solution; as a consequence, continuous perfusion is not necessary. TLM has been shown to prolong the preservation period and reduce pancreatic injury caused by warm ischemia and reperfusion. A first clinical trial showed that with TLM the morphologic quality of human pancreas graft after reperfusion was excellent compared with a pancreas stored in UW, with no acute rejection episode. ${ }^{122}$ TLM has also been shown to be beneficial for other organs, such as heart and small bowel. ${ }^{123-125}$

\subsection{MODELS TO INVESTIGATE THE MICROVASCULAR CONSEQUENCES OF ISCHEMIA/REPERFUSION AND TRANSPLANTATION}

In the present study, microcirculatory effects of ischemia/reperfusion and transplantation were investigated in muscle tissue, since of all CTA tissues, muscle tissue is most sensitive to ischemia. ${ }^{51}$

A suitable model for investigation of the microcirculation in muscle tissue in case of $\mathrm{I} / \mathrm{R}$ and transplantation should allow distinct analysis of microcirculatory and microhemodynamic mechanisms and advanced assessment of cellular mechanisms, such as cell-cell interactions among leukocytes, platelets, and endothelium. ${ }^{8}$ Intravital microscopy represents the only method for analyzing skin and muscle microcirculation by direct visualization of the microvasculature. ${ }^{126}$ The method enables detailed in 
Table 21

Composition of varilous preservatipn solutions

\begin{tabular}{|c|c|c|c|c|}
\hline Components [mrnoll]] & EC & UW & HTK & CEL \\
\hline $\mathrm{Nat}$ : & 10 & 30 & 15 & 100 \\
\hline$k+$ & 115 & 120 & 9 & 15 \\
\hline $\mathrm{Ca}^{2+}$ & 8 & 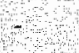 & 0.015 & 0.25 \\
\hline $\mathrm{Mg}^{2+}$ & 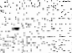 & 5 & 4 & 13 \\
\hline Glutamate & 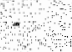 & 3 & 3 & 20 \\
\hline Ketogluiarate & 3 & 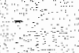 & 1 & 3 \\
\hline Typtophan & 2 & 8 & 2 & 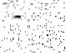 \\
\hline Phosphat buiffer & 100 & 25 & 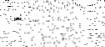 & 8 \\
\hline Bicarbonat buffer & 10 & & 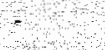 & 3 \\
\hline Lactobionate & 3 & 100 & 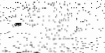 & 80 \\
\hline Mannitol & 4 & 3 & 30 & 50 \\
\hline Raffinose & 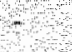 & 30 & 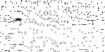 & 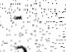 \\
\hline Reduced glutathione & + & 2 & 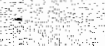 & 3 \\
\hline HES (g/) & 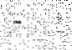 & ? & 50 & 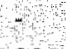 \\
\hline Histidine & 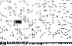 & 4 & 180 & 30 \\
\hline Osmolarity (mOsm/l) & 404 & 320 & 327 & 320 \\
\hline
\end{tabular}

vivo studies of interactions between platelets, leukocytes, and endothelial cells, ${ }^{127-130}$ endothelial barrier dysfunction, ${ }^{131}$ endothelial molecular binding, ${ }^{82}$ and necrotic and apoptotic cell death. ${ }^{9}$ Therefore, intravital microscopy represents an ideal tool to study the microvascular consequences of ischemia and reperfusion in muscle tissue.

More than 100 years ago, the first experimental studies utilizing intravital microscopy, were performed on the tongue of the frog and the wing of bats (see: ${ }^{127}$ ). Later, the thin mesentery was used to study the microcirculation. ${ }^{132}$ Nowadays, the microcirculation can be visualized in many organs and tissues, applying advanced optical equipment, with either trans-illumination or incident-illlumination, resulting in improved image quality. A widespread spectrum of laboratory animal species can be used, including dog, pig, rabbit, rat, hamster and mouse; the latter can easily be genetically modified.

Several models have been developed to study microvascular consequences of ischemia and reperfusion in muscular tissue. The cremaster muscle has been used to study microcirculation for more than 
30 years. The cremaster is a thin, translucent muscle, which allows clear visualization of microvessels and quantification of various microvascular: parameters. In addition, the muscle is easily accessible.

The model was first described by Baez. ${ }^{133}$ Meininger and Franken performed detailed anatomical studies. ${ }^{134,135}$ Microvascular development was studied by Wang and Prewitt. ${ }^{136}$ The cremaster can be used as an island flap, first described by Anderson and Acland. ${ }^{137}$ This model was used in various studies. ${ }^{137-141}$

The cremaster model has several advantages for studies on the effects of $I / R$ and transplantation on the microcirculation. This muscle can be isolated on its vascular pedicle ${ }^{137}$ and perfused with a preservation solution. ${ }^{142}$ Therefore, clinical conditions of free flap applications can be simulated and the effects of various perfusates on I/R injury can be studied. The model can be used to simulate clinical conditions of transplantation. ${ }^{139,143,144}$ Ischemia can be induced by placing a vascular clamp on the femoral artery (after isolation of the pedicle). ${ }^{139,143,144}$ To simulate free tissue transfer, however, the rat cremaster model needs to be surgically isolated in a way that its only attachment to the body is a single neurovascular pedicle. Ten to 15 side branches need to be ligated and cut from the aorta to the pudic-epigastric truncus. ${ }^{135,139}$ One should be aware that long periods of ischemia decrease the transparency of the muscle, leading to difficulty in obtaining data.

Siemionow and Nanhekhan introduced the cremaster muscle chamber technique for long-term intravital microscopy in rats. ${ }^{145}$ This cremaster chamber model proved to be useful for chronic microcirculatory measurements for at least 24 hours. ${ }^{145}$ The model allowed intravital microscopic evaluation of the same muscle island flap downstream from a compromised pedicle (arterial flow reduction) for three consecutive days. ${ }^{146}$ Measurements were taken only as long as 3 days after chamber implantation to exclude possible effects of neovascularization from tissue surrounding the cremaster muscle pedicle.

Evaluation of microcirculation under an intravital microscopy system allows recording of hemodynamic changes and metabolic effects in the most distal part of the cremaster muscle flap. The ability to make direct observations of the various segments of the microcirculation in the cremaster muscle provides knowledge concerning reperfusion injury.

The present thesis utilizes the cremaster muscle preparation and microcirculation methods to assess muscle perfusion and leukocyte-endothelium interactions in studies on the effects of various preservation solutions after ischemia-reperfusion and transplantation. 


\section{REFERENCES}

1. Langer RM, Kahan BD. Alexis Carrel's legacy: visionary of wascular surgery and organ transplantation. Transplant Proc. 2002;34:1061-6.

2. Friedewald VE, Crossen C. Vascular anastomosis Science \& Medicine 1994;1:68-79.

3. Jacobson JH, 2nd. Microsurgical technic in repair of the tranmatide extremity. 1963. Cin Orthop Relat Res. 1995:4-7.

4. Daniel RK, Taylor GI. Distant transfer of an island flap by microvascular anastomoses. A clinical technique. Plast Recownt Surg . 1973:52:111-7.

5. Kuntscher MV, Hartmann B, Germann $G$. Remote ischemic preconditioning of falps: a review. Microsurgery. 2005;25:346-52.

6. Siemionow M, Arsian $\mathbb{E}$. Ischemia/reperfusion injury: a review in relation to free tissue transfers. Microsurgery. 2004;24:468-75.

7. Granger DN. Ischemia-reperfusion: mechanisms of microvascular dystunction and the influence of risk factors for cardiowascular disease. Michocimulation. 1999;6:167-78.

8. Menger MD, Laschike MW, Amon M. Schramm R, Thorlacius H., Rucker M., Vollmar B. Experimental models to study microcirculatory dysfunction in muscle ischemiareperfusion and osteomyocutaneous flap transfer. Langenbecks Arch Surg. $2003,388: 281-90$.

9. Menger MD, Vollmar B. Role of microcirculation in transplantation. Microcinculation. 2000;7:291-306.

10. Genden EM, Rinaldo A, Suarez C, Wei WI, Bradley PJ, Ferlito A. Complications of free lap transfers for head and neck reconstruction following cancer resection. Oral Oncol. $2004,40: 979-84$.

11. Chien W, Varvares MA, Hadlock T, Cheney M, Deschler DG. Effects of aspirin and low wose heparin in head and neck reconstruction using microvascular free flaps. Larymgoseope. 2005;115973-6.

12. Kerrigan CL. Stolland MA. Ischemia reperfusion injury: a review. Microwngery. $1993,14: 165-75$.

13. Nakatsuka T, Hani K. Asato H, Takushima A, Ebihara S, Kimata Y, Yamada A, Ueda

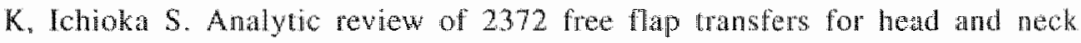
reconstruction following cancer resection. I Reconstr Microswg. 2003; 19:363-8: discussion 369.

14. Chen CH, Lin GT, Fu YC. Wu CF, Shieh TY, Huang IY, Shen YS, Chen CM. Comparison of deltopectoralis flap and free radial forearm flap in reconstruction after oral cancer ablation. Oral Oncol. 2005:41:602-6.

15. Lewin JS, Barringer DA, May AH, Gillenwater AM, Amold KA, Roberts DB, Yu P. Functional outcomes after circumferential pharyngoesophageal reconstruction. Larygoncope. 2005:115:1266-71. 
16. Lipa JE, Novak CB, Binhammer PA. Patient-reported donor-site morbidity following anterolateral thigh frec flaps. J Reconst Michosurg. 2005:21:365-70.

17. LuII R. An open proposal for clinical composite rissue allotransplantation. Transplant Proc. 1998:30:2692-6; discussion 2697-703.

18. Hewith $\mathrm{CW}$. Update and outline of the experimental problems facing clinical composite tissue transplantation. Transplant Proc. 1998;30:2704-7.

19. Kann BR. Furnas DW, Hewitt CW. Past, present, and future research in the field of composite tissue allotransplantation. Microsurgery 2000;20:393-9.

20. Petit F, Minns AB, Dubernard JM. Hettaratchy S, Lee WP. Composite tissue allotransplantation and reconstructive surgery: first clinical applications. An Surg. $2003: 237: 19-25$.

21. Tai C, Goldenberg M, Schuster KM, Kann BR, Hewitt CW. Composite tissue allotransplandation. I thest Surg. 2003; 16:193-201.

22. Hewitt CW, Black KS, Fraser LA, Howard EB, Martin DC, Achauer BM. Furnas DW. Composite tissue (limb) allografts in rats. 1. Dose-dependent increase in survival with cyclosporine. Thansplanahion. 1985;39:360-4.

23. Lehtola A. Harjula A, Heikkila L, Hammainen P, Taskinen E, Kurki T, Salmenpera M. Mattila S. Single lung allotransplantation in pigs. A morphologic study of tissue preserwation with modified Euro Collins and fluorocarbon solutions. Transplantation. $1990 ; 49: 1066-74$.

24. Schweizer E, Gassel A, Deltz E, Schroeder P. Morphologic and histologic alterations after small-bowel transplantation-a comparison of different perfusion solutions. Transplant Proc. 1992:24:1087.

25. Delfino VD, Gray DW, Leow CK, Shimizu S, Ferguson DJ, Morris PJ. A comparison of four solutions for cold storage of pancreatic islets. Transplantation. 1993;56:1325 30 .

26. Miyagawa Y. Imamura H, Soeda J, Matsunaga K, Mochida S, Fujuwara K. Matsuyama $Y$, Kawaselki S. Fate of hepatocyte and sinusoidal lining cell function and kinetics after extended cold preservation and transplantation of the rat liver. Liver Transpl. $2002: 8: 370-81$

27. Nardo B, Beltempo P, Bertelli R, Montalti R, Vivarelli M, Urbani L, Masetti M, Di Naro A, Filipponi F, Mosca F. Pinna A, Cavallari A. Comparison of Celsior and University of Wisconsin solutions in cold preservation of liver from octogenarian donors Thansplow Proc. 2004;36:523-4.

28. van der Heijden EP, Kroese AB. Stremel RW, Bar PR, Kon M, Werker PM. Contracrile propertics of rat skeletal muscles following stornge at 4 degrees $\mathrm{C}$. Clin Sci (Lond). $1999,97: 45-57$

29. "Hat NA, van der Plats A, Leuwenink HG, Wiersena-Buist J, Olinga P. wan Luyn MJ, Verkerke GJ, Rakhorst G. Ploeg RI. Initial blood washout during organ procurement determines liver injury and function after preservation and reperfusion. An J Tranxplown. 2004:4:1836-44. 
30. Cohen B. John Hunter's application of science to surgery. Am $R$ Coll swg Engl. $1984: 66: 59-62$

31. Turk IL. Inflammation: John Hunter"s "A treatise on the blood. inflammation and gun-shor wounds". Int I Exp Pathol. 1994:75:385-95.

32. Hauben DJ, Baruchin A, Mahler A. On the histroy of the tree skin gaft. Am Plont Sing $1982 ; 9: 242-5$.

33. Ben-Bassat H. Performance and safety of skin allografts. Clin Demanol. $2005 \cdot 23: 365-75$

34. McDowell F. Successful attempt of reconstruction of a nose from a completely separated piece of skin from the leg, by Prof. Dr. Bunger, Marburg, Germany (Joumal. der Chinrgie and Augenheilkunde, 4: 569, 1822). Translated from the German by Dr. Hans May. Plant Reconsir Surg. 1969:44:486-90.

35. Paton RT Comeal transplantation; a historical review. Am J Oph hahol 1950;33:3-5.

36. Lesky E. [The first renal transplantation. Emerich Ullmann (1861-1937) (author's trans1)1. MMW Munch Med Wochenschr. 1974;116:1081-4.

37. Friedman SG. Alexis Cétrel: Jules Veme of cardiovascular surgery. Am I Surg. $1988 ; 155: 420-4$

38. Carrel A. The transplantation of organs: a prediminary communication. 1905 [classical article]. Yate al Biol Med. 2001;74:239-41.

39. Murray JE. Remembrances of the early days of renal transplantation. Transplom Proc. $1981: 13: 9-15$.

40. Stanzl TE, Iwasuki S, Van Thiel DH, Gartner JC, Zilelli B., Matack JJ, Schade RR. Shaw BW, Jr, Hakala TR, Rosenthal JT, Porter KA. Evolution of liver transplantation. Hepatology. 1982;2:614-36.

41. Barnard CN. The operation. A human cardiac transplant an interim teport of a successful operation performed at Groote Schum Hospital, Cape Town. S Afr Med J. $1967: 41: 1271-4$.

42. Cooper DK. Christiam Barnard and his contributions to hadrt tansplantation. I Heart Lang Transplant. 2001:20:599-610.

43. Veith FJ, Koerner SK, Hagstrom JW, Anai L, Bloomberg A, Jacobson E. Nagashima H. Boley SJ, Gliedman ML. Experience in climical lung transplantation. Jana. $1972: 222: 779-82$.

44. Veith $\mathbb{F}$, Kambolz SI, Mollenkopf FP. Montefusco CM. Lung transplantation 1983. Transplantation. $1983,35,271-8$.

45. Taylon GS, Prather JC, Nonman DJ, de Mattos AM, Mogilishetty G, Conlin MJ, Barry JM. Living unrelated donor renal transplantation. a single center experience. I Urol. 2005:174:223-5.

46. Southard JH, Belzer FO. Organ preservation. Anm Rew Med 1995:46:235-47.

47. Beluer FO. Ashby BS, Dunphy JE. 24-hour and 72-hour preservation of canine kudneys. Lancet. $1967 ; 2: 536$. 
48. Collins GM. Bravo-Shugarman M. Terasaki Pl. Kidney preservation for Iransportation. Imital perfusion and 30 hours ice storage Lancet 1969:2:1219-22.

49. Southand JH, Belzar FO. New concepts in organ preservation. Chin Transplast. $1993 ; 7: 1347$.

50. Belzer FO, Sounard $\mathrm{HH}$. Organ Preservation. In: Sabiston DC, Lyerly HK, eds. Textbook of Surgery. The biological basis of modern surgical practice. 15 thed. Philadelphifa, Pennsylvania 19106: W.B. Saunders company; 1997:455-461.

51. Blaisdell FW. The pathophysiology of skeletal muscle ischemia and the reperfusion syndrome: a review. Cardiovasc Surg. 2002;10:620-30.

52. Rosenthal EL Dixon SF. Free flap complications: when is enough, enough? Curr Opin Otolaryngol Head Neck Surg. 2003;11:236-9.

51. Disa JJ, Pusic AL, Hidulgo DH, Cordeiro PG. Simplifying microvascular head and neck reconstruction: a rational approach to donor site selection. Ann Plast Surg. $2001,47: 385-9$

54. Haughey BH, Wilson E, Kluwe L, Piccirillo J, Fredrickson J, Sessions D, Spector O. Free flap reconstruction of the head and neck: analysis of 241 cases. Otolaryngol Head Nerk Sirg. 2001;125:10-7.

55. Lee WP, Mathes DW. Hand transplantation: pertinent data and future outlook. $J$ Hond Surg /Am/. 1999;24:906-13.

56. Lee WP, Yaremchuk MI, Pan YC, Randolph MA, Tan CM, Weiland AJ. Relative antigenicity of components of a vascularized limb allograft. Plast Reconsm Surg. $1991 ; 87: 401-11$.

57. Jones JW, Jr. Ustuner ET, Zdichavsky M, Edelstein J, Ren X, Maldonado C, Ray M, Jevans AW, Breidenbach WC, Gruber SA, Barker JH. Long-term survival of an extremity composite tissue allograft with FK506-mycophenolate mofetil therapy. Surgery. 1999;126:384-8.

58. Guimberteau JC, Baudet J, Panconi B, Boileau R. Potaux L. Human allotansplan of a digital flexion system vascuarized on the ulnar pedicle a preliminary report and I yean follow-up of two cases. Plast Reconstr Sturg. 1992;89:1 135-47.

59. Mackinnon SE, Doolubh VB, Nowak CB. Thulock EP. Clinical outcome following nerve allograft transplantation. Plast Reconsf Surg. $2001: 107: 141929$.

60. Dubemard JM, Owen E, Herberg G. Lanzetta M, Martin X, Kapila H, Dawara M. Hakim NS. Human hand allograft: report on first 6 months. Lancet 1999;353:1315-20.

61. Jones IW. Gruber SA. Burker JH, Breidenbach WC. Successful thand transplantation. One-yentrollow-up. Louisville Hand Transplant Team. NEng/J Med. 2000;343:468 73.

62. Francois $\mathrm{CG}$, Breidenbach WC, Maldonado $\mathrm{C}$, Kakoulidis TP Hodges $\mathrm{A}$, Dubernard JM, Owen EN, Pei G, Ren X. Barker JH. Hand transplantation: comparisons and observations of the furst four clinical cases. Microsugery. $2000,20: 360 \mathrm{~m} 71$. 
63. Cooney WP Hentz VR. Hand transplantation-primum non nocere. J Howd Shrs IAm/. $2002 \times 27: 165 \% 8$.

64. Barker JH, Francois CG, Frank JM, Maldonado C. Composite tissue allotransplantation. Thansplantanom. 2002;73:832-5.

65. Strome M. Stein J, Esclamado R, Hicks D, Lorenz RR, Braun W, Yetman R, Elinchar 1. Mayes J. Laryngeal transplantation and 40-month follow-up. N Engl I Med. 2001;344:1676-9.

66. Hofmann GO, Kirschner MH. Clinical experience in allogeneic vascularized bone and joint allograting. Microsurgery. 2000;20:375-83.

67. Lee WP, Rubin JP, Bourget JL, Cober SR, Randolph MA, Nielsen GP Ierino FL, Sachs DH. Tolerance to limb tissue allografts between swine matched for major histocompatibility complex antigens. Plast Reconstr Sufg. 2001;107:1482-90; discussion $1491-2$.

68. Menger MD, Rucker M. Vollmar B. Capillary dysfunction in strited muscle ischemia/reperfusion: on the mechanisnts of capillary "no-reflow". Shock 1997:8:2-7.

69. Morris SF, Pang CY, Zhong A, Boyd B. Forrest CR. Assessment of ischemiamduced reperfusion injury in the pig latissimus dorsi myocutaneous flap model. Plast Reconsin Surg. 1993:92:1162-72.

70. Belkin M, Brown RD, Wriglt JG, LaMorte WW, Hobson RW. 2nd. A new quantitative spectrophotometric assay of ischemia-reperfusion injury in skeletal muscle, Am J Surg. 1988; 156:83-6.

71. Labbe R, Lindsay T, Walker PM. The extent and distribution of skeletal muscle necrosis after graded periods of complete ischemia. $f$ Vasc Surg. 1987;6:152 7.

72. Harris $A G$, Leiderer R, Peer F, Messmer K. Skeletal muscle microvenscular and tissue injury after varying durations of ischemia. An J Physiol. 1996;271:H2388-98.

73. Grisham MB, Granger DN, Lefer DJ. Modulation of leukocyte-endothelial interactions by reactive metabolites of oxygen and nitrogen: relevance to ischemic heart disease. Free Rodic BHol Mod 1998:25:404-33.

74. Ley K. The role of selectins in inflammation and disease. Trends Mol Med. $2003: 9: 263 \cdots 8$.

75. Nusster AK. Wittel UA, Nussler NC. Beger HG. Leukocyles, the Jänus cells in inflammatory disease. Langenbecks Arch Surg. 1999;384:222-32.

76. Muller WA. Leukocyte-endohehal-cell interactions in leukocyte transmigration and the inflammatory response. Thends Immunol. 2003;24:327-34.

77. Dahlback LO . Rais O. Morphologic changes in striated muscle following ischemin. Immediate postischemic phase. Acta Chir Scand. 1966;131:430 40.

78. Carden DL, Korthuis RJ. Mecharisms of postischemic wasculan dystunction in skeletal muscle: implications for therapeutic intervention. Microcirc Errdohelwm Lymplatics. 1989:5:277-98. 
79. Gute DC, Ishida T, Yarimizu K, Korthuis RJ. Inflammatory responses to ischemia and reperfusion in skeletal muscle. Mol Cell Bhochem. 1998:179:169-87.

80. Korthus. RJ, Gute DC. Postischemic leukocyte/erdothelall cell interactions and microvascular barrier dystunction in skeletal muscle: cellular mechanisms and effect of Daflon $500 \mathrm{mg}$. Int J Microcinc Chin Exp. 1997;17 Suppl 1:11-7.

81. Russell J, Okayama N, Alexander IS, Granger DN, Hsia CI. Pretreatment with polynitroxyl albumin (PNA) inhibits ischemia-reperfusion induced leukocyle endohelial cell adhesion. Free Radic Biol Med. 1998;25:153-9.

82. Hofmian JN, Volmar B, Romisch I, Inthom D, Schildberg FW, Menger MD. Antithrombin effects on endotoxin-induced microcinculatory disorders ane mediated mainly by its interaction with microvascular endothelium. Crit Care Med. $2002 ; 30: 218-25$.

83. Yang H, Shi M, Richardson A, Vijg J, Guo Z. Attenuation of leukocyte-endothelium interaction by antioxidant enzymes. Free Radic Biol Med. 2003;35:266-76.

84. Hattan JM. Winn RK. Leukocyte-endothelial interactions: clinical trials of antiadhesion therapy. Crit Care Med. 2002,30:5214-9.

85. Yonekawa $\mathrm{K}$, Harlan $\mathrm{JM}$. Targeting leukocyte integrins in human diseases. J Lewkoc Biol. $2005 ; 77: 129 \times 40$.

86. Jerome SN, Akimisu T, Gute DC, Korthuis RJ. Ischenic preconditioning attenuates capillary no-reflow induced by prolonged ischemia and reperfusion. Am J Physiol. $1995: 268: 12063-7$.

87. Akimitsu T, Gute DC, Korthuis RJ. Ischemic preconditioning attenuates postischemic leukocyle adhesion and emigration. Am J Phywol. 1996;271:H2052-9.

88. Ishida T, Yarimizu K, Gute DC, Konthuis RJ. Mechanisms of ischemic preconditioning. Shock 1997;8:86-94.

89. Adanali G, Ozer K, Siemionow M. Early and late effects of ischemic preconditioning on microcirculation of skeleal muscle flaps. Plast Recomstr Surg. 2002;109:1344. 51 .

90. Kuntscher MV, Kastell T, Sauerbier M, Nobiling R, Gebhard MM, Gemann G. Acute nemote ischemic preconditioning on a rat cremasteric muscle flap model. Microsurgery: 2002:22:221-6.

91. Kuntseher MV. Juran S, Altmann J, Menke H, Gebhard MM, Germann G. Role of nitric oxide in the mechanism of preclamping and remote ischemic preconditioning of adipocutaneous flaps in a rat model. I Reconst Microsurg. 2003; 19:55 60.

92. Massberg $S$, Messmer $\mathbb{K}$. The nature of ischemia/reperfusion injury. Transplant Proc. $1998: 30: 4217-23$

93. Massberg S. Sausbier M. Klatt P, Bauer M, Pfeifer A, Siess W, Fassler R, Ruth P, Krombach $F$, Hofmann F. Increased adhesion and aggregation of platelets lacking cyclic guanosine 3',5-monophosphate kinase I. I Exp Med. 1999; 89:1255-64. 
94. Langer S. Nolte D. Koeller M. Stemau HU, Khandoga A, Homann HH. In wivo visuatization of plateletendothelim cell interaction in muscle flaps. Ann Post Surg. $2004: 53: 137-40$.

95. Belzer FO, Solthard JH. Principles of solid-organ preserwation by cold storage: Transplaniavion. 1988:45:673-6.

96. Matsuno N Sakurai E, Tamaki I, Uchiyama M. Kozaki K. Kozaki M. The effet of machine perfusion preservation versus cold storage on the lunction of kidneys from non-heart-beating donors. Transplantation. 1994,57:293-4.

97. Brook NR, Waller JR, Nicholson ML. Nonheart-beaning kidney donation: current practice and future developments. Kidney Int. 2003;63:1516-29:

98. Wight $J$, Chilcot $J$. Holmes $M$, Brewer $\mathbb{N}$. The clinical and costeffectiveness of pulsatile machine perfusion versus cold storage of kidneys for transplatation retrieved from heart-beating and non-heart-beating donors. Healh Techwol Assess. $2003 ; 7: 1 \cdot 94$.

99. Muhlbacher F, Langer F, Mithermayer C. Preservation solutions for transplantation. Transplant Proc. 1999:31:2069-70.

100. Salahudeen AK. Consequences of cold ischemic injury of kidneys in clinical transplantation. J Investig Med. 2004:52:296-8.

101. MeLaren AJ, Friend PJ. Trends in organ preservation. Transp/ Mn. 2003:16:701-8.

102. Salahudeen AK. Cold ischemic injury of transplanted kidneys: new insights from experimental studies. Am J Physiol Renal Physiol. 2004;287:F181-7.

103. Fuller BJ, Pegg DE. The assessment of renal preservation by normothermic bloodless perfusion. Cryobiology. 1976;13:177-84.

104. Jahan ia MS, Sanchez JA, Narayan P Lasley RD, Mentzer RM, Jr. Heart preserwation for transplantation: principles and strategies. Ann Thorch Surg. 1999;68:1983-7.

105. Collins GM. Halasz NA. Forty-eight hour jce storage of" kidneys: importance of cation content. Surgery. 1976:79:432-5.

106. Southard JH, wan Gulik TM, Ametani MS. Vteugdenhil PK, Lindell SL, Plenaar BL, Belzer FO. Important components of the UW solution. Transplantarion. 1990:49:251-7.

107. Ploeg RJ, Goossens D, Vreugdenhil P, MCAntuty JF, Southard JH, Beller FO. Successful 72-hout cold storage kidney preservation with UW solution. Tramsplant Proc: $1988 ; 20,935-8$.

108. Jamieson NV, Sundberg R, Lindell S, Claesson K, Moen J, Vreugdenhil PK, Wight DG, Southard JH, Beber FO. Preservation of the catnine liver for 24 . 48 hours using simple cold storage with UW solution. Thansplantation 1988:46:517-22.

109. Bretschneider H. Myocardial protection. Thorac Cardiovasc Surg. $1980 ; 28: 295$. 302.

110. Canelo R, Hakim NS. Ringe B. Experience with hystidine tryptophan ketoglutarate versus University Wisconsin preservation solutions in transplantation. In Surg. $2009: 88: 145-51$. 
111. Potdar $\$$, Malek $\mathrm{S}$, Eghtesad B. Shapiro R, Basu A, Patel K, Broznick B, Fung J. Intial experience using histidine-tryptophan-ketoglutarate solution in clinical pancreas transplantation. Clin Thansplant. 2004:18:661-5.

112. Groentwotid AF, de Boen J A report of the eurotransplant randomized multicenter study comparing kidney graft preservation with HTK, UW and EC solutions. HTK study group. Transpl Mn. 1994:7 Suppl 1.9479-80.

113. de Boer J, De Meester J, Smits JM, Groenewoud AF, Bok A, van der Velde O. Doxiadis, II, Persin GG. Eurotransplant randomized multicenter kidney graft preservation sudy comparing HTK with UW and Euro-Collins. Tramspl Int. $1999 ; 12: 447-53$

1 4. Pokorny H, Rasoul-Rockenschaub S, Langer F, Windthager T, Rosenstingl A, Lange $\mathrm{R}$, Konigsraner A. Ringe B, Muhbacher F, Steininger R. Histidine-tryptophanketoglutate solution for organ preservation in human liver transplantation-a. prospective multi-centre observation study. Tronspl Int. 2004:17:256-60.

115. Audet M, Alexandre E, Mustun A, David P, Chenard-Neu MP, Tiollier J, Jaeck D, Cinqualbre J, Wolf P. Boudjema $\mathrm{K}$. Comparative evaluation of Celsior solution versus Viaspan in a pig liver transplantation model. Transplantotion. 2001;71:1731-5.

1 16. Kanm G, Compagnon P. Hourmant M. Despins P, Duveau D, Noury D, Boudjema K. A single solution for multiple organ procurement and preservation. Traspl Int. $2005 ; 18: 657 \cdot 63$

117. Ohwada S, Sunose Y, Tsutsumi H, Iwazaki S, Aiba M, Kasahara M, Kawashima Y, Takeyoshi 1, Matsumoto K, Morishita Y. Celsior is stperior to UW for graft preservation from non heart-beating donors in a canine liver transplantation model. Thansplant Proc. 2001:33:922-3.

118. Matsumoto S, Kuroda Y. Perfluorocarbon for organ preservation before transplantation. Transplankation. 2002; 74:1804-9.

119. Lowe KC. Davey MR. Power JB. Perfluorochemicals: their applications and benefts to cell culture. Trends Biofechnol. 1998,16:272-7.

120. Kuroda $X$, Kawamuna T, Suzuki $Y$, Fujiwara H, Yamamoto K. Saitoh Y. A new, simple method for cold storage of the pancreas using perfuorochemical. Transplantation. 1988;46:457-60.

121. Tanioka Y, Sullerland DE, Kuroda Y, Gilmore TR, Asaheim TC. Kronson JW, Leone JP. Excallence of the two-layer method (University of Wisconsin solution/perfluorochemical) in pancreas preservation before islet isolation. Surgery. $1997 ; 122,435-41$; discussion 441-2.

122. Matsumoto $S$. Clinical application of perfluorocarbons for otgan preservation. Antif Ceth Blowd Swbith Immobil Biotechnol. 2005;33;75 82. 


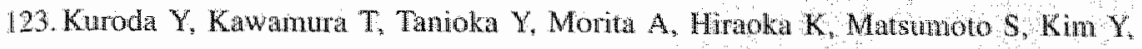
Fujno Y, Suzuki $Y, K u Y$, et al. Heart preserwation asing a cavilary two-libyer University of Wisconsin solution/perfluorochemical) cold stortage method. Transplantation. 1995;59:699-701.

124. Kuroda Y, Sakai T. Suzuki Y, Tanioka Y, Matsumoto S. Kim Y. Fujuta H, Hamano M, Hasegawa Y, Ku Y, Saitoh Y. Small bowel preservation using a cavitury two-layer (University of Wisconsin solution/pertluorochemical) cold storage method. Transplantarion. 1996;61:370-3.

125. Matsumoto S. Qualley SA. Goel S, Hagman DK, Sweer IR; Poitont V. Strong DM, Robertson RP, Reems JA. Effect of the two-layer (University of Wisconsin solutionperfluorochemical plus $\mathrm{O} 2$ ) method of pancreas preserwation on human isler isolation, as assessed by the Edmonton 1solation Protocol. Transplantation. 2002;74:1414-9.

126. Menger MD, Laschke MW, Vollmar $B$. Viewing the microcirculation through the window: some twenty years experience with the hamster dorsal skinfold chamber. Eur Surg Res. 2002,34:83-91.

127. Menger MD, Lehr HA. Scope and perspectives of intravital microscopy--bridge over from in vitro to in vivo. Lmmunol Today 1993;14:519-22.

128. Beuk RJ, Heineman E, Tangelder GJ, Quaedackers JS, Marks WH, Lieberman JM, oude Egbrink MG. Total warm ischemia and reperfusion impairs tow in all rat gut layers but incresses leukocyte-vessel wall interactions in the submucosa only. Am Surg. $2000 ; 231: 96-104$.

129. oude Egbrink MG, Janssen GH, Ookawa K, Slaaf DW, Reneman RS, Wehrens XH, Maajwee KJ, Ohshima N, Struijker Boudier HA. Tangelder GJ. Especially polymorphonuclear leukocytes, but also monomorphonuclear leukocytes, roll spontaneously in venules of intact rat skin: involvenent of E-selectir. $J$ mest Dermatol. 2002:118:323-6.

130. van Gestel MA. Heemskerk JW, Slat DW, Heijnen VV, Reneman RS, oude Egbrink MG. In wivo blockade of platelet ADP receptor P2Y 12 reduces embollus and thrombus formation but not thrombus stability. Arteriascler Throwb Vase Biol. 2003; 23:518-23.

131. Hoffmarn JN, Volmar B, Inthorn D. Schidberg FW, Menger MD. Antithrombin reduces leukocye adhesion during chronic endotoxemia by modulation of the cyclooxygenase pathway. An J Physol Cell Physiol $2000,279: \mathrm{C} 98-\mathrm{C} 107$.

132. Zweifach BW. The microcirculation in the intestinal mesentery. Marowase Res. $1973: 5: 363-7$.

133. Baez S. An open cremaster muscle preparation for the study of blood vessels by in vivo microscopy. Microvasc Res. 1973,5:384-94.

134. Meininger GA, Fehr KL, Yates MB. Antomic and henodynamic chatucteristics of the blood vessels feeding the cremaster skeletal muscle in the rat. Microvasc Res. $1987: 33: 81-97$ 
135. Framken RU, Peter FW, Anderson GL, Wang WZ, Werker PM, Schuschke DA, Kon M. Barker JH. Anatomy of the feeding blood vessels of the cremaster muscle in the vat. Microsurgery. 1996;17:402-8.

136. Wang $\mathrm{DH}$, Prewitt R. Microvascular development during normal growth and reduced blood flow: introduction of a new model. Am J Physiol. 1991:260:H1966-72.

137. Anderson GL. Acland RD, Siemionow M, MCCabe SI. Vascular isolation of the rat cremaster muscle. Microvasc Res. 1988;36:56-63.

138. Acland RD , Anderson G, Siemionow M, McCabe S. Direct in vivo observations of embolic events in the microcirculation distal to a small-vessel anastomosis. Plast Reconstr Surg. 1989:84:280-8; discussion 289.

139. Siemionow M, Wang WZ. Anderson G; Firrell J. Lewkocyte-endothelial interaction and capillary perfusion in ischemia/reperfusion of the rat cremaster muscle. Microcirc Endothetium Lymphatics. 1991:7:183-97.

140. Barker JH, Acland RD. Anderson GL, Patel I. Microcirculatory disturbances following the passage of emboli in an experimental free-flap model. Plast Reconstr Surg. 1992:90:95-102; discussion 103-4,

141. Wang WZ, Anderson G, Firrel JC. Arteriole constniction following ischemia in denervated skeletal muscle. J Reconstr Microsurg. 1995;1 1:99-106.

142. Franken RJ, Werker PM, Peter FW, Overgoon ML, Wang WZ, Anderson GL, Sohuschke DA, Banis JC, Jr., Kon M, Barker JH. Microcirculatory changes following different temperature washous in a free flap model. Microwngery. 1999; 19:2 [4-22.

143. Wang WZ, Anderson G, Maldonado $C$, Barker J. Attenuation of vasospasm and capillary no-reflow by ischemic preconditioning in skeletal muscle. Microsurgery. $1996: 17: 324-9$

144. Alper M, Ozek C, Erdem O, Denk M, Colen LB. Prewit R. Effects of University of Wisconsin and lactated Ringer"s solutions to uschemia-reperfusion injury in isolated cremaster flap. Microsurgery. 2002;22:69-73.

145. Siemionow M. Nahekhan LV. Introduction of cremaster muscle chamber technique for long-lerm intravital microscopy. Ann Plast Surg. 1999:43:161 66.

146. Nanhekhan LV, Sicmionow M. Microcirculatory hemodynamies of the rat cremaster muscle nap in reduced blood flow states. Ann Plast Swrg. 20035 $51: 182-8$. 



\section{CHAPTER 3 \\ Effect of HTK on the microcirculation in the rat cremaster muscle during warm ischemia and reperfusion}

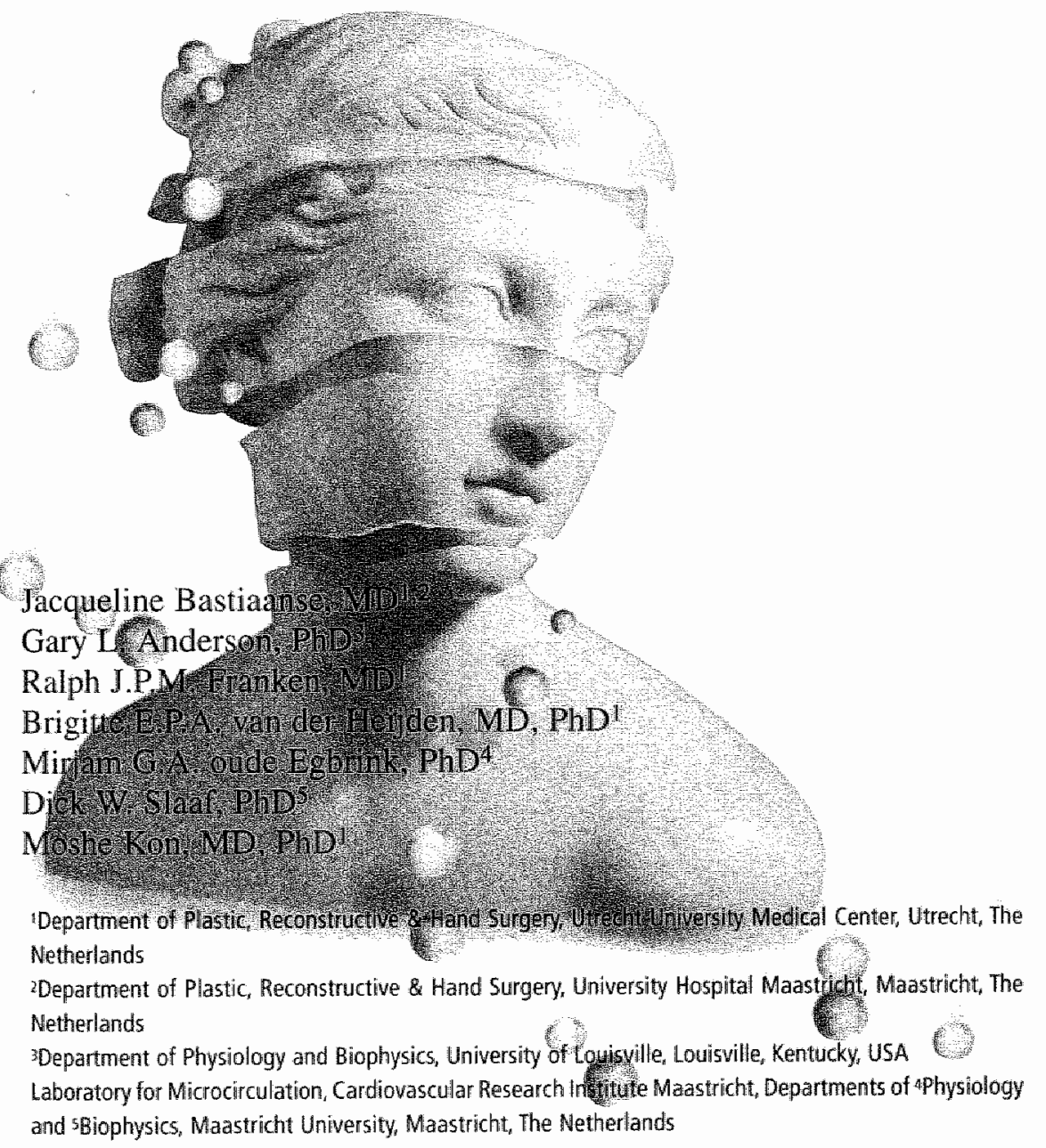

Microsurgery 2005;25:174-80 


\section{Abstract}

Histidine-Tryptophan-Ketoglutarate (HTK) preserves rat muscle function during cold storage. We examined, the effect of HTK perfusion on preservation of microvascular function during 4 hours of warm ischemia and subsequent reperfusion (I/R) in rat cremaster muscle. Leukocyteendothelium interactions, capillary perfusion, and arteriole diameters were quantified prior to HTK-perfusion and/or ischemia, and at 0,1 , and 2 hours after restoration of blood flow. In all groups, number of rolling leukocytes increased with time, whereas $I / R$ induced a slight increase in leukocyte adhesion. After ischemia, capillary perfusion rapidly recovered to about $50 \%$ and retumed to near normal $(90 \%)$ after 2 hours. HTK at $22^{\circ} \mathrm{C}$ did not affect the assessed microcirculation variables, whereas HTK at $4^{\circ} \mathrm{C}$ reduced leukocyte rolling, but not adhesion. Therefore, microvascular function of HTK perfused muscles was not better preserved fluring warm I/R than that of non-perfused muscles. Contrary to other preservation solutions, HTK perfusion in itself was not detrimental to the microcirculation. 


\section{INTRODUCTION}

Major tissue defects are usually reconstructed by transfer of local, distant or free vascularized flaps or by autologic transplantations. Survival rate of these flaps is very high $(95-98 \%) .{ }^{1}$ Occasional, unexpected flap loss can lead to devastating consequences for the patient. ${ }^{2}$ In more complex cases, in which function of the lost part often cannot be adequately duplicated by the chosen replacement part, ${ }^{3}$ results may be vastly improved by replacing missing tissue with analogue cadaver tissue, so-called composite-tissue allografts (CTA's). These grafts may be composed of various tissues such as skin, muscle, bone, fat, cartilage, nerve and blood vessels. At present, the best preservation strategy clinically used for isolated CTA's is surface cooling. ${ }^{4,5}$ Survival of transplanted tissue requires not only cellular protection, but also preservation of the vascular bed.

After an ischemic period, tissue may get damaged due to reperfusion with oxygenated blood." Severity of the damage produced by ischemia and reperfusion $(I / R)$ is proportional to duration of ischemia. ${ }^{6}$ In several animal models the consequences of $I / R$ can be examined directly by vital imaging. I/R is characterized by an increase in leukocyte-endothelium interactions and a decrease in microvascular perfusion. 7,8

Of all tissues present in CTA's, muscle is one of the least tolerant to ischemia. Therefore, in previous studies we assessed the potential of immersion in various preservation solutions to protect isolated muscles of the rat during cold storage. It was found that at $4^{\circ} \mathrm{C}$, contractility of isolated rat muscles was best preserved in HTK-Bretschneider solution (HTK; Table 3.1). HTK is an

Table 3.1

Composition of Histidine Inptophan-Ketoglutarate Bretscheider solution (HTK)

(mmolili)

\begin{tabular}{|c|c|}
\hline Component & \\
\hline $\mathrm{NaCl}$ & 15 \\
\hline $\mathrm{KCl}$ & 9 \\
\hline $\mathrm{MgCl}_{2}$ & 4 \\
\hline $\mathrm{CaCl}_{2}$ & 0,015 \\
\hline Ketoglunarate: & 1 \\
\hline Histidine & 180 \\
\hline Histidine $\mathrm{HCl}$ & 18 \\
\hline Mannitol & 30 \\
\hline Irptophan & 2 \\
\hline Osmolarity (mosm) & 327 \\
\hline $\mathrm{pH}+$ & 11 \\
\hline
\end{tabular}


intracellular type preservation solution with a low viscosity. The basic philosophy behind this solution is that cellular protection occurs because of introduction of histidin, a very potent buffer system, while the two substrates tryptophan and ketoglutarate can be utilized by the muscle for basic metabolism. ${ }^{9}$ Rat skeletal muscles were preserved during 16 hours without measurable function loss. ${ }^{10}$ In large human muscles, however, cold storage by immersion in a preservation solution at $4^{\circ} \mathrm{C}$ may not be sufficient, because diffusion distances may be too large. Perfusion with HTK throughout the muscle's vasculature may improve the preservation of such isolated muscles.

At this moment, little is known about the effect of tissue perfusion with preservation solutions of various temperatures on the consequences of $I / R$ in the microvasculature of isolated muscles. Alper et al. ${ }^{11}$ perfused rat cremaster muscle with lactated Ringer"s and University of Wisconsin (UW) solution prior to reperfusion. It turned out, however, that these two preservation solutions were harmful to the tissue instead of protective. In the present study rat striated muscle is perfused with HTK just prior to an ischemic period. The aim of this study was to assess in skeletal muscle microcirculation the influence of perfusion with $\mathrm{HTK}$ at 4 and $22^{\circ} \mathrm{C}^{12}$ on the consequences of 4 hours of warm ischemia with subsequent reperfusion. We used an in-vivo muscle flap, the rat cremaster muscle, which allows for direct inspection and assessment of various microcirculation parameters during perfusion, washout, and reperfusion, including leukocyte-endothelium interactions, capillary perfusion, and dynamic changes in arteriole caliber.

\section{Materials and Methods}

\section{Animals}

Male Wistar rats (110-170 grams) were used. Rats were housed in pairs on a 12:12 hour (light-dark) cycle and were provided a standard rodent diet and water ad libitum. All animals received care in compliance with the European Convention guidelines and the local ethics committee approved all protocols. Rats were anesthetized with fentanyl-fluanisone (Hypnorm ${ }^{\mathrm{TM}}$, Janssen Pharmaceutica, Beerse, Belgium) at an intramuscular dose of $0.5 \mathrm{ml} / \mathrm{kg}$, and sodium pentobarbital (Nembutal ${ }^{\text {M }}$, Sanofi Sante B.V. Maassluis, The Netherlands) at a subcutaneous dose of $15 \mathrm{mg} / \mathrm{kg}$. Additional injections were given when necessary. A blood pressure cannula (PE 50) was inserted into the left carotid artery to monitor systemic arterial pressure and a 
tracheal tube (PE 160) was placed to maintain an open airway. Pilot experiments demonstrated that this procedure maintained normal blood gas values. During the experiment, body and cremaster temperatures were maintained at $36-37^{\circ} \mathrm{C}$ and at $33-34^{\circ} \mathrm{C}$, respectively, using heating lamps.

\section{Surgical procedure}

Dissection of the cremaster muscle on its vascular pedicle was performed as previously described. ${ }^{13,14} \mathrm{~A}$ left paramedian incision was made from the tip of the scrotum to its base and carried laterally towards the anterior iliac spine. Connective tissue of the scrotal sac was removed from the cremaster muscle by careful blunt dissection. During dissection, tissues were kept moist by irrigation using normal saline. The cremaster muscle was spread out with 5-0 silk sutures onto a specially designed, glasscovered optical port for microscopic observation. Using bipolar cautery, the full thickness of the abdominal wall muscles was divided for $1 \mathrm{~cm}$ cranial and parallel to the inguinal ligament. Subsequently, the vascular sheath of the femoral vessels was opened. All irrelevant branches of the iliac vessels were ligated leaving all possible donor vessels for the cremaster musculature intact, including the deep circumflex iliac artery (DCIA), the superior external pudendal artery (SEPA), the hypogastric trunk (HT) with its continuations and the inferior epigastric artery (IEA)(Fig. 3.1). This insured that no arterial blood could enter the

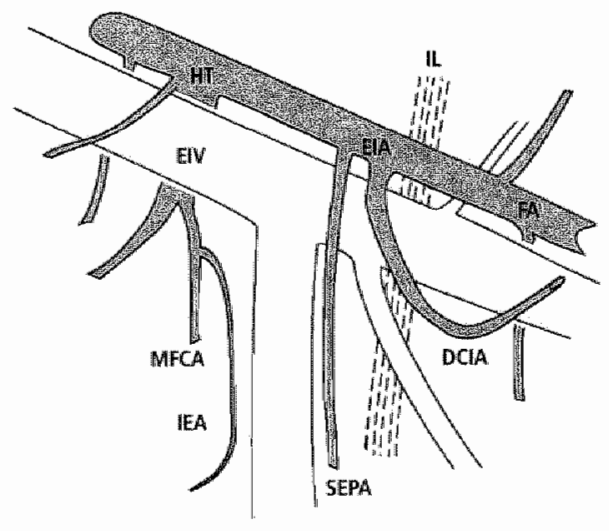

Fig. 3.1

Anatomy of vascular supply to the rat cremaster muscle Abbrewiations

DCIA. Deep circumflex liac artery

EIA External iliac artery

EIV Externalliliac we in

FA Femoral artery

HT Hypogastric trunc

IEA Inferior epigastric artery

IL Inguinal ligament

MFCA Medial femoral circumflex artery

SEPA Superior external pudendal artery

cremaster when the common iliac artery was clamped and that all of the HTK-infusate would flow into the cremaster muscle during infusion. At the end of the isolating dissection, the cremaster muscle had no attachment to the body except the vascular pedicle. To enable perfusion with HTK, 
a catheter (PE 50) was inserted retrograde into the distal end of the femoral artery. The catheter was connected to a microprocessor controlled tubing pump (Ismatec Reglo Digital, Ismatec SA, Glattbrugg-Zuirich, Switzerland) and its outflow tip was positioned within close proximity of the pedicle artery of the cremaster muscle.

\section{Experimental procedure}

Animals were placed on a specially designed Plexiglas observation platform. The cremaster muscle was carefully spread and covered with gas-impermeable plastic film (Saran Wrap ${ }^{\text {TM}}$; presoaked for 24 hours in distilled water to remove chemical residues). The platform was then placed on the stage of the intravital microscope. Tissue stabilization was allowed for 30 minutes $^{15}$ prior to observations and measurements. The thin cremaster muscle in young rats allows clear visualization of microvessels.

To start the ischemic period, a single Acland-type microvascular clamp was placed on the iliac artery between the HT and either the DCIA or the SEPA vessels (Fig. 3.1), dependent on the vascular anatomy of that particular muscle. ${ }^{14}$ Perfusion with HTK (Table 3.1) was accomplished at a rate of $40 \mu \mathrm{J} / \mathrm{min}$ during 10 minutes under continuous monitoring of perfusion pressure through the femoral artery catheter to avoid high pressures in the cremaster muscle. Infusion rate was calculated to be approximately equal to the normal blood flow to the cremaster. ${ }^{16}$

Five experimental groups were studied:

1) Control group (control; $n=6$ ) that was not exposed to HTK perfusion or ischemia, but otherwise treated the same as the experimental groups.

2) HTK perfusion group (HTK; $\mathrm{n}=6)$ in which the cremaster was perfused for 10 minutes, at a rate of $40 \mu \mathrm{l}$ per minute with HTK at $22^{\circ} \mathrm{C}$; the muscle was subjected to a brief (10-minute) period of ischemia.

3) Ischemia reperfusion group $(1 / \mathrm{R} ; \mathrm{n}=6)$ in which the blood flow to the cremaster was stopped by placing a vascular clamp on the iliac artery for 4 hours. No perfusion washout was used. The muscle surface temperature was kept at $33-34^{\circ} \mathrm{C}$. After 4 hours of ischemia the clamp was released to restore the natural blood flow to the muscle (reperfusion).

4) and 5) HTK perfusion $+I / R$ groups in which the cremaster was perfused for 10 minutes with HTK at $22^{\circ}$ (group 4: $\mathrm{HTK}_{22} \mathrm{~L} / \mathrm{R} ; \mathrm{n}=6$ ) or at $4^{\circ} \mathrm{C}$ (group 5: $\mathrm{HTK}_{4} \mathrm{I} / \mathrm{R} ; \mathrm{n}=6$ ) prior to 4 hours of warm $\left(33-34^{\circ} \mathrm{C}\right.$ ) ischemia and 2 hours of reperfusion. 
In all groups, baseline measurements (pre-ischemic and pre-perfusion) were performed after a stabilization period of 30 minutes following surgical preparation. Subsequent measurements were performed at the start of reperfusion, after 4 hours of ischemia (TO), and after 1 and 2 hours of reperfusion (T1 and T2, respectively). In the control and HTK perfusion groups, measurements were performed at similar time points, i.e., at 4, 5 , and 6 hours after baseline.

\section{Microcirculation Measurements}

The microvascullature was observed using an intravital microscope (Zeiss (Jena, Germany) Axiotech microscope) equipped with a $2 / 3$-inch Sony CCD camera coupled to a closed-circuit video system. Microvascular images were recorded on videotape using a video recorder (Panasonic).

\section{Arteriolar diameters}

Special care was taken to evaluate a major part of the arteriolar tree, including distributing arterioles (A1 and A2 branch orders) and terminal arterioles (A3 and A4 branch orders). About 8-10 distributing and 25-30 terminal arterioles were examined in each animal. Observation started at the major feeding arteriole (Al). Using a 10x objective lens (numerical aperture 0.25), each branch was sequentially followed down to the fourth order arterioles (A4). Arteriolar lumen diameter was measured at the narrowest point along each designated vessel segment. A vessel segment was defined as the part of vessel between two consecutive branches along the arteriole, regardless of segment length. At each time point during reperfusion, the same segments were measured again. Diameter measurements were only performed on vessels with blood flow. Arterioles with flow during the baseline period, but no flow during the reperfusion period were classified as "no-reflow arterioles". The number of no-reflow vessels was counted for each cremaster muscle. Measurement of arteriolar diameters was performed off-line on the recorded video image with a calibrated micrometer.

\section{Capillary Perfusion}

To determine capillary perfusion, parts of the cremaster muscle were observed to assess the number of perfused capillaries. At three different locations, nine adjacent fields of view were evaluated with a $20 \mathrm{x}$ objective (numerical aperture 0.40). As a result, the number of perfused capillaries was quantified in 27 fields of view. One field of view measured $300 \times 400 \mu \mathrm{m}$. The same locations were measured throughout the experiment. Results are expressed as the average number of perfused capillaries per location (of 9 fields). 


\section{Leukocyte-endothelium interactions}

At each of the three locations observed for capillary perfusion, a thirdorder venule was examined to assess leukocyte-endothelium interactions. Leukocytes rolling along the wall were counted for a period of 60 seconds. Rolling leukocytes moved along the endothelial wall at a velocity noticeably slower than that of the free flowing red blood cells. The number of leukocytes adhering to the vascular endothelium was assessed in a segment of $100 \mu \mathrm{m}$ length. Adherent leukocytes remained stationary on the endothelial wall for at least 30 seconds.

\section{Statistics}

Data are presented as means \pm SEM. They are normalized by expressing them as percentage of baseline values. Repeated-measures ANOVA was used to compare data groups, followed by a multiple comparison procedure for specific differences (using Bonferroni correction) for capillary perfusion. Because of non-normality of data, nonparametric tests (Mann Whitney and Wilcoxon tests) were used to test specific differences in numbers of rolling and adhering leukocytes (leukocytevessel wall interactions). A p-value $<0.05$ was considered significant.

\section{RESULTS}

Mean carotid artery pressure ranged from 85 to $105 \mathrm{mmHg}$ and remained stable throughout the experiments. Prior to perfusion with HTK, femoral artery pressure was about equal to systemic blood pressure. During perfusion with HTK, pressure measured in the femoral artery decreased to $25-65 \mathrm{mmHg}$.

Perfusion with HTK resulted within a few minutes in complete removal of all blood cells from the microcirculation. Even leukocytes adherent to the vessel wall were removed.

\section{Arterioles}

At baseline, average diameters of the distributing arterioles in the various groups ranged from 70 to $78 \mu \mathrm{m}$, while diameters of the terminal arterioles ranged from 13 to $19 \mu \mathrm{m}$ (Table 3.2). Four hours of ischemia did not influence these dimensions. The same holds for the experiments with intra-arterial infusion of HTK, with or without ischemia and at both temperatures. In addition, no differences in the diameters of distributing (A1/A2) or terminal (A3/A4) arterioles were observed in the course of time during reperfusion (Table 3.2 ). 
Table 32

Artenolar diameters (micrometer i in all experimental groups, and at all time points, Values are expressed as mean \pm sem, No significant differences were observed.

\begin{tabular}{|c|c|c|c|c|c|}
\hline & Control & 18 & HIK & $\mathrm{HIK}_{2} \mathrm{UP}_{\mathrm{R}}$ & HIK, IR \\
\hline \multicolumn{6}{|c|}{ Distributing arterioles } \\
\hline baseline & $75 \pm 31$ & $70 \pm 29$ & $73+13$ & $74 \pm 2.8$ & $78+296$ \\
\hline 10 & $71+32$ & $72+11$ & $69+23$ & $73+26$ & $76 \div 3,35$ \\
\hline II & $72+29$ & $68 \pm 35$ & $72+3.4$ & $68 \pm 21$ & $71=2.63$ \\
\hline 12 & $68+29$ & $71+33$ & $67 \pm 34$ & $70 \pm 3,3$ & $75=229$ \\
\hline \multicolumn{6}{|c|}{ Terminal arterioles } \\
\hline baseline & $14 \pm 02$ & $14+03$ & $16+08$ & $13+0.2$ & 1940,7 \\
\hline T1 & $15+04$ & $15 \pm 03$ & $15+10$ & $13 \pm 0,4$ & $20+073$ \\
\hline $\mathrm{TH}$ & $14 \pm 02$ & $14+05$ & $15+0.6$ & $13+03$ & $19 \pm 0.63$ \\
\hline $\mathrm{T}$ & $13 \pm 0,2$ & $14+04$ & $14+06$ & $15 \pm 02$ & $19+07$ \\
\hline
\end{tabular}

At the start of reperfusion, after 4 hours of ischemia, flow through the arterioles was reduced in all groups (qualitative observations). This reduction disappeared in most arterioles within the first hour of reperfusion. Although all arterioles were filled with blood at start of reperfusion, in some of the arterioles stagnant blood was observed at reperfusion.

\section{Capillary perfusion}

At baseline, we observed an overall average number of $111 \pm 2$ perfused capillaries per location ( 9 fields of view) with no differences between groups. After 6 hours, capillary perfusion had not changed in control conditions. HTK perfusion alone did not affect the number of capillaries perfused during the whole observation period.

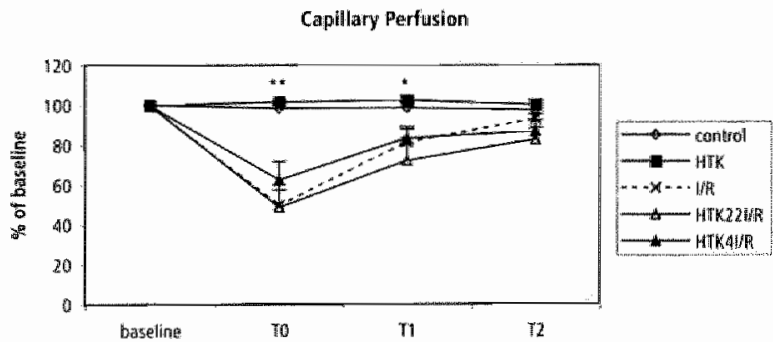

Fig. 3.2

Effects of $\mathrm{HTK}$ and/or $\mathrm{I} / \mathrm{R}$ on capillary perfusion in rat cremaster muscle. Data are presented as means $\mathrm{x}$ SEM. * $\mathrm{p}<0.05$ and * $\mathrm{p}<0.01$ as compared to all $1 / \mathrm{R}$ groups.

$T 0, T 1, T 2: 0,1$ or 2 hours after start of reperfusion; in control and HTK groups TO,T1, T2:4, 5 or 6 hours after baseline. 
This was different in the I/R groups, where capillary perfusion resumed in about half of the capillaries after release of the clamp at the end of the ischemic period ( $<<0.01$; Fig. 3.2). Subsequently, the number of perfused capillaries increased almost to baseline levels in the next 2 hours. HTK perfusion did not influence these effects of $\mathrm{I} / \mathrm{R}$ on capillary perfusion, irrespective of the temperature $\left(22\right.$ or $\left.4^{\circ} \mathrm{C}\right)$ of the solution.

\section{Leukocyte-endothelial interactions}

\section{Leukocyte rolling}

At baseline, average level of leukocyte rolling ranged from 15 to 43 cells/minute. In the control group, this level increased significantly during the 6-hour observation period to more than 2.5 times baseline level $(\mathrm{p}<0.05$; Fig. 3.3). Similar increases were observed in the HTK, I/R and $\mathrm{HTK}_{22} \mathrm{I} / \mathrm{R}$ groups. Perfusion with cold HTK prior to ischemia $\left(H_{T K} \mathrm{I} / \mathrm{R}\right)$ resulted in a significantly lower level of leukocyte rolling during reperfusion as compared to the levels observed in the I/R and HTK ${ }_{22} L / R$ groups $(p<0.01)$.

Rolling Leukocytes

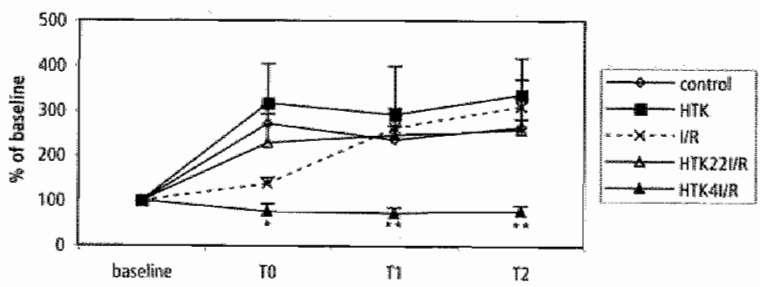

Fig. 3.3

Effects of HTK and/ar IR on number of rolling leukocytes in venules in rat cremaster muscle. Data are presented as means \pm SEM. *indicates $p<0.05$ compared to other groups.

$T 0, T 1, T 2: 0,1$ or 2 hours after start of reperfusion; in control and HTK groups. T0, T1, $\pi 2: 4,5$ or 6 hours after baseline.

\section{Leukocyte adhesion}

At baseline, the average number of adhering leukocytes per $100 \mu \mathrm{m}$ vessel segment ranged from $1.4 \pm 0.2$ to $2.2 \pm 0.9$ in the various groups. In the control group, this level did not change during the 6-hour observation period. This also holds for the HTK group. In the I/R group the level of leukocyte adhesion increased from $1.7 \pm 0.2$ at baseline to 4.4 \pm 0.6 after 2 hours of reperfusion. Perfusion with $\mathrm{HTK}$, both at $22^{\circ} \mathrm{C}$ and $4^{\circ} \mathrm{C}$, prior to ischemia, did not significantly influence this increase in leukocyte adherence (Fig. 3.4). 
Fig. 3,4

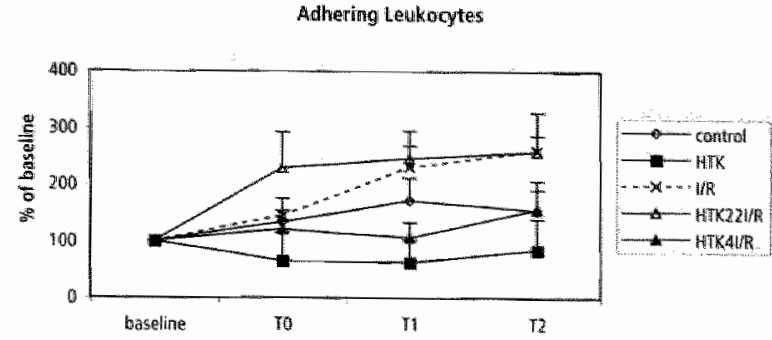

Effects of HTK and/or I/R on leukocyte adhesion in venules in rat cremaster muscle. Data are presented as. means \pm SEM.

TO, T1, T2: 0,1 or 2 hours after start of reperfusion; in control and HTK groups T0, T1, T2: 4,5 or 6 hours after baseline.

\section{Discussion}

In reconstructive surgery, transferred vascularized flaps are always subjected to a certain period of ischemia followed by post-ischemic reperfusion. This may lead to significant injury and reduced survival of the tissue flaps, at least partly mediated by the microvascular consequences of ischemia and reperfusion. ${ }^{7}$ In the present study, we investigated whether perfusion of rat skeletal muscle with HTK-Bretschneider solution (HTK) prior to the ischemic period improves the microvascular conditions after 4 hours of warm ischemia $\left(33-34^{\circ} \mathrm{C}\right)$ with subsequent reperfusion (I/R). Whereas I/R did not affect arteriolar diameters, capillary perfusion started at about $50 \%$ in the first hour of reperfusion with an almost complete recovery to baseline in the second hour. Perfusion with HTK, both at 4 and $22^{\circ} \mathrm{C}$ resulted in complete washout of blood cells prior to ischemia and did not influence the gradual recovery in tissue perfusion. The same holds for the increase in leukocyte adhesion that was induced by I/R: perfusion with HTK at both temperatures could not prevent this inflammatory response. I/R-induced injury to skeletal muscle is a common clinical problem associated with significant morbidity and mortality. ${ }^{17}$ Temporal decrease in microvascular perfusion (no-reflow phenomenon) and occurrence of endothelial cell injury leading to increased microvascular permeability have become commonly accepted consequences of post-ischemic reperfusion. ${ }^{18,19}$ In the present study, 4 hours of warm ischemia of the rat cremaster muscle resulted in a transient reduction in tissue perfusion, with an almost complete recovery during the 2 hour reperfusion period: capillary perfusion and arteriolar flow returned to baseline levels. Considering that arterioles were patent throughout the experiment - no 
closure of vessels was observed-interaction of blood cells with the vessel wall must have caused the stasis. Therefore, a period of 4 hours of ischemia only transiently decreases cremaster muscle perfusion, and this is not influenced by pre-ischemic perfusion with HTK. Reperfusion after HTK perfusion also resulted in stasis after initial inflow of blood, which disappeared at the same rate as no HTK-treatment. We expect, however, that HTK perfusion is more beneficial if the cremaster muscle is subjected to longer periods of ischemia. Previous studies indicate that irreversible changes occur in skeletal muscle after 4 to 6 hours of warm ischemia. ${ }^{20-24}$ Six hours of ischemia under normothermic conditions proved to be lethal for rat cremaster muscle flaps..$^{22}$

In our model, 4 hours of total warm ischemia induced an increase in leukocyte adhesion during the reperfusion period. It is a well-known phenomenon that $I / R$ stimulates leukocyte-endothelium interactions through upregulation of endothelial adhesion molecules. ${ }^{25}$ This will lead eventually to increased transmigration of activated leukocytes into the tissue. Data from a study by Forbes et al. ${ }^{19}$ suggest that the onset of parenchymal injury in skeletal muscle following ischemia is caused by the presence of activated leukocytes. Perfusion with HTK did not prevent this inflammatory reaction to $\mathbb{I} / \mathrm{R}$. The level of leukocyte rolling, which is a necessary prerequisite for adhesion to occur, ${ }^{26}$ was diminished by perfusion with cold HTK (at $4^{\circ} \mathrm{C}$ ) prior to ischemia. This suggests that the expression of endothelial selectins, involved in rolling, 27 may be reduced by cold HTK. However, since the increase in leukocyte adhesion in this group was similar to the one found in the I/R group without HTK perfusion, the decrease in leukocyte rolling was without beneficial consequences for the tissue.

HTK has been introduced as a physiologic cardioplegic solution with a low viscosity and is particularly used for cardiac preservation. ${ }^{9}$ Exposure to HTK during 10 minutes, without subsequent $I / R$, had no adverse effects on microcirculatory parameters: arteriolar diameters, capillary perfusion and numbers of rolling and adhering leukocytes were unaffected, which suggests that HTK by itself is not detrimental to the endothelium. However, HTK did not influence the effects of 4 hours of warm ischemia and reperfusion in our model as well. In this respect, HTK differs from UW and lactated Ringer's solutions that proved to be harmful to microcirculatory parameters in the same preparation. ${ }^{11}$ No-reflow phenomenon occurred in 6 of 8 rats in experiments in which UW solution was used as perfusion solution, while diameters of A1 arterioles decreased 
after perfusion with lactated Ringer's solution. UW is the most frequently used preservation solution for livers, kidneys and pancreases with excellent clinical and experimental preservation results. The disadvantage of UW, however, is its high viscosity and its high price; in addition, the radical scavenger glutathion cannot be detected in the solution by chemical analysis. ${ }^{9}$ Perfusion with a crystalloid cardioplegic solution $\left(16 \mathrm{meg} \mathrm{K}^{+}\right)$ induced arteriolar vasoconstriction (27\% decrease in diameter) during reperfusion in the hamster cremaster muscle. ${ }^{28}$ Pre-ischemic perfusion with an acellular physiologic solution delays the no-reflow phenomenon and improves tissue survival in rat epigastric free flaps following 18 and 24 hours of normothermic ischemia. ${ }^{29}$ The suggested efficacy of HTK is attributed to the high buffering capacity provided by histidine/histidinehydrochloride, which suppress ischemia-induced tissue acidosis. This high buffering capacity of histidine, combined with the membraneprotecting effects of tryptophan and $\alpha$-ketoglutarate may also protect the endothelial membrane against free-radicals during reperfusion. 30

After onset of HTK perfusion pressure in the femoral artery decreased, as a result of low viscosity of HTK and a low perfusion rate $(40 \mu \mathrm{l} / \mathrm{min})$. Upon reperfusion, no rise in femoral perfusion pressure was observed, which is in contrast with other studies showing a significant rise in perfusion pressure after preservation in UW. ${ }^{31}$ These effects have been attributed to the high potassium content of UW (124 mmol/l), which may have an injurious impact on vascular endothelium or vascular smooth muscle leading to an impaired vascular relaxation after extended preservation periods. HTK contains only small amounts of potassium ( 9 $\mathrm{mmol} / \mathrm{l}$ ) and this may account for the fact that we did not lind any major alterations in the vascular perfusion characteristics.

\section{Conclusions}

Pre-ischemic tissue perfusion with HTK, at both 4 and $22^{\circ} \mathrm{C}$, does not improve the microvascular consequences of 4 hours of total, warm ischemia with subsequent reperfusion of rat cremaster muscle. Perfusion with HTK per se, without I/R, was not harmful to the tissue. It is possible that HTK is able to reduce I/R injury when longer periods of ischemia are imposed. 


\section{ACKNOWLEDGEMENTS}

The authors thank the contributions of Paul M.N. Werker, MD, PhD, and the biotechnicians from the Utrecht University Central Animal Facilities, We thank Cas Kruitwagen, consultant biostatistician, for assistance in data analysis. 


\section{References}

1. Kerrigan CL, Stotland MA. Ischemia reperfusion injury: a review. Micorurgery. 1993:14:165-75.

2. Carroll WR, Esclamado RM. Ischemia/reperfusion injury in micovenscular surgery. Head Neck. 2000:22:700 13.

3. Llull R, Beko KR, Black KS, Hewit CW. Composite tissue allotransplantation: perspectives concerning eventual clinical exploitation. Transpl Rev, 1992;6:175-88.

4. Llull R. An open proposal for clinical composite tissue allotransplantation. Transplant Proc 1998-30:2692-6; discussion 2697-703.

5. Kann BR. Furnas DW, Hewit CW. Past, present, and future research in the fietd of composite tissue allotransplantation. Microsurgery. 2000;20:393-9.

6. Monis SF Pang CY, Zhong A, Boyd B, Forrest CR. Assessment of ischemia-induced reperfusion injury in the pig latissimus dorsi myocutaneous tlap model. Plast Reconstr Shrg. 1993:92:1162-72.

7. Lee YH, We FC, Lee J, Su MS, Chang YC. Effect of postischemic reperfusion on microcirculation and lipid metabolism of skeleal muscle. Microsurgery. $1995 ; 16: 522-7$

8. Gute DC, Ishida $\mathrm{T}$, Yarimizo $\mathrm{K}$, Korthuis RJ. Inflammatory responses to ischemia and reperfusion in skeletal muscle. Mol Cell Biochem. 1998;179;169-187.

9. Muhubacher $\mathrm{F}$, Langer $\mathbb{F}$, Mittermayer $C$. Preservation solutions for transplantation. Transplant Proc. 1999:31:2069-70.

10. van der Heijden EP, Kroese AB, Werker PM, de With MC, de Smet M, Kon M, Bar DP. Improving the preservation of isolated rat skeletal muscles stored for 16 hours at 4 degrees C. Transplanation. 2000,69:1310-22.

11. Alper M. Ozek C, Erdem O, Denk M, Colen LB, Prewit R. Effects of Universily of Wisconsin and lactated Ringer"s solutions to ischemia-reperfusion injury in isolated cremaster Map. Microswgery. 2002;22:69-73.

12. Franken RJ. Werker PM. Peter FW, Overgoor ML, Wang WZ, Anderson GL. Schuschke DA. Banis IC. Jr., Kon M. Burker IH. Microcirculatory changes following different temperature washouts in a free thap model. Microsugery. 1999:19:214-22.

13. Anderson GL. Acland RD, Siemionow M. McCabe SJ. Vascular isolation of the nat cremaster nuscle. Microwase Res. 1988:36:56-63.

14. Firnken RJ. Peter FW, Anderson GL, Wang WZ, Werker PM., Schuschke DA, Kon M. Barker JH. Anatomy of the feeding blood vessels of the cremaster muscle in the rat. Michosurgery. 1996;17:402-8.

15. Seaber AV. Experimental vasospasm. Microsurgery 1987:8:234-41.

16. Meininger GA, Fehr KL, Yates MB. Anatomic and hemodynamic characteristics ol" the blood vessels feeding the cremaster skeletal muscle in the rat. Micmolase Rex. $1987.33: 81-97$ 
17. Duman WW. Takenaka H, Hobson RW. 2nd Microvascullar pathophysiology of sketetal muscle uschemia reperfusion. Semin Vasc Smrg. 1998:11:203-14.

18. Smith TL, Curl WW, Smith BP, Holden MB, Wise T, Mart A, Koman LA. New skeletal muscle model for the longitudinal study of alterations in microcirctation following contusion and cryatherapy. Microsurgery. 1993;14:487-93.

19. Forbes TL, Harris KA, Jamieson WG, DeRose $G$, Carson M. Potter RF. Leukocyte activity and lissue injury following ischemin-reperfusion in skeletal muscle. Michovasc Res. 1996;51:275-87.

20. Harris AG, Leiderer R, Peer F. Messmer K. Skeletal muscle microvascular and tissue injury after warying durations of ischomia. An J Physiol. 1996;27 1:H2388-98.

21. Dahback LO, Rass $O$. Morphologic changes in striated muscle following ischemia. Immediate postischemic phase. Acta Chir Scand. 1966;131:430-40.

22. Siemionow M. Manikowski W, Gawronski M. Histopathology of muscle fap microcirculation following prolonged ischemia. Micosurgen 1995; 16:515-21.

23. Brunelli GA, Brunelli OR. Tissue changes at different periods of ischemia. Int Angiol. 1995; 14:253 63.

24. Siemionow M, Romanowsk L, Lister G. Leukocyte-depleting effect of hypothermia on muscle flap microcirculation following ischenia-reperfusion injury. I Hand Surg (Aml. 1993:18:963-71.

25. Menger MD, Laschke MW. Amon M, Schramm R, Thorlacius H, Rucker M, Vollmar B. Experimental models to study microcirculatory dysifunction in muscle ischemiareperfusion and osteomyocutaneous flap transier. Langenbecks Arch Surg. 2003:388:281-90,

26. Kubes P. Granger DN. Leukocyte-endothelial cell interactions evoked by mast cells. Cardionasc Res. 1996;32:699-708.

27. Lozano DD, Kahl EA, Wong HP, Stephenson LL, Zamboni WA. L-Selectin and leukocyte function in skeletal muscte reperfusion injury. Arch Surg. 1999:134:1079. 81.

28. Keller MW, Geddes L, Spotmitz W, Kaul S, Duling BR. Microcirculatory dystunction following perfusion with hyperkallemic, hypothermic, cardioplegic solutions and blood repertusion. Effects of adenosine. Circulation. 1991;84:2485-94.

29. Rosen HM. Slivjak MJ. McBrearty FX. Preischemic hap washout and its effect on the no-rellow phenomenon. Plast Reconstr Surg. 1985;6:737-47.

30. Saitoh Y, Hashimoto M, Ku K. Kin S. Nosaka S, Masumura S, Nakayama K. Heart preserwation in HTK solution: role of comonary wasculature in recovery of cardiac function. Ann Thorac Surg. 2000;69:107-12.

31. Minor T, Vollmar B, Menger MD, Isselhard W. Cold preserwation of the small intestine with the new Celsior-solution. First experimental results. Transpl Int. $1998 ; 11: 32-7$. 


\section{CHAPTER 4 \\ Effect of hypothermia and HTK on \\ the microcirculation in the rat cremaster muscle after ischemia}

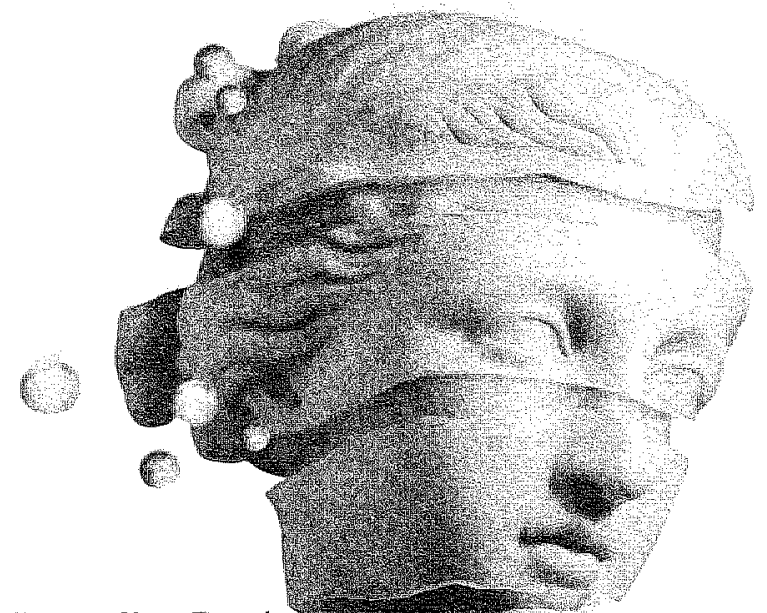

Wacqueline Bastiaan

Dick W. Slaaf, $\mathrm{Ph}$

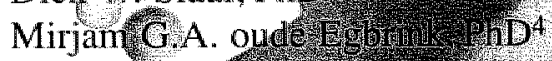

Gary L. Ander renr Phil)

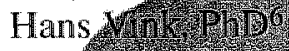

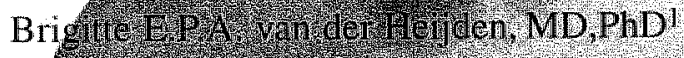

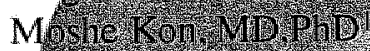

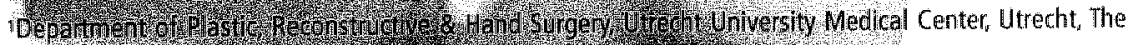
Nethertands

aDepartment of Plastic, Reconstructive \& Netherlands

Laboratory for Microcirculation, Cardiovascular Research Institute Maastricht, Depahyents of 3 Biophysics and sPhysiollogy, Maastricht University, Maastricht, The Netherlands

sDepartment of Physiology and Biophysics, University of LOWiswille, Louisville, Kentucky, USA

Department of Medical Physics, Acadermic Medical Center, Amsterdam, The Netherlands

Part published in: Clin Csi (Lond). 2005;109:117-23 


\section{ABSTRACT}

Hypotherma is an important preservation method for tissues and solid organs. Aim of this study was to assess in rat cremaster muscle effects of bypothermia, with or without pre-ischemic Histidine-TryptophanKetoglutarate solution (HTK) perfusion, on microvascular consequences of 4 or 6 hours ischemia and 2 hours reperfusion. Intravital microscopy was applied to examine capillary perfusion and leukocyte-endothelium interactions. The cremaster muscle was subjected to 4 or 6 hours cold $\left(4^{\circ} \mathrm{C}\right)$ or 6 hours warm $\left(33-34^{\circ} \mathrm{C}\right)$ isehemia and 2 hours reperfusion. Measurements were performed at baseline, prior to HTK perfusion and ischemia, and at 0,1 and 2 hours after blood flow restoration. Hypothermia completely prevented the $50 \%$ reduction in capillary perfusion observed at start of reperfusion after 4 hours warm ischemia. After 6 hours warm ischemia perfusion resumed in only $45 \%$ of capilaries and remained at this low level during reperfusion. In contrast, only a slight decrease $(<10 \%)$ in capillary perfusion was observed after 6 hours cold ischemia. Pre-ischemic HTK perfusion had no beneficial effect on tissue perfusion. Four hours warm ischemia significantly increased venular leukocytevessel wall interactions, which was attenuated by both bypothermia and HTK. Combined application of both interventions had no additional effects. After 6 hours warm ischemia no increase in leukoeyte-vessel wall interactions was observed, possibly due to venular flow reduetion. In conclusion, hypothermia preserves capillary pelfusion and prevents an increase in leukocyte-vessel wall interactions during reperfusion after muscle tissue ischemia. Pre-ischemic perfusion of the vasculature with HTK does not improve the results of cold storage, but attenuates inflammatory response independent of temperature effect. HTK provides additional protective effect. 


\section{INTRODUCTION}

Free flap transplantation has become a standard procedure in reconstructive surgery. Survival rate of these flaps is very high." However, reconstruction of complex tissue defects often results in loss of tissue function. This may be improved by replacing missing tissue with analogue cadaver tissue, socalled composite-tissue allografts (CTAs). ${ }^{2}$ Hypothermia is currently the most important preservation method for solid organs in the ischemic periods during transplantation, because it decreases cellular metabolism and acidification. ${ }^{3}$ It was also shown to be beneficial for skeletal muscle preservation. ${ }^{4}$ Other investigations, however, report that hypothermia itself can evoke tissue-damaging effects as well, such as increased vascular leakage and tissue swelling. 5.6 Reduction of the surface temperature to $8^{\circ} \mathrm{C}$ for 30 minutes caused arteriolar vasoconstriction in the dorsal skinfold preparation in striated muscle of hamsters. ${ }^{6}$ These seemingly contradictory findings may be related to differences in experimental approach, and degree and duration of cooling. Only few studies on vascular responses to local hypothermia are based on direct microcirculatory observations. Modest tissue cooling $\left(26^{\circ} \mathrm{C}\right)$ has a direct, although transient, depressant effect on microvascular smooth muscle tone leading to vasoconstriction in the rat cremaster muscle. ${ }^{7}$

One way of improving the protective effect of hypothermia during tissue ischemia and transplantation is the use of specially designed preservation solutions. Histidine-Tryptophan-Ketoglutarate Bretschneider solution (HTK; table 4.1) is an intracellular type preservation solution with a low viscosity. It was originally designed as a cardioplegic solution with good results for cardiac preservation. ${ }^{8,9}$ HTK also showed beneficial effects on preservation of other organs as liver, kidney, pancreas.9-11 In a previous study in our laboratory ${ }^{12}$ the potential of several preservation sollutions to protect isolated muscles of the rat during cold storage was assessed. It was found that both contractility and cytoarchitecture of the muscles were best preserved in HTK solution at $4^{\circ} \mathrm{C}$. However, beside preservation of contractility, preservation of the vascular bed and tissue perfusion is of major importance for flap survival. Moreover, in larger muscles, surface cooling alone may not be sufficient for tissue preservation. Pre-storage tissue perfusion with cold HTK may provide additional protection during cold storage in HTK for both vasculature and muscle tissue. Knowledge about the effect of preservation solutions on the microvasculature is very limited and based mainly on in vitro studies using cultured endothellium. ${ }^{13}$ 
In transplantation studies, it is hard to distinguish between preservation of muscle tissue and preservation of the vasculature when protective perfusion solutions are used. In one of our previous studies, we focused on the preservation of function of muscle tissue. ${ }^{14}$ In another recent study, we examined the effects of pre-ischemic perfusion with HTK on the microcirculation during ischemia and reperfusion in rat cremaster muscle. ${ }^{15}$ After 4 hours of warm ischemia, a transient decrease in capillary perfision was observed that was not changed by pre-ischemic HTK perfusion. Apparently, 4 hours of warm ischemia is a relatively short period which induces only reversible damage (microvascular alterations) in muscle tissue. Longer periods of ischemia may be necessary to induce irreversible microvascular changes and to investigate the protective potential of pre-ischemic HTK perfusion and hypothermia for muscle vascullature during transplantation.

It was the aim of the present study to assess the protective effects of hypothermia, with or without pre-ischemic perfusion with a preservation solution (HTK), on consequences of 4 or 6 hours of complete ischemia and 2 hours of reperfusion of muscle tissue on capillary perfusion and leukocyteendothelium interactions in rat cremaster muscle by intravital microscopy.

\section{Materials AND METHODS}

\section{Animal model}

Male Wistar rats of 110-170 grams were used. The rats were housed in pairs on a 12:1.2 hour (light-dark) cycle and were provided a standard diet and water ad libitum. All animals received care in compliance with the European Convention guidelines and all protocols were approved by the local ethics committee. Rats were anesthetized with fentanyl-fluanisone (Hypnorm ${ }^{\mathrm{TM}}$. Janssen Pharmaceutica, Beerse, Belgium) at an intramuscular dose of $0.5 \mathrm{ml} / \mathrm{kg}$, and sodium pentobarbital (Nembutal $\mathrm{rm}$, Sanofi Sante B.V. Maassluis, The Netherlands) at a subcutaneous dose of $15 \mathrm{mg} / \mathrm{kg}$. Additional injections were given when necessary. A blood pressure cannula (PE 50) was inserted into the left carotid artery to monitor systemic arterial pressure and a tracheal tube (PE 160) was placed to maintain an open airway. Pilot experiments clemonstrated that this procedure maintained normal blood gas values. During the experiment, and also during warm ischemia, body and cremaster temperatures were maintained at 36 to $37^{\circ} \mathrm{C}$ and at 33 to $34^{\circ} \mathrm{C}$, respectively, using heating lamps and temperature sensors to measure tissue temperature. During cold ischemia, cremaster 
temperature was maintained at $4^{\circ} \mathrm{C}$ by a custom-made cooling device consisting of a copper tray filled with ice and covered with polystyrene foam. Re-warming of the cremaster muscle was achieved by using heating lamps and temperature sensors. It took about 10 minutes to rewarm the tissue to $33-34^{\circ} \mathrm{C}$.

At the end of the experiment, the animals were euthanized via intracardial injection of an overdose of sodium pentobarbital (Nembutal ${ }^{\mathrm{TM}}$, Sanofi Sante B.V., Maassluis, The Netherlands).

\section{Surgical procedure}

Dissection of the cremaster muscle on its vascular pedicle was performed as previously described. ${ }^{16,17}$ Briefly, a left paramedian incision was made from the tip of the scrotum to its base and carried laterally towards the anterior iliac spine. The connective tissue of the scrotal sac was removed from the cremaster muscle by blunt dissection. Tissues were kept moist by irrigation using normal saline during dissection. The cremaster muscle was spread out for observation. Using bipolar cautery, the full thickness of the abdominal wall muscles was divided for $1 \mathrm{~cm}$ cranial and parallel to the inguinal ligament. The vascular sheath of the femoral vessels was opened and irrelevant branches of the iliac vessels were ligated, leaving all possible donor vessels for the cremaster muscle intact. ${ }^{17}$ This insured that no arterial blood could enter the cremaster when the common iliac artery was clamped and that during infusion all infusate would flow into the cremaster muscle. At the end of the isolating dissection, the cremaster muscle had no attachment to the body except the vascular pedicle. To enable perfusion with HTK, a catheter (PE 50) was inserted into the femoral artery. The catheter was connected to a microprocessor controlled tubing pump (Ismatec Reglo Digital, Ismatec SA, Glattbrugg-Zürich, Switzerland) and its tip was placed within close proximity of the pedicle attery of the cremaster muscle.

\section{Experimental procedure}

The animals were placed on a specially designed Plexiglas observation platform. The cremaster muscle was carefully spread and covered with gas-impermeable plastic film (Saran Wrap ${ }^{\mathrm{TM}}$; presoaked for 24 hours in distilled water to remove chemical residues). The platform was then placed on the stage of the intravital microscope. Tissue stabilization was allowed for 30 minutes ${ }^{18}$ before the first observations and measurements started (baseline measurements). The thin cremaster muscle in young rats allows clear visualization of microvessels. Earlier we demonstrated that capillary perfusion is stable over at least 6 hours. ${ }^{15}$ 
To start the ischemic period, a single Acland-type microvascular clamp was placed on the iliac artery ${ }^{17}$ resulting in cessation of flow. Perfusion with HTK (table 4.1 ) at $4^{\circ} \mathrm{C}$ was accomplished at a rate of $40 \mu \mathrm{l} / \mathrm{min}$ during 10 minutes ${ }^{19}$ under continuous monitoring of perfusion pressure through the femoral artery catheter to ensure that high pressures in the cremaster muscle were avoided. The infusion rate was calculated to be approximately equal to normal blood flow to the cremaster. ${ }^{20}$ During washout with $\mathrm{HTK}$, the cremaster microcirculation was carefully observed to ensure that all blood was cleared from the cremaster muscle.

Table 41

Composition of Histidine Tryptophan Ketoglutarate (HTK) solution (mmolih)

\begin{tabular}{|c|c|}
\hline Component & \\
\hline $\mathrm{NaCl}$ & 15 \\
\hline $\mathrm{Ka}$ & 9 \\
\hline $\mathrm{MgCl}_{2}$ & 4 \\
\hline $\mathrm{CaCl}_{2}$ & 0015 \\
\hline Ketoglutarate & 1 \\
\hline Histidine & 180 \\
\hline Histidine $\mathrm{HCl}$ & 18 \\
\hline Mannitol & 30 \\
\hline Tryptophan & 2 \\
\hline Osmolarity (mosm) & 327 \\
\hline $\mathrm{pH}$ & 4, \\
\hline
\end{tabular}

\section{Experimental groups}

Eight experimental groups of 6 animals each were studied. In all groups, baseline measurements were performed after a stabilization period of 30 minutes after surgical preparation. Subsequent measurements were performed at 0,1 , and 2 hours of reperfusion. The ischemic period lasted either 4 or 6 hours.

Warm ischemia and reperfusion (warm I/R)

After baseline measurements, a microvessel clamp was placed on the iliac artery for 4 (warm I/R,4) or 6 (warm $I / R, 6$ ) hours to induce complete ischemia of the cremaster muscle. The muscle surface temperature was kept at $33-34^{\circ} \mathrm{C}$. After 4 or 6 hours of ischemia the clamp was released. 
HTK Perfusion followed by warm ischemia and reperfusion (HTK + warm IIR) After baseline measurements, HTK $\left(4^{\circ} \mathrm{C}\right.$ ) was infused for 10 minutes into the cremaster circulation at a rate of $40 \mathrm{ml}$ per minute. Next, a microvessel clamp was placed on the iliac artery for 4 (HTK + warm I/R,4) or 6 (HTK + warm I/R,6) hours. The muscle surface temperature was kept at $33-34^{\circ} \mathrm{C}$.

Cold Ischemia and Reperfusion (cold I/R)

After baseline measurements, a microvessel clamp was placed on the iliac artery for 4 (cold $I / R, 4$ ) or 6 (cold I/R,6) hours. The muscle surface temperature was cooled to $4^{\circ} \mathrm{C}$ and kept at that temperature during the entire ischemic period. After 4 or 6 hours of ischemia the clamp was released and cooling was ended.

HTK Perfusion and cold ischemia and reperfusion (HTK + cold I/R) After baseline measurements, HTK $\left(4^{\circ} \mathrm{C}\right)$ was infused for 10 minutes into the cremaster circulation at a rate of $40 \mu$ per minute. A microvessel clamp was placed on the iliac artery for 4 (HTK + cold I/R,4) or 6 (HTK + cold I/R,6) hours. During this ischemic period, the muscle surface temperature was cooled to $4^{\circ} \mathrm{C}$ and kept at this temperature. After 4 or 6 hours of ischemia the clamp was released and cooling was ended.

\section{Microcirculation Measurements}

The microvasculature was observed using an intravital microscope (Zeiss (Jena, Germany) Axiotech microscope) equipped with a $2 / 3$-inch Sony CCD camera coupled to a closed-circuit video system. Microvascular images were recorded on videotape using a video recorder (Panasonic).

\section{Capillary Perfusion}

Parts of the cremaster muscle were observed to assess the number of perfused capillaries. At three different locations, the number of perfused capillaries was quantified in nine adjacent fields of view with a $20 \mathrm{x}$ objective lense (numerical aperture 0.40). One field of view measured $300 \times 400 \mu \mathrm{m}$. The same locations were measured throughout the experiment. Results are expressed as the average number of perfused capillaries per location (of 9 fields of view).

\section{Leukocyte-endothelium interactions}

At each of the three locations observed for capillary perfusion, a thirdorder venule was examined to assess leukocyle-endothelium interactions. The number of leukocytes rolling along the vessel wall was counted for 
a period of 60 seconds. Leukocytes were considered to be rolling if they moved along the endothelial wall at a velocity noticeably slower than the velocity of the free flowing red blood cells.

Free flowing blood cells (red cells, platelets, and leukocytes) cannot be seen individually under nomal flow conditions. They appear as streaks in the image. Any cells individually identifiable, must therefore interact with the vessel wall. In most cases, one can actually observe the rolling, i.e. the detaching and attaching of the leukocyte to the wall with the concomitant shape changes. ${ }^{2 \|}$ The number of leukocytes adhering to the vascular endothelium was assessed in a segment of $100 \mu \mathrm{m}$ length. Adherent leukocytes remained stationary on the endothelial wall for at least 30 seconds.

\section{Statistics}

Data are presented as means \pm SEM. They are normalized by expressing them as percentage of baseline values. Repeated-measures ANOVA was used to compare data groups, followed by a multiple comparison procedure for specific differences (using Bonferroni correction) for capillary perfusion. Because of non-normality of data, nonparametric tests (Mann Whitney and Wilcoxon tests) were used to test specific differences in numbers of rolling and adhering leukocytes (leukocytevessel wall interactions). A $\mathrm{p}$-value $<0.05$ was considered significant.

\section{RESULTS}

\section{Capillary perfusion}

At baseline, average capillary perfusion groups varied between $100 \pm 0.8$ and $112 \pm 1.2$ capillaries per 9 fields of view in the various experimental groups. Capillary perfusion resumed in $50 \%(\mathrm{p}<0.01$ compared to baseline $)$ of the capillaries after 4 hours of warm ischemia, and recovered to $93 \%$ ( $p<0.05$ vs baseline) during the 2 hour reperfusion period (Fig. 4.1 A). After 6 hours of warm ischemia, however, capillary perfusion was $45 \%$ of baseline at the start of reperfusion $(p<0.001)$ and remained at a low level for the next 2 hours ( $<<0.01$; Fig. 4.1B). Pre-ischemic perfusion with HTK did not diminish this decrease in capillary perfusion, independent of the duration of the ischemic period.

Cold ischemia and reperfusion appeared to protect the microvasculature from the detrimental effects of warm ischemia and reperfusion. After 4 hours of cold ischemia perfusion resumed in $99 \%$ of all capillaries and stayed at that level $(97 \%)$ at the end of the reperfusion period (Fig. 4.1A). 
After 6 hours of cold ischemia capillary perfusion was $99 \%$ of baseline at the start of reperfusion, and remained at that level $(90 \%$ at 2 hours of reperfusion) (Fig. 4.1B). Pre-ischemic perfusion with HTK did not influence the minor effects of cold ischemia and reperfusion on capillary perfusion.

A Capillary Perfusion $4 h$

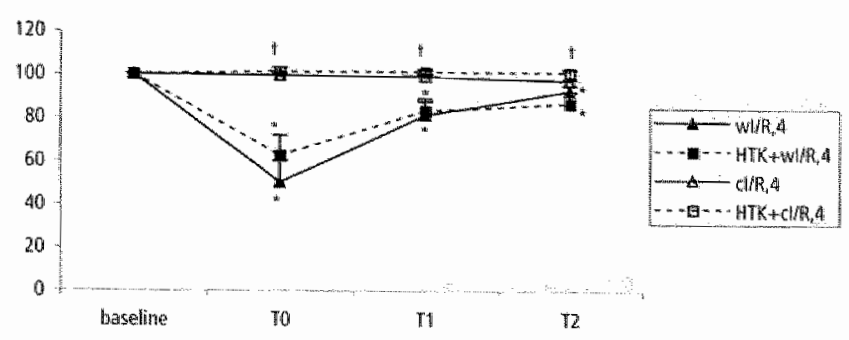

B

Capillary Perfusion $6 \mathrm{~h}$

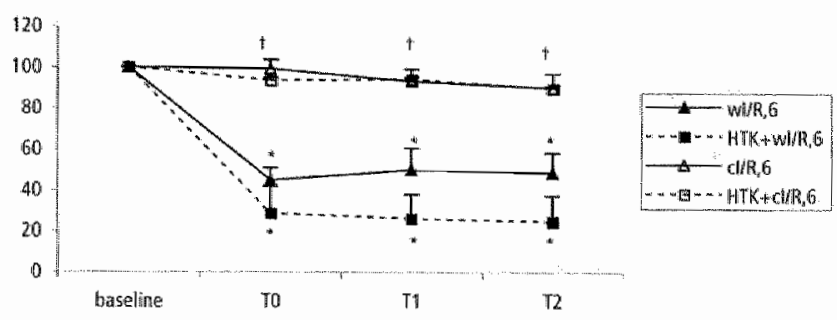

\section{Fig. 4:1}

Capillary perfusion before (baseline) and after 0,1 , and 2 hours (TO, T1, and T2, respectively) of a period of 4 hours (A) or 6 hours $(B)$ ischemia. Data are expressed as percentage of control. HTK does not influence perfusion. Cooling leads to normalization of perfusion. $w=$ warm; $c=c o l d$. * significantly different from baseline, $t$ cold significantly different from warm. For levels of statistical significance, see text.

\section{Leukocyte-endothelial interactions}

At baseline, the number of rolling leukocytes varied between $15 \pm 2.3$ and $45 \pm 8.8$ per minute in the various groups. Four hours of warm ischemia induced an increase in the number of rolling leukocytes to $138 \%$ at the start of reperfusion (NS compared to baseline) and to $310 \%$ after 2 hours of reperfusion ( $p<0.05 \mathrm{vs}$ baseline). This increase was significantly diminished by pre-ischemic infusion with HTK $(p<0.05$ at the start of reperfusion (TO) and $p<0.01$ after 2 hours of reperfusion; Fig. 4.2A). After 4 hours of cold ischemia the increase in leukocyte rolling was nonsignificant. No additional effect of pre-ischemic HTK perfusion was observed (Fig. 4.2A). 
After 6 hours of warm ischemia, the level of leukocyte rolling decreased to $66 \%$ of baseline at the onset of reperfusion $(p<0.05)$; thereafter, it returned again to baseline level (112\%) in the next 2 hours (Fig. 4.2B). Pre-ischemic HTK perfusion did not significantly influence this effect, although no return to baseline level was seen during reperfusion (Fig. 4.2B). In case of 6 hours of cold ischemia the level of leukocyte rolling also reduced to $66 \%$ of baseline at the start of reperfusion and remained at that level after 2 hours of reperfusion ( $46 \%$; both $\mathrm{p}<0.05$ vs baseline; Fig. $4.2 \mathrm{~B}$ ). Due to the large variation in data, the effect of 6 hours of cold ischemia was significantly different from the changes observed after 6 hours of warm ischemia at the end of the reperfusion period only; HTK perfusion had no additional effects.

A Rolling leukocytes $4 \mathrm{~h}$

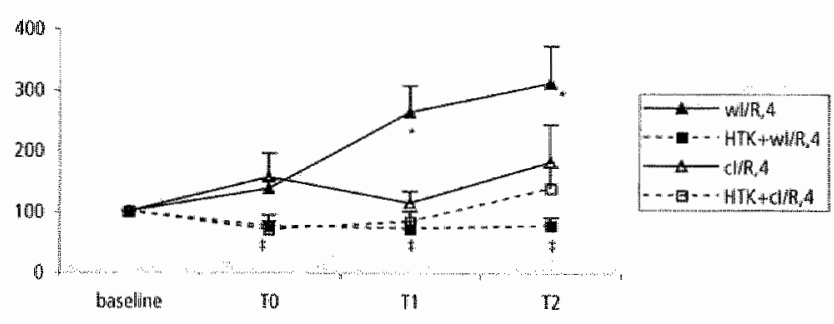

Ralling leukacytes $6 \mathrm{~h}$

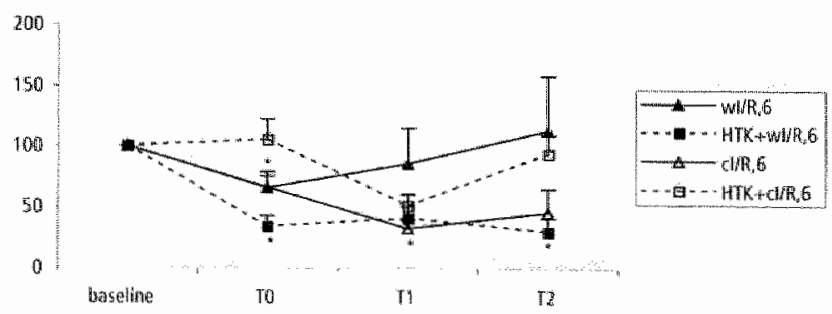

Fig. 4.2

Number of rolling leukocytes before (baseline) and after 0,1 , and 2 hours (TO, 11 , and $\mathrm{T} 2$, respectively) of a period of 4 hours (A) or 6 hours (B) ischemia. Data are expressed as percentage of control. Four hours of warm ischemia increased number of rolling levkocytes, which was. attenuated by both hypothermia and HTK. Combined application of the two interventions had no additional effects.

At baseline, small numbers of adhering leukocytes were observed (ranging from $0.83 \pm 0.14$ to $1.7 \pm 0.2$ adhering leukocytes per $100 \mu \mathrm{m}$ vessel length). Four hours of warm ischemia induced a significant increase in the level of leukocyte adhesion during reperfusion, which was absent 
in case of pre-ischemic HTK perfusion or hypothermia during the ischemic period (Fig. 4.3A). After 6 hours of warm ischemia leukocyte adhesion did not change significantly; pre-ischemic HTK perfusion led to a decrease in the level of leukocyte adhesion $(p<0.01$ at TO; Fig. 4.3B).

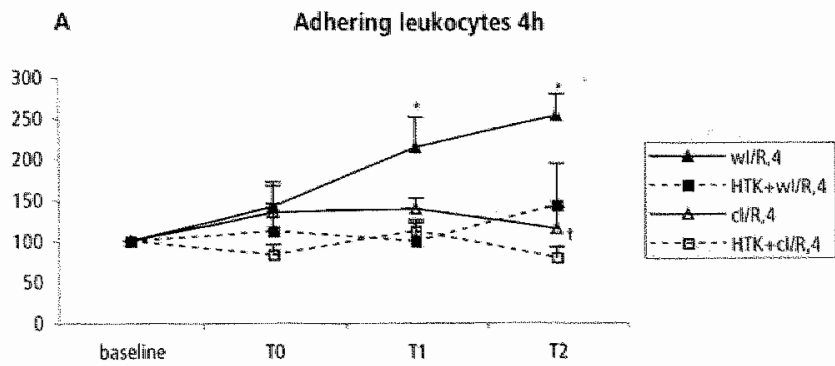

B

Adhering leukocytes $6 \mathrm{~h}$

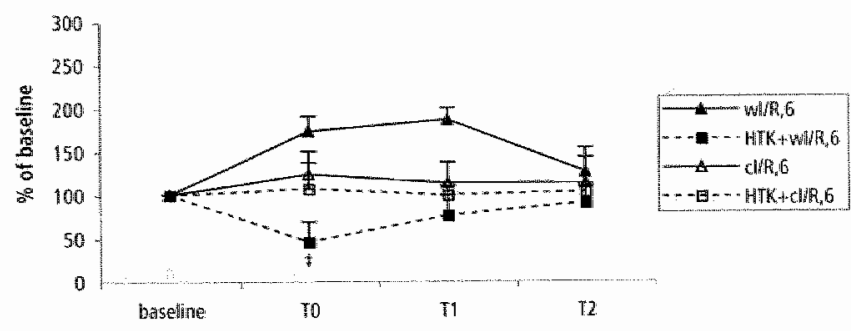

Fig 4.3

Number of adhering leukocytes before (baseline) and after 0,1 , and 2 hours $\left(T_{0}, T 1\right.$, and $T 2$. respectively) of a period of 4 hours $(A)$ or 6 hours $(B)$ ischemia. Data are expressed as percentage of control.

Number of adhering leukocytes increased during reperfusion after 4 hours of warm ischemia. Hypothermia prevented this increase after 2 hours of reperfusion (I). HTK reduced le ukocyte adherence at start of reperfusion after 6 hours of warm ischemia.

$w=w_{a r m ;} c=$ cold, "significantly different from baseline, $t$ cold significantly different from warm, + HTK perfusion significantly different from no perfusion. For levels of statistical significance, see text.

\section{Discussion}

In the rat cremaster muscle model we studied the effects of hypothermia, with or without pre-ischemic tissue perfusion with the preservation solution HTK, on the microvascular consequences of both 4 and 6 hours of total ischemia followed by 2 hours of reperfusion. The detrimental effect of warm ischemia on capillary perfusion could be prevented by cooling of the 
cremaster to $4^{\circ} \mathrm{C}$ during the whole ischemic period (4-6 hours). Preischemic HTK perfusion had no effect on tissue perfusion, both after warm and cold ischemia. Both hypothermia and pre-ischemic HTK perfusion prevented the increase in leukocyte rolling and adhesion that was observed after 4 hours of warm ischemia. Combined application of the two interventions had no additional effects. After 6 hours of warm ischemia no increase in leukocyte-vessel wall interactions was observed, possibly due to venular flow reduction (see below).

Cold preservation significantly improved capillary perfusion after 4 or 6 hours of ischemia. After the cold ischemic period, perfusion resumed at about the same level as before occlusion, whereas the number of perfused capillaries transiently or permanently reduced to $50 \%$ or less after 4 and 6 hours of warm ischemia, respectively. Up to now there is no consensus in the literature with regard to the effect of local cooling on microvascular hemodynamics, although it is known that hypothermia is an important preservation method due to its decreasing effects on cellular metabolism and acidification. ${ }^{3}$ Tissue metabolic rate and oxygen consumption are inversely related to local temperature. ${ }^{6,22}$ By diminishing the demand of metabolically active tissue for oxygen, hypothermia may improve the ability of an organ or tissue to withstand relatively long periods of hypoxia and prevent endothelial cell injury. ${ }^{23}$

Literature on the effects of cooling on the microcirculation in muscle is scarce and usually describes the situation during cooling. It should be noted that in the present study the microcirculation was not observed during the cooling (and ischemic) period; instead, the hypothermia effects were studied during reperfusion. During the cooling period, the muscle was not perfused and, therefore, transmural pressures were low. As a result, hydrostatic pressure in the venular section of the microcirculation was low, preventing edema formation. This condition parallels that described by Smith ${ }^{24}$ and Vanhoutte, 25 who reported venodilation and suggested that this condition favors fluid reabsorption and attenuates edema formation. Other studies performed during hypothermia report arteriolar constriction ${ }^{26}$ and reduced flow (dorsal skinfold preparation). 6,26 Such effects may also have occurred in our preparation, but were not visualized due to the complete interruption of flow by the clamp. The finding of Beris ${ }^{27}$ that hypothermia protects arteries from excessive spasm during ischemia and lessens the reactive hyperemia, may explain the prompt return to normal perfusion after cold ischemia of our preparation. 
Skeletal muscle ischemia and reperfusion is recognized as one form of acute inflammation in which activated leukocytes play a key role. Reperfusion initiates a complex series of reactions which may result in leukocyte recruitment and diapedesis, microvascular barrier disruption, and edema formation. ${ }^{28}$ The vascular endothelium has a number of functions that may mediate many of the ischemia-reperfusion (IR) phenomena. Vascular adhesion molecules (integrins, selectins) are upregulated or expressed to mediate the adherence and subsequent destructive effects of neutrophils as they interact with the endothelium. ${ }^{29}$ In the present study, the levels of leukocyte rolling and adhesion are significantly increased during reperfusion after 4 hours of warm ischemia. Previously, we showed that the levels of leukocyte rolling and adhesion are significantly increased during reperfusion after 4 hours of warm ischemia. ${ }^{15}$ Cooling during the ischemic period reduced this increase. Therefore, hypothermia may cause downregulation of adhesion molecules. This decreasing effect of hypothermia is less pronounced than that described by Siemionow who reported absence of leukocyte vessel wall interactions. ${ }^{30}$

Six hours of warm ischemia and reperfusion did not result in increased leukocyte rolling and adhesion. One explanation may be that capillary perfusion and, hence, venular blood flow was significantly reduced during the entire two hour reperfusion period in this group. As a result, delivery of leukocytes to the venules may have been restricted. ${ }^{31}$ Cooling of the tissue to $4^{\circ} \mathrm{C}$ during the 6 hour ischemia period prevented the decrease in tissue perfusion during reperfusion, and did not significantly influence leukocyte-vessel wall interactions.

In our experiments, pre-ischemic tissue perfusion with HTK resulted in removall of blood cells from the cremaster during the ischemic period. This means that, in these experiments, leukocytes interacting with the endothelium during reperfusion had not been exposed to ischemia and/or hypothermia $\left(4^{\circ} \mathrm{C}\right)$. Since HTK pretreatment did not alter the number of perfused capillaries nor the level of leukocyte-vessel wall interactions after cold ischemia, we may conclude that alterations in leukocyte properties like the ones described by $\mathrm{Nash}^{32}$ (transit time of leukocytes to flow through $8-\mu \mathrm{m}$ pores in filters increased with decreasing temperature), and Forsyth ${ }^{33}$ could not occur, and hence, did not influence the cremaster microcirculation. In case of 4 or 6 hours of warm ischemia, however, HTK pretreatment did significantly reduce leukocyte rolling during the reperfusion period, whereas it did not influence capillary perfusion. Possibly, HTK decreased the venular upregulation of endothelial selectins after warm ischemia and reperfusion. ${ }^{34}$ 
In a previous study, we showed that cold storage in HTK is necessary for the preservation of muscle contractility of isolated rat skeletal muscles. ${ }^{12}$ The present study indicates that cooling of the tissue is required for the preservation of muscle perfusion as well. Pre-ischemic perfusion of the vasculature with HTK does not improve the results of cold storage (in HTK), but attenuates the inflammatory response independent of temperature effect. HTK provides additionall protective effect.

\section{ACNKNOWLEDGMENTS}

We acknowledge the contributions of Rik Mansvelt Beck and the biotechnicians from the Utrecht University Central Animal Facilities. 


\section{REFERENCES}

1. Kerrigun CL, Stotand MA. Ischemia reperhsion injury: treview. Microsurgery. $1993: 14: 165-75$.

2. Llull R. Beko KR. Black $\mathbb{K}$ S. Hewit CW. Composite tisste allotransplantation: perspectives conceming eventual clinical explotation. Transp/ Rev. 1992;6:175-88.

3. Belzer FO. Southard JH. Prineiples of solid-organ preservation by cold storage. Thansplanianon. 1988;45:673-6.

4. Brumelli GA, Brunelli GR. Tissue changes at diferent periods of ischemia. Int Angio:. 1995; 14:253-63.

5. Farry PJ, Prentice $N G$, Hunter $A C$, Wakelin CA. Ice reament of injued ligaments: an experimental model. $N 2 \mathrm{Med} J$. 1980:91:12-4.

6. Thorlacius H, Volmar B. Westermann S, Torkvist L, Menger MD. Effects of local cooling on microvascular hemodynamics and leukocyle adhesion in the striated muscle of hamsters. If Trama. 1998;45:715.9.

7. Faber JE. Effect of local tissue cooling on microwascular smooth muscle and. posijunctional alpha 2-adrenoceptors. Am a Phyriol 1988;255:H1121-30.

8. Kober IM, Obermayr RP, Brull T, Ehsani N, Setheider B, Spieckermann PG. Comparison of the solutions of Bretschneider, St. Thomas' Hospital and the National Institutes of Health for cardioplegic protection during moderate hypothermic anest. Eur Surg Res, 1998;30:243-51.

9. Muhlbacher F, Langer F, Mittemayer C. Preservation solutions for transplantation. Thansplanit Proc. 1999:31:2060-70.

10. Splegel HU, Schleimer K, Freise H, Diller R, Drews G, Kranz D. Organ preserwation with $E C$. HTK, and UW, solution in orthotopic rat liver transplantation. Part II. Morpllological study. J Invest Surg. 1999:12:195-203.

11. Troisi R, Meester D. Van Den Broecke C. Cuvelier CA, Fers T, de Hemptine B. Hesse U. Functional and structural integrity of porche puncrentic gratts subjected. to a period of wam ischemia and cold preservation with histidine-tryptophanketoglutarate (custodiol) or University of Wisconsin solution. Transplantation. $2003.75: 1793-9$

12. van der Heijden EP. Kroese AB, Stremel RW, Bar PR, Kon M, Werke PM. Contractile properties of rat skeledal muscles following storage an 4 degrees C. Clin Sci (Lond). $1999: 97: 45-57$.

13. Eberl T, Steinlechner R. Hengster P, Herold M. Schrocksnadel H, Salvenmoser W. Rltomberg M, Gmaiger E. Margneiter R. Assessment of endothelial preservation in humangell cultures. Am Therty Shr. 1996,62:526-32.

4. var der Heijden EP, Kroese AB, Werker PM, de With MC, de Smet M, Kon M. Bar DP. Improwing the presenvation of isolated rat skeletal muscles stored for 16 hours at 4 degrees C. Thansplantation. 2000;69:1310-22 


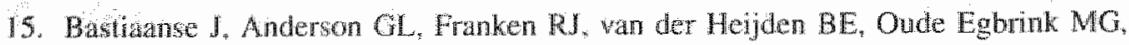
slat DW, Kon M. Effect of HTK on the microcirculation in the rat cremaster muscle during warm ischemia and reperfusion. Micosurgery. 2005;25:174-80.

16. Anderson GL, Acland RD, Simionow M. McCube SJ. Vascular isolation of the rat cremaster muscle. Microvasc Res. 1988,36:56-63.

17. Franken RJ. Peter FW, Anderson GL, Wang WZ, Werker PM. Schuschke DA, Kon $M$, Barker $J H$. Anatomy of the feeding blood wessels of the cremaster muscle in the uat: Micwswgery. 1996:17:402-8.

18. Seaber AV Experimental vasospasm. Microsurgery. 1987:8:234-41.

19. wan der Heijden EP, Kroese AB, Werker PM, Kon M, de With MC, Bar DP. Preservalion of ral skeletal musele function during storage for 16 h at 4 degrees $C$ is not improved by pre-stonge perfusion. Clin Sci (Lond). 2003;105:29-37.

20. Meininger $G A$, Fehr KL. Yates MB. Anatomic and themodynamic characteristics of the blood wessels feeding the cremaster skeletal muscle in the rat. Microwas Res. $1987 ; 33: 81-97$.

21. aude Egbrink. MG. Tangelder G. Stat DW, Reneman RS. Influence of plateletvessel wall interactions on leukocyle rolling in viwo. Circ Rés. 1992:70:355-63.

22. Fuhrman GJ, Fuhrman FA, Oxygen consumption of animals and tissues ats a function of temperature. J Gen Physiol. 1959;42:715-22.

23. Jurkovich G., Pitt RM, Curreri PW, Granger DN. Hypothemia prevents increased capillary permeability following ischema-repertusion injury. I Surg Res. $1988 ; 44: 514-21$.

24. Smith TI. Cun WW, Smith BP, Holden MB, Wise T, Marr A. Koman LA. New skeletal muscle model for the longitudinal study of alterations in microcirculation following contusion and cryotherapy. Microsurgery. 1993:14:487-93.

25. Vanhoute PM, Miller VM. Alpha 2-adrenoceptors and endothelium-derived relaxing factor: Am J Med. 1989:87:15-55.

26. Olson IE, Surano VD. A review of cryotherapy. Phys $T h \%$. 1972:52:840-53.

27. Beris AE, Soucacos PN. Seaber AV. Urbaniak JR. Eufects of cold ischemia on reflow: patcons in the tat cremaster muscle microeirculation. In Amgiot 1995;14:248-52.

28. Gute DC. Ishda T, Yamizu K. Korthuis RJ. Inflammatory responses to ischemiat and reperfusion in skeletal muscle. Mol Cell Biochen. 1998;179:169-87.

29. Verrier E. The microvascular cell and ischemiateperfusion injury. I Cardiovase Phammacol. 1996:27 Suppl 1:S26-30.

30. Siemionow M, Romanowski L. Lister G. Leukocytedepleting eftect of hypothermiat on muscle thap microcirculation following ischemia-reperfusion injury. I Hard Surg |Aml. 1993:18:963.71.

31. Finger EB, Puri $\mathbb{K} D$, Alon R, Lawrence MB, von Andrian UH, Springer TA Adhesion through L-selectin requires a threshold hydrodynamic shear. Nature. 1996;379:266-9. 
32. Nash GB, Abbit KB. Tate $\mathrm{K}$, Jetha $\mathrm{KA}$, Egginton $\mathrm{S}$. Changes in the mechnical and adhesive behaviour of human neurophils on cooling in vitro. Pfhgens Anh. $2001: 442-762-70$.

33. Forsyth KD, Levinsky RJ. Preparative procedures of cooling and re-waming increase leukocyte integrin expression and function on nentrophils. I hmmol Merhods. $1990 ; 128: 159-63$.

34. Korthuis RJ, Gute DC. Adhesion molecule expression in postischemic microvascular dysfunction: activity of a micronized purified lawonoid fraction. J Vasc Res. 1999,36 Suppl 1:15-23. 



\section{CHAPTER 5 \\ Do preservation solutions protect rat cremaster microcirculation during ischemia and reperfusion?}

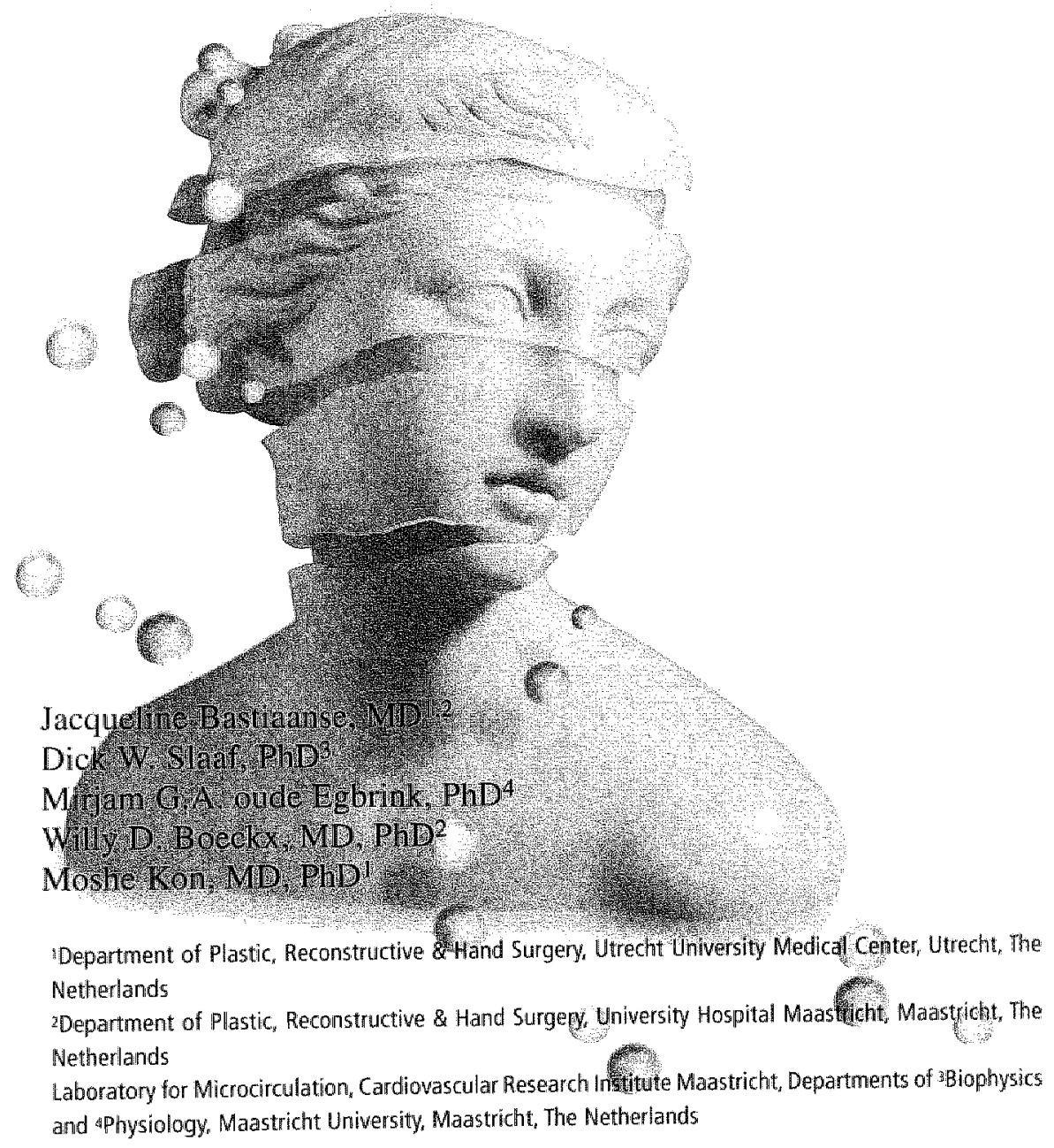

J Surg Res 2005;125:182-8. 


\section{ABSTRACT}

Our aim was to investigate the potential of the preservation solution Celsior to protect the rat cremaster muscle microcirculation during ischemia and reperfusion, and to compare its effects with those of HTK (Histidine-Tryptophan-Ketoglutarate-Bretschneider solution), Because of its antioxidant contents, we expected Celsior to be more protective than HTK.

Capillary perfusion and leukocyte-endothelium interactions were examined in rat cremaster muscle using intravital microscopy. After perfusion with Celsior or HTK ( $4^{\circ} \mathrm{C}$ ), the cremaster was subjected to 4 or 6 hours of warm $\left(33-34^{\circ} \mathrm{C}\right)$ ischemia and 2 hours of reperfusion. Measurements were performed prior to perfision and/or ischemia, and 0,1 and 2 hours after restoration of flow.

Without Celsior or HTK, capillary perfusion transiently decreased to $50 \%$ of baseline after 4 hours of ischemia, it remained low ( $45 \%$ ) after 6 hours of ischemia, Whereas HTK had no significant influence, Celsior deteriorated capillary perfusion: it remained low after 4 hours of ischemia (39-48\%) and decreased even further after 6 hours of ischemia (18-8\%). Both preservation solutions similarly reduced the increase in leukocyteendothelium interactions after ischemia.

Pre-ischenic tissiae perfusion with Celsior had an adverse effect on capillary perfusion in rat cremaster muscle after 4 and 6 hours of ischemia, whereas HTK did not significantly influence this parameter. Both preservation solutions similarly prevented the increase in leukocyte-endothelium interactions after ischenia. These data suggest that HTK is more suited as preservation solution for muscular tissue than Celsior especially when the known protective effects of HTK on misscle function are taken into account. 


\section{INTRODUCTION}

In replantation and tissue transplantation an ischemic period is inevitable until blood flow is reestablished. Ischemia and reperfusion lead to the production of free radicals that can scavenge endothelium-derived nitric oxide (NO) and induce endothelial dysfunction, associated with loss of regulatory and protective properties, ${ }^{1}$ which ultimately can lead to tissue injury. Storage of the tissue in preservation solutions with a powerful antioxidant capacity may decrease or prevent endothelial cell injury from oxygen-derived free radicals during reperfusion following an ischemic period. $^{2}$

Celsior (Table 5.1) is an extracellular solution specifically designed for cardiac preservation. It combines the general principles of preservation solutions with properties specific of the heart such as prevention of the development of ischemic contracture and dysfunction due to edema. ${ }^{3}$ The major principles addressed by the Celsior formulation include (1) prevention of cell swelling (by mannitol and lactobionate), (2) prevention of oxygen-derived free radical injury (by reduced glutathione, histidine and mannitol), and (3) prevention of contracture by enhancement of energy production (glutamate) and limitation of calcium overload (high magnesium content, slight degree of acidosis). Celsior was found to be effective for preservation of heart function in vitro, in an isolated isovolemic buffer-perfused rat heart model, and in viva, in a rabbit:

Table 5 ,

Composition of the preservation solutions Celsior and HTK-Bretschneider

\begin{tabular}{|c|c|c|}
\hline Components [mmoll]] & Celsior: & HTK \\
\hline $\mathrm{Na}^{+} \mathrm{C}$ & 100 & 15 \\
\hline$K$ & 15 & 9 \\
\hline $\mathrm{Ca}^{2+}$ & 0.25 & 0015 \\
\hline $\mathrm{Mg} 2+$ & 13 & 4 \\
\hline Glutamate & 20 & 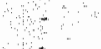 \\
\hline Ketoglutarate & 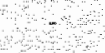 & 1 \\
\hline Typtophan & & 2 \\
\hline Lactobionate & 80 & 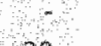 \\
\hline Mannitol. & 60 & 30 \\
\hline Reduced glutathione & 3 & 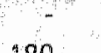 \\
\hline Histidine & 30 & 180 \\
\hline Histidine $\mathrm{HCl}$ & 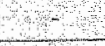 & 18 \\
\hline
\end{tabular}


heterotopic heart transplantation model. 3,4 The effects of Celsior on endothelial function and microcirculation in wivo are unknown.

In previous studies, we evaluated the potential of Histidine-TryptophanKetoglutarate-Bretschneider solution (HTK) to preserve skeletal muscle during cold storage in HTK (Table 5.1). This solution was found to be effective in preserving muscle function of isolated rat skeletal muscles after 16 hours of cold storage $\left(4^{\circ} \mathrm{C}\right)$ in HTK ${ }^{5}$ We hypothesized that pre-ischemic perfusion with HTK, resulting in removal of blood cells from the microvasculature prior to ischemia and exposure of the microvasculature to HTK during ischemia would reduce the adverse microvascular effects of ischemia and reperfusion. However, pre-ischemic perfusion of the cremaster muscle with HTK did not change tissue perfusion after 4 and 6 hours of warm ischemia and reperfusion, although a decrease in leukocyte endothelium interactions during reperfusion was observed. ${ }^{6,7}$ The protective effects of Celsior in this situation, if any, are unknown. Because of the high amount of free-radical scavengers in Celsior, we hypothesized that preischemic perfusion with Celsior would show more beneficial effects on the preservation of the muscular microvasculature than HTK.

The present study was designed to evaluate the potential of Celsior to preserve the cremaster muscle microcirculation during ischemia and reperfusion, and to compare its effects with those of HTK. Because hypothermia during the ischemic period has been shown to prevent the detrimental microvascular consequences of 4 and 6 hours of ischemia and reperfusion, ${ }^{7}$ the protective capacity of the two preservation solutions was investigated in a model of warm ischemia and reperfusion. We used the rat cremaster muscle model (suitable for perfusion) and assessed the microvascular effects of pre-ischemic perfusion with the preservation solutions after a period of 4 or 6 hours of warm ischemia.

\section{Materials AND Methods}

\section{Animal model}

Male Wistar rats of $105-180$ grams were used. The rats were housed in pairs on a 12:12 hour (light-dark) cycle and were provided a standard diet and water ad libitum. All animals received care in compliance with the European Convention guidelines and the local ethics committee approved all protocols. Rats were anesthetized with fentanyl-fluanisone (Hypnorm ${ }^{\mathrm{TM}}$, Janssen Pharmaceutica, Beerse, Belgium) at an intramuscular dose of $0.5 \mathrm{~m} / \mathrm{kg}$, and sodium pentobarbital (Nembutal ${ }^{\mathrm{TM}}$, Sanofi Sante B.V. Maassluis, The 
Netherlands) at a subcutaneous dose of $15 \mathrm{mg} / \mathrm{kg}$. Additional injections were given when necessary. A blood pressure cannula (PE 50) was inserted into the left carotid artery to monitor systemic arterial pressure and a tracheal tube (PE 160) was placed to maintain an open airway. Pilot experiments demonstrated that this procedure maintained normal blood gas values. During the experiment, and also during warm ischemia, body and cremaster temperatures were maintained at 36 to $37^{\circ} \mathrm{C}$ and at 33 to $34^{\circ} \mathrm{C}$, respectively, using heating lamps.

At the end of the experiment, the animals were euthanized by an intracardial injection of an overdose of sodium pentobarbital.

\section{Surgical technique}

The cremaster muscle of young animals is suited for clear, microscopic observation of microvessels. Dissection of the cremaster muscle on its vascular pedicle was performed as previously described. ${ }^{8,9}$ During dissection, the tissues were kept moist by irrigation using normal saline. The cremaster was opened and spread out for observation. The full thickness of the abdominal wall muscles was divided for $1 \mathrm{~cm}$ cranial and parallel to the inguinal ligament. Irrelevant branches of the iliac vessels were ligated to insure that no arterial blood could enter the cremaster muscle when the common iliac artery was clamped, and to insure that all infusate would flow into the cremaster muscle during infusion. Due to the isolating dissection, the cremaster had no attachment to the body except the vascular pedicle.

To enable perfusion with Celsior or HTK a catheter (PE 50) was inserted retrograde into the distal end of the femoral artery. The catheter was connected to a microprocessor controlled tubing pump (Ismatec Reglo Digital, Ismatec SA, Glattbrugg-Zürich, Switzerland) and its outflow tip was positioned within close proximity of the pedicle artery of the cremaster muscle.

\section{Experimental procedure}

The animals were placed on a specially designed Plexiglas observation platform. The cremaster muscle was carefully spread and covered with gas-impermeable plastic film (Saran Wrap ${ }^{\mathrm{TM}}$; presoaked for 24 hours in distilled water to remove chemical residues). The platform was then placed on the stage of the intravital microscope. Tissue stabilization was allowed for 30 minutes ${ }^{10}$ before the first observations and measurements started (baseline measurements).

To start the ischemic period, a single Acland-type microvascular clamp 
was placed on the iliac artery. ${ }^{8}$ Pre-ischemic perfusion with Celsior or HTK (table 5.1 ) at $4^{\circ} \mathrm{C}$ was accomplished at a rate of $40 \mu \mathrm{l} / \mathrm{min}$ during 10 minutes under continuous monitoring of perfusion pressure through the femoral artery catheter to ensure that high pressures in the cremaster muscle were avoided. The infusion rate was calculated to be approximately equal to normal blood flow to the cremaster." During washout with Celsior or HTK, the cremaster microcirculation was observed to ensure that all blood was cleared from the cremaster muscle.

\section{Experimental protocol and groups}

Ischemia was induced in six experimental groups of 6 animals each: two control groups (I/R4 and I/R6) in which 4 or 6 hours of ischemia was induced without the use of a preservation solution; two groups in which Celsior was infused prior to the ischemic period (Celsior IR4 and Celsior IR6) and two groups in which HTK was infused (HTK IR4 and HTK IR6). After the stabilization period of 30 minutes following surgical preparation, in all groups baseline measurements of capillary perfusion and number of rolling and adhering leukocytes were performed. Subsequent measurements were performed at 0,1 , and 2 hours of reperfusion. The cremaster muscle surface temperature was kept at $33-34^{\circ} \mathrm{C}$ during the entire experiment. In an additional group (Celsior control group), Celsior was perfused during 10 minutes and subsequently, perfusion was allowed to re turn. This group was used to determine the effects of Celsior per se, without ischemia, $4,5,6,7$, and 8 hours after Celsior perfusion. Effects of HTK per se have been studied previously. ${ }^{6}$

\section{Microcirculation Measurements}

The microvasculature was observed using an intravital microscope (Zeiss (Jena, Germany) Axiotech microscope) equipped with a $2 / 3$-inch Sony CCD camera coupled to a closed-circuit video system. Microvascular images were recorded on videotape using a video recorder (Panasonic).

\section{Capillary Perfusion}

To determine capillary perfusion, parts of the cremaster muscle were observed to assess the number of perfused capillaries. At three different locations, the number of perfused capillaries was quantified in nine adjacent fields of view with a $20 \mathrm{x}$ objective (numerical aperture 0.40 ). One field of view measured $300 \times 400 \mu \mathrm{m}$. The same locations were measured throughout the experiment. Results are expressed as the average number of perfused capillaries per location (of 9 fields). 


\section{Leukocyte-endothelium interactions}

Three pre-selected third-order venules (diameter 30-60 $\mu \mathrm{m}$ ) were examined at each of the three locations of the muscle flap. For each venule, the number of leukocytes rolling through the lumen and the number of leukocytes adhering to the vascular endothelium in a segment of $100 \mu \mathrm{m}$, were counted for a period of 60 seconds. Leukocyte rolling was defined as movement of the leukocytes along the endothelial wall at a velocity noticeably slower than the axial velocity of the red blood cells. Adherent leukocytes were defined as leukocytes remaining stationary on the endothelial wall for at least 30 seconds.

\section{Statistics}

Data are presented as means \pm SEM. They are normalized by expressing them as percentage of baseline values. Repeated-measures ANOVA was used to compare data groups, followed by a multiple comparison procedure for specific differences (using Bonferroni correction) for capillary perfusion. Because of non-normality of data, nonparametric tests (Mann Whitney and Wilcoxon tests) were used to test specific differences in numbers of rolling and adhering leukocytes (leukocytevessel wall interactions). A p-value $<0.05$ was considered significant.

\section{RESULTS}

\section{Capillary perfusion}

A 10 minute period of perfusion with Celsior did not affect capillary perfusion; capillary perfusion was $97.3 \pm 1.3$ capillaries per location at baseline measurements and $90.7 \pm 2.3(93 \%)$ after 8 hours (Celsior control group). The same was true for HTK. ${ }^{6}$

After 4 hours of warm ischemia capillary perfusion resumed in $50 \%$ of capillaries ( $p<0.01$ vs. baseline) and increased to $93 \%$ in the 2 subsequent hours. After 6 hours of warm ischemia, capillary perfusion remained low $(45 \%)$ during the entire reperfusion period $(p<0.01$ vs. baseline; Fig. 5.1).

Pre-ischemic perfusion of the muscle with Celsior did not result in improved tissue perfusion. Instead, capillary perfusion deteriorated further both after 4 and 6 hours of warm ischemia (Fig. 5.1). In the Celsior-treated animals, initial capillary perfusion after 4 hours of ischemia was $39 \%$ of baselline and did not recover during the reperfusion period ( $\mathrm{p}<0.05$ vs. IR4 at T1 andT2). After 6 hours of ischemia with pre- 
ischemic Celsior perfusion, capillary perfusion was $18 \%$ of baseline at start of reperfusion ( $<<0.01$ vs. baseline) and remained low ( $8 \%$ of baseline) during the subsequent 2 hours of reperfusion ( $<<0.05$ vs. IR6). Pre-ischemic tissue perfusion with HTK did not significantly influence the effects of ischemia and reperfusion on capillary perfusion (Fig. 5.1).

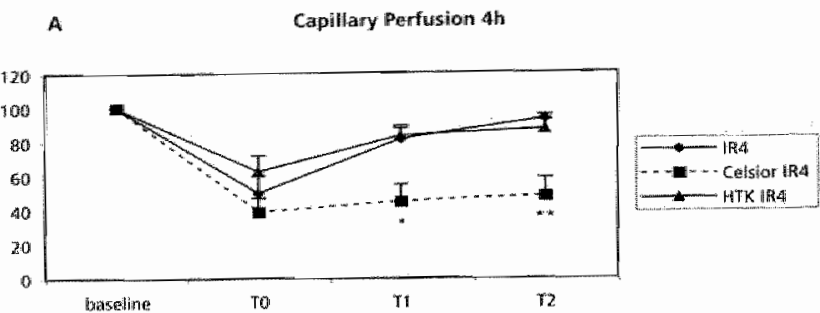

$\mathbf{B}$

Caphlary Perfusion $6 \mathrm{~h}$

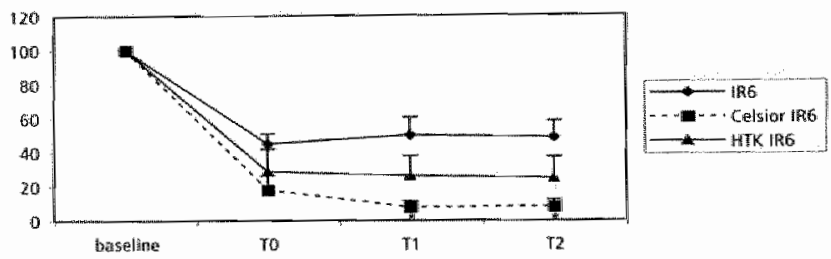

Fig. 5.1

Effects of pre-ischemic perfusion with either Celsior or HTK on capillary perfusion in rat cremaster muscle. Capillary perfusion was measured before (baseline) and 0,1 , and 2 hours $(T 0, T 1$, and $T 2$, respectively) after a period of 4 hours $(A, 4 R 4)$ or 6 hours $(B, I R 6)$ ischemia. Data are expressed as percentage of baseline.

${ }^{*} p<0.05_{2}^{* * *} p<0.01$ us. UR

\section{Leukocyte-endothelium interactions}

A 10 minute period of perfusion with Celsior had no significant influence on leukocyte rolling (Celsior control group): the number of rolling leukocytes was $20.2 \pm 3.6$ per minute during baseline measurements, $26.2 \pm 5.6$ per minute after 6 hours of observation, and $26.5 \pm 5.6$ per minute after 8 hours of observation. The number of adhering leukocytes remained stable as well $(0.89 \pm 0.11$ during baseline and $0.94 \pm 0.22$ after 6 hours). Perfusion with HTK without ischemia resulted in a threefold increase in the number of rolling leukocytes compared to baseline and had no effect on the number of adhering leukocytes. ${ }^{6}$

Four hours of warm ischemia induced an increase in the level of leukocyte rolling during reperfusion (up to $310 \%$ of baseline; $\mathrm{p}<0.05$ ). After pretreatment with either Celsior or HTK no increase in leukocyte 

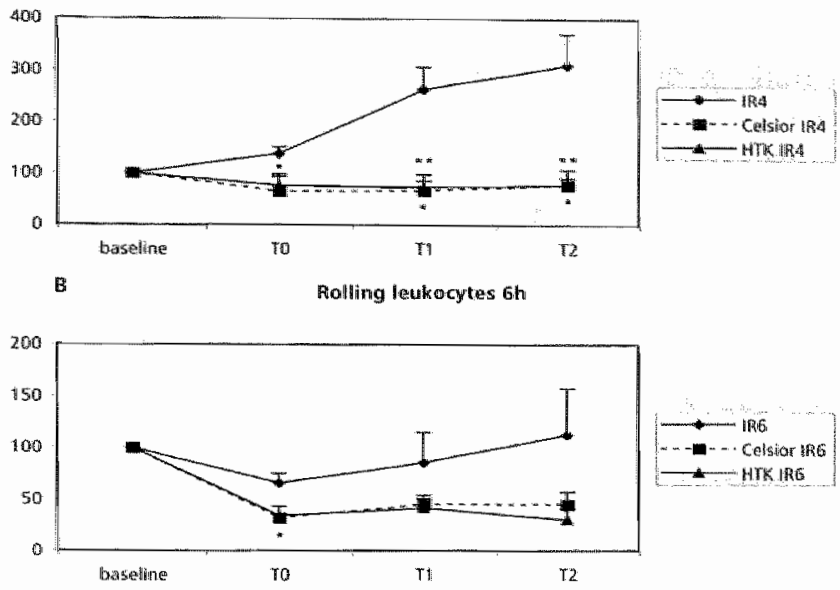

Fig. 5.2

Effects of pre-ischemic perfusion with either Celsior or HTK on leukocyte rolling in venules in rat cremaster muscle. Number of rolling leukocytes was measured before (baseline) and 0,1 , and 2 hours (TO, T1, and $\pi 2$, respectively) after a period of 4 hours $(A, I R 4)$ or 6 hours $(B, I R 6)$ ischemia. Data are expressed as percentage of baseline.

$p<0.05$, $p<0.01$ w. IR

A Adhering leukocytes 4 h
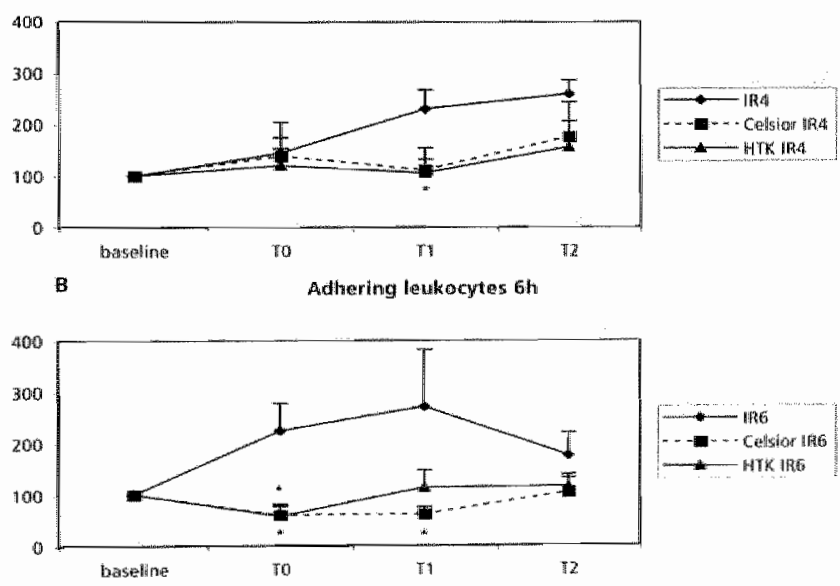

Fig. 5.3

Effects of pre-ischemic perfusion with either Celsior or HTK on leukocyte adhesian in venules in rat cremaster muscle. Number of adhering leukocytes was measured before (baseline) and 0,1 , and 2 hours $(T 0, T 1$, and $T 2$, respectivelly? after a period of 4 hours $(A, I R, 4)$ or 6 hours $(B, I R 6)$ ischemia. Data are expressed as percentage of baseline.

${ }^{*} p<0.05$ ws. $\mathbb{R}$. 
rolling was observed during reperfusion (Fig. 5.2). As a result, the level of leukocyte rolling during reperfusion was significantly lower in rats pretreated with either Celsior or HTK than in untreated animals $(\mathrm{p}<0.05$; Fig. 5.2). Consistent with these data on leukocyte rolling, we found that the increase in leukocyte adhesion, that occurred during reperfusion after 4 hours of warm ischemia ( $<<0.05$ vs. baseline at $\mathrm{Tl}$ ), was also absent in the rats pretreated with one of the preservation solutions (Fig. 5.3).

Six hours of warm ischemia resulted in an initial decrease in the number of rolling leukocytes (to $66 \%$ of baseline at start of reperfusion; $p<0.05$ ), which normalized in the subsequent 2 hours (Fig. 5.2). Pre-ischemic perfusion with Celsior or HTK resulted in a stronger reduction of leukocyte rolling at $\mathrm{TO}(32$ and $34 \%$ of baseline, respectivelly $(\mathrm{p}<0.05$ compared to IR6), while no normalization occurred (Fig. 5.2). Leukocyte adhesion showed a transient increase to a maximal level of $272 \%$ at T1 in the IR6 group ( $\mathrm{p}<0.05$ vs. baseline). This increase was absent in the Celsior and HTK treated animals $(p<0.05$ vs. IR6 at TO and T1 in the Celsior IR6 group and at T0 in the HTK IR6 group; Fig. 5.3).

\section{Discussion}

In the present study, we investigated the potential of Celsior to protect the rat cremaster muscle during warm ischemia and reperfusion by evaluating the effects of pre-ischemic perfusion with Celsior on microcirculatory parameters after a period of 4 or 6 hours of ischemia during 2 hours of reperfusion. The effects of Celsior were compared to those of HTKBretschneider solution (HTK). It turned out that neither Celsior nor HTK improved capillary perfusion after 4 or 6 hours of ischemia. In contrast, Celsior pre-treatment induced a further decrease in capillary perfusion, which remained low during the entire reperfusion period. On the other hand, we also found that both Celsior and HTK eliminated the increase in leukocyte-vessel wall interactions observed after 4 or 6 hours of warm ischemia.

Organ preservation is based on three general principles: reduction of metabolic rate by hypothermia, provision of a biochemical medium to maintain tissue viability, and minimization of reperfusion injury. The preservation solution Celsior addresses these issues by including mannitol and lactobionate to prevent cell edema, whereas reduced glutathione, histidine, and mannitol are included to prevent oxygen-derived free radical injury; glutamate is added to prevent myocyte contracture by enhancing 
energy production. In addition, it has a high magnesium content and a slight degree of acidosis to limit calcium overload. ${ }^{12}$ Celsior has been found to be effective in heart, lung, kidney, small bowel, and liver preservation in experimental and clinical studies. ${ }^{13-15}$ Effects on the microvascular effects of a period of ischemia, however, were not investigated before.

Previously, we studied the effects of 10 minutes of pre-ischemic perfusion with HTK on the microvascular consequences of 4 and 6 hours of ischemia. ${ }^{6,7}$ HTK did not influence the (transient) decrease in tissue perfusion observed after ischemia and reperfusion. Because of the high amount of free-radical scavengers in Celsior, we expected this preservation solution to be more beneficial for the muscular microcirculation than HTK. In contrast to our expectations, pre-ischemic perfusion of rat cremaster muscle with Celsior did not improve tissue perfusion during reperfusion; instead, it had an adverse effect. Without pretreatment with a preservation solution capillary perfusion transiently decreased to $50 \%$ of baseline during reperfusion after 4 hours of warm ischemia, and remained lower than $50 \%$ after 6 hours of warm ischemia. With Celsior pretreatment capillary perfusion remained lower than $50 \%$ after 4 hours of ischemia and decreased even further after 6 hours of ischemia. Hence, pre-ischemic perfusion with Celsior deteriorates cremaster muscle perfusion after a period of warm ischemia. Whether this deterioration of tissue perfusion leads to impaired muscle function remains to be elucidated.

The unexpected finding that Celsior worsens cremaster muscle perfusion after an ischemic period suggests that the protective effects for this parameter, if any, of the antioxidants in Celsior are overruled by detrimental effects of other components of this preservation fluid. In a study by Wilson et al. ${ }^{16}$ it was shown that Celsior was inferior to HTK in preserving endothelial function in vascular tissue exposed to ischemia (acetylcholine induced relaxation: $91 \%$ with HTK versus $57 \%$ when Celsior was used). This may indicate that tissue perfusion is better preserved when HTK is used as preservation solution compared to Celsior, due to a better preservation of endothelial function. The underlying mechanism has not yet been elucidated. Wilson and colleagues suggest that the large amount of the potent $\mathrm{pH}$ buffer histidine in HTK, and not in other solutions like Celsior, may be one possible explanation for the rellatively good preservation of endothelial function with HTK. ${ }^{16}$ Wildhirt et al. ${ }^{17}$ demonstrated that in Celsior preserved hearts levels of endothelin-1 (ET) gene expression were significantly increased, while ET plasma levels were elevated as well. Upregulation of the ET system leads to 
vasoconstriction and may contribute decreased tissue perfusion. Moreover, the same study also showed increased iNOS expression and enhanced NO production in the Celsior group, which may lead to free radical damage due to the formation of peroxynitrite. ${ }^{17}$

In contrast to the lack in improvement of tissue perfusion after pretreatment with Celsior and HTK, both had a favorable effect on the initial inflammatory reaction to warm ischemia and reperfusion. This effect was especially clear after 4 hours of warm ischemia, where the increase in both leukocyte rolling and adhesion during reperfusion was prevented by Celsior and HTK. The effect after 6 hours of warm ischemia may have been influenced by the significant and ongoing decrease in capillary perfusion and, hence, venular blood flow in all experimental groups. This may have resulted in reduced deliverance of leukocytes to the venules and, hence, reduced leukocyte-vessel wall interactions. ${ }^{18}$ The protective effect of both Celsior and HTK is likely to be due to an effect on the endothelial cells inside the cremaster muscle, since blood cells were removed from the muscle during pre-ischemic perfusion. After wash-out, Celsior and HTK were present in the systemic circulation at at low concentration only. Endothelial cells are most susceptible to injury during reperfusion. ${ }^{19}$ Ischemia and reperfusion initiates a cascade of deleterious cellular responses leading to inflammation, cell death and organ failure. ${ }^{20}$ The radical scavengers present in Celsior solution may have reduced endothelial cell reactions to ischemia and reperfusion, such as the expression of adhesion molecules involved in leukocyte rolling and adhesion. ${ }^{21,22}$ The fact that HTK had similar protective effects, however, suggests that other component(s) present in both solutions are responsible. The protective capacity of Celsior appears to depend on the tissue or organ in which it is used. This may be related to the fact that the microcirculation in different tissues reacts differently to ischemia/reperfusion: critical ischemia time varies in different tissue types. ${ }^{23}$ Critical ischemia time implies the maximum length of time that a tissue can tolerate complete ischemia and remain viable once circulation is restored. In addition, the degree of tissue injury caused by ischemia/reperfusion depends on the duration of ischemia. Only a few minutes of hypoxia in the brain can be deleterious, whereas heart muscle can sustain some 45-60 minutes of ischemia before irreversible injuries develop. Skeletal muscle is more tolerant to ischemia and can survive up to 3-4 hours of total ischemia ${ }^{26}$ Irreversible muscle cell damage starts after 3 hours of ischemia and is nearly complete after 6 hours of ischemia. These muscle changes are paralleled by progressive microvascular damage. ${ }^{27}$ Skin and 
bone seem to be more resistant to ischemia than other tissues. ${ }^{23}$ Such tissue differences may underlie the fact that the reaction to Celsior in a situation of ischemia/reperfusion is different in skeletal muscle than in other organs. In heart transplantation, the use of Celsior as preservation solution yielded good results and was found to be superior to HTK and UW solution. ${ }^{28}$ When Celsior was used as cardioplegic and storage solution, the intensity of perinuclear vacuolization and interstitial edema were reduced, and endothelial swelling was less extensive compared with HTK and UW groups; the wavy shape myocardial fibers in myocardial biopsies were absent. ${ }^{29}$ Celsior allowed for better post transplantation heart recovery and accounted for a lower incidence of vasculopathy in the midterm follow-up compared to UW and HTK solutions. ${ }^{28}$ As in cremaster muscle, Celsior appears to be detrimental for reperfusion of pancreatic tissue. Uhlmann and coworkers ${ }^{30}$ reported capillary perfusion failure and enhanced tissue edema after porcine pancreas preservation in Celsior. Their data suggest that Celsior is not as effective as UW in preventing pancreatic ischemia/ reperfusion injury. ${ }^{30}$

The finding that Celsior did not improve cremaster muscle perfusion after ischemia/reperfusion, in spite of its antioxidant capacity, cannot be explained by the experimental setup of the present study. For antioxidants to become effective, the reperfusion period should include a reflow period, in which oxygen enters the tissue and free radicals are formed. In the present study as well as in a previous study, ${ }^{6}$ we demonstrated that -after a period of 4 hours of total normothermic ischemia- capillary perfusion resumed at $50 \%$ of pre-ischemic baseline levels right at start of reperfusion. Within the subsequent 2 -hour reperfusion period this parameter recovered almost completely to baseline levels. Therefore, our 2-houm observation period after start of reperfusion includes an early, low flow period, but also a later, reflow period. The free radicals produced during reflow may cause tissue damage and induce endothelial adhesion molecule expression resulting in leukocyte-vessel wall interactions. ${ }^{31}$ We observed an increase in both leukocyte rolling and adhesion during the 2-hour reperfusion period, suggesting that this period indeed included the time frame in which free radicals are active. After 6 hours of ischemia, the decline in capillary perfusion (reduced to $30 \%$ of baseline measurements) did not recover during the 2 -hour reperfusion period. In this setting antioxidant treatment may be less efficient.

In the present study, we showed that pre-ischemic perfusion with the preservation solution Celsior was detrimental to capillary perfusion of rat cremaster muscle after 4 and 6 hours of warm ischemia, while perfusion 
with HTK had no effect. Both Celsior and HTK prevented an increase in leukocyte-vessel wall interactions during reperfusion, indicating a reduction of the initial inflammatory response. Our data suggest that Celsior is not the preservation solution of choice to reduce ischemiareperfusion in skeletal muscle. HTK may be more suitable than Celsior, especially when the protective effects of HTK on muscle function ${ }^{5}$ are taken into account. 


\section{REFERENCES}

1. Flavahan NA. Vanhoute PM. Endothellal cell signaling and endothelial dystunction. An J Hyperters. 1995;8:28S-41S.

2. Sellke FW, Shafique T, Ely DL, Weintrab RM. Coronary endothelial injury after cardiopulmonary bypass and ischemic cardioplegia is mediated by oxygen-deriwed free radicals. Circulation. 1993;88:11395-400.

3. Menasche P, Termignon JL, Pradier F, Grousset C, Mouas C. Albenici G, Weiss M. Piwnica $A$. Bloch $G$. Experimental evaluation of Celsion, a new heat preservation solution. Eur J Cardiothorac Surg. 1994:8:207-13.

4. Menasche P. Pradier F, Grousset C, Peynet J, Mours C. Bloch O, Piwnica A. Improved recovery of heart transplants with a specific kit of preservation solutions. I Thorac Candiowasc Surg. 1993;105:353-63.

5. van der Heijden EP, Kroese AB, Stremel RW, Bar PR, Kon M, Werker PM. Contractile properties of rat sheletal muscles following stonge at 4 degrees C. Chin Si (Lond). $1999 ; 97: 45-57$.

6. Bastianse I, Anderson GL, Franken RJ, van der Heijden BE, Oude Egbrink MG, Slaaf DW, Kon M. Effect of HTK on the microcirculation in the rat cremaster muscle during warn ischemia and reperfusion. Microsurgery. 2005,25:174-80.

7. Bastianse J, Slaaf DW, oude Egbrink MG, Anderson GL, Vink H, van der Heijden BE, Kon M. Effect of hypothermia and HTK on the microcirculation in the rat cremaster muscle after ischaemia. Clin Sci (Lond), 2005;109:117-23.

8. Franken RJ, Peter FW, Anderson GL, Wang WZ, Werker PM, Schuschke DA, Kon M. Barker JH. Anatomy of the feeding blood vessels of the cremaster muscle in the nat. Microsurgery. 1996;17:402-8.

9. Anderson GL, Acland RD, Stemionow M, McCabe SJ. Vascular isolation of the rat cremaster muscle. Microvasc Res. 1988:36:56-63.

10. Seaber AV. Experimental vasospasm. Mickontrgery 1987:8:23441.

11. Meininger GA, Fehr KL, Yates MB. Anatomic and hemodynamic chanacteristics of the blood ressels feeding the cremaster skeletal muscle in the rat. Microwso Res. $1987 ; 33: 81-97$

12. Vega ID, Ochsmer $\mathbb{I L}$, Jeevanandam V, McGifin DC, McCurry KR, Mentzer RM. Jr., Stringham JC, Pilerson RN. 3nd, Frazier OH, Menkis AH, Staples ED, Modry DL, Emery RW, Piccione W, Jr., Carrier M, Hendry PJ, Azrz S. Furkkawa S, Pham SM. A multicenter, randomized, controlled trial of Celsior for flush and hypothermic storage of cardiac allogralts. Ann Thorac Surg. 2001:71:1442-7.

13. Ohwada S. Sunose Y, Tsutsumi H, Iwazaki S, Aba M, Kasahara M, Kawasthima $Y$, Takeyoshi $\mathbb{1}$. Matsumoto K. Morishita Y. Celsior is superior to UW for gyaft preservation from non-heart-beating donors in an canine liwer transplantation model. Transplant Proc. 2001;33:922-3. 
14. Vatero $R$, Amenara $R$, Garcia-Valdecasas IC, Beltan J, Net M, Capdevila L, Lopez Boado MA, Gonzalez FX, Taura $P$, Visa J, Manyalich M. Usefuness of Celsion in graft preservation of liwers obtained from non heart beating donors in experimental (pigs) liver transplantation: comparative study with University of Wisconsin solution. Tronsplant Proc. 1999,31:2433-4.

15. Audet M. Alexandre E, Mustun A, David P, Chenard-Neu MP, Tiollier J, Jaeck D. Cinqualbre $J$, Wolf $\mathrm{P}, \mathrm{B}$ oudjema $\mathrm{K}$. Comparative evaluation of Celsior solution versus Viaspan in a pig tiver transplantation model. Thansplantation. 2001;71:1731-5.

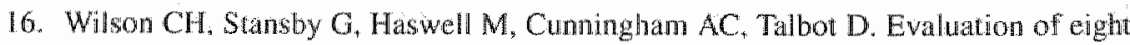
preserwation solutions for endothelial in situ preservation. Transplantation. $2004: 78: 1008-13$.

17. Wildhir SM, Weis M. Schulze C. Conrad N, Rieder G, Enders G, Thnken K, von Scheidt W, Reichart B. Effects of Celsior and University of Wisconsin preserwation solutions on hemodynamics and endothelial function after cardiac transplantation in humans: a single-center, prospective, randomized trial. Transpl Imt. 2000:13 Suppl 1:5203-11.

18. Eppihimer MJ, Granger DN. Ischemia/reperfusion-induced leukocyte-endothelial interactions in postcapillary venules. Shock. 1997:8:16-25.

19. Clavien PA. Sinusoidal endothelial cell injury during hepatic preservation and reperfusion. Hepatology. 1998:28:281-5.

20. McCord JM. Oxygen-derived free vadicals in postischemic tissta injury. $N$ Engl J Med. 1985:312:159-63.

21. Carroll WR, Esclamado RM. Ischemia/repertusion injury in microvascular surgery. Head Neck. 2000:22:700-13.

22. Krieglstein CF, Granger DN. Adhesion molecules and their role in wascular disease. Ann I Hypertens. 2001;14:44S-54S.

23. Sicmionow M. Arstan E. Ischemidreperfusion injury: A review in relation to free lissuc transfers. Microsurgery. 2004:24:468-475.

24. Massberg $\mathrm{S}$. Messmer $\mathrm{K}$. The nature of ischemia/reperfusion injury. Transplant Proc. $1998: 30: 4217-23$.

25. Beuk RJ, Heineman $\mathbb{E}_{\text {, }}$ Tangelder GJ, Kurvers HA, Bonke HJ, oude Egbrink MG. Effects of different durations of total wam ischemia of the gut on rat mesenteric microcirculation. J Surg Res. 1997:73:14-23.

26. Gustatson U. Gidlor A, Povlsen B, Sirsjo A. Skeletal muscle tissue oxygen pressure distribution during early reperfusion after prolonged ischatemia. Eur IVAsc Endovasc Surg. 1999;17:41-6.

27. Blaisdell FW. The pathophysiology of skeletal muscle ischemia and the reperfusion syudrome: a review. Cavdiovasc Stag . 2002;10:620-30.

28. Gaticki M. May preservation solution affect the incidence of graft vasculopathy in transplanted heart? Ann Transplant. 2003;8:19-24. 
29. Garlicki M, Kolcz J, Rudzinski P. Kapelak B, Sadowski J, Wojcik S, Pietryk E. Frasik W, Drukala J. Dziatkowiak A. Myocardial protection for transplantation. Transplan Proc. 1999:31:2079-83.

30. Uhmann D. Armann B, Ludwig S, Escher E, Pietsch UC, Tannapfel A, Teupser D. Hruss J, Witzigmann H. Comparison of Celsior and UW solution in experimental pancreas preservation. J Surg Res. 2002; 105:173-80.

31. Grisham MB, Granger DN, Lefer DJ. Modulation of leukocyle-endothelial interactions by reactive metabolites of oxygen and nitrogen; relevance to ischemic heart disease. Free Radic Biol Med. 1998:25:404-33. 


\section{CHAPTER 6 \\ Preservation of rat cremaster muscle microcirculation after prolonged cold storage and transplantation}

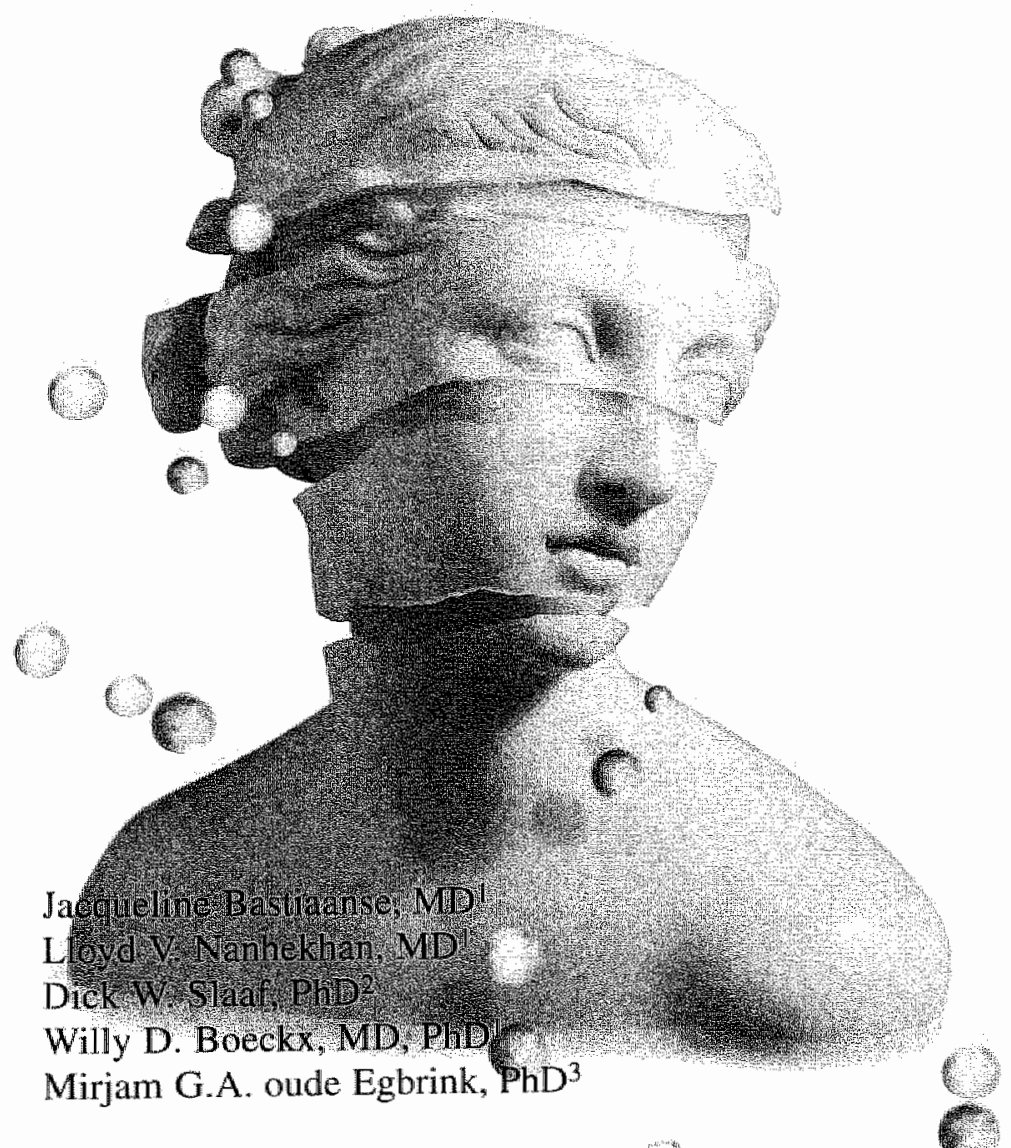

Department of Plastic, Reconstructive \& Hand SurgeV University Hospital Maasthent, Maastuchtht, The Netherlands

Laboratory for Microcirculation, Cardiovascular Research Institute Maastricht, Departments of zBiophysics and 3 Physiology, Maastricht University, Maastricht, The Netherlands

J Surg Res 2006;131:41-8 


\section{ABSTRACT}

Microvascular surgery for reconstruction of complex defects involves an ischemic period, which may cause flap failure due to ischemia reperfusion injury. We assessed the microvascular consequences of rat cremaster muscle transplantation after prolonged periods of cold storage in HTKBretschneider solution (HTK).

Cremaster muscle transplantations were performed immediately, or after 8 or 24 hours of cold storage in HTK or saline. Intravital microscopy was used to quantify capillary perfusion and venular leukocyte-endothelium interactions following transplantation.

The transplantation procedure itself resulted in 50-65 minutes of ischemia. After direct transplantation capillary perfusion was $90 \%$ of control. Transplantation after 8 hours of cold storage in either HTK or saline did not deteriorate capillary perfusion. When the tissue was stored for 24 hours, HTK was superior to saline in preserving capillary perfusion (HTK: 76$83 \%$ of control, saline: $30 \%$ ). Immediate transplantation induced a small increase in leukocyte adhesion. Prolonged cold storage in either fluid resulted in reduced flow velocities (qualitative observations) and edema formation, which hampered quantification of leukocyte-endothelium interactions.

Even after 8 or 24 hours of cold storage in HTK, transplantation of rat cremaster muscle was successful with good capillary perfusion. Capillary perfusion was better preserved in HTK than in saline. 


\section{INTRODUCTION}

Complex defects are usually reconstructed by transfer of local, distant, or free vascularized flaps or by autologic transplantations with success rates greater than $95 \%$. However, a problem frequently occurring after transplantation is function loss. Furthermore, donor site morbidity can occur when large parts of autologous tissue have to be transplanted. Loss of graft function is often caused by ischemia/reperfusion (I/R) injury. 1,2 The microcirculation of transplanted tissues plays an important role in post transplant graft failure; ${ }^{3}$ microcirculatory derangements, such as capillary perfusion failure and inflammation associated leukocyte recruitment, are major determinants for manifestation of graft dysfunction.2,4

The problems caused by loss of graft function and donor site morbidity may be reduced by using composite tissue allografts (CTA's). Of all tissues present in CTA's, muscle is one of the least tolerant to ischemia. ${ }^{5-8}$ The consequences of ischemia/reperfusion and transplantation for muscular microcirculation can be studied in detail in the cremaster muscle preparation. ${ }^{9}$ This muscle can be dissected on its vascular pedicle and allows in vivo assessment of various microcirculatory parameters related to tissue perfusion and blood cell-vessel wall interactions. ${ }^{7-10}$ The group of Siemionow has already performed many studies related to $U / R^{11-13}$ and transplantation of cremaster muscle. ${ }^{2,7,14}$ In 1998 and 2002 they reported successful, immediate cremaster transplantations in rats ${ }^{14}$ and in mice, 7 respectively. These procedures involved an ischemic period of about

Table 6.1

Composition of Histidine Typtopham Ketoglutarate (HTK) solution (mmolil)

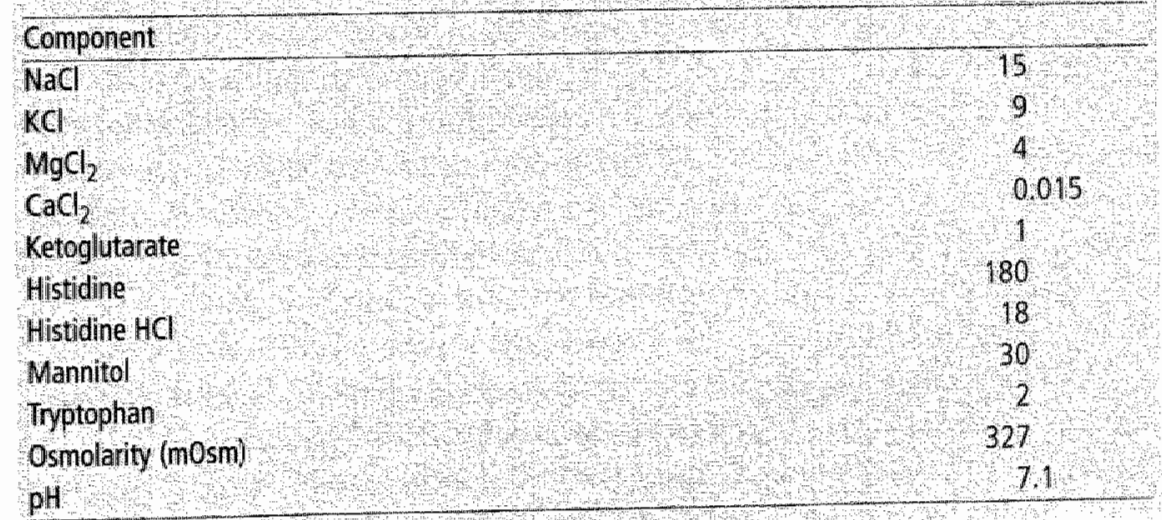


75 minutes. In transplantation surgery, however, a longer time delay may occur between the moment the donor organ becomes available and the moment transplantation in the recipient can actually be performed. Damage to the organ or tissue due to such a prolonged ischemic period has to be minimized. In clinical practice, cold storage $\left(4-6^{\circ} \mathrm{C}\right)$ of organs or tissues is used, which protects arteries from excessive spasm during ischemia and also decreases reactive hyperemia. ${ }^{15}$ In larger muscle tissue parts, however, cold storage may not be sufficient to prevent damage, and submersion in specific preservation solutions may be required. It was shown previously that storage in Histidine-Tryptophan-Ketoglutarate (HTK) (Table 6.1) was more effective for preservation of contractility of isolated rat skeletal muscles than storage in other preservation solutions (Krebs-Henseleit, Euro Collins, St. Thomas' Hospital solution). 16,17 Nevertheless, histology of these muscles showed an increasing muscle fiber derangement with increasing storage time. ${ }^{17}$

The consequences of prolonged storage for microvascular functions in transplanted tissue are not known. Therefore, it was the aim of the present study to investigate the microcirculation in the transplanted rat cremaster muscle, after immediate transplantation and after 8 or 24 hours of cold storage in the preservation solution HTK. Saline was used as control solution. We focused on the consequences of prolonged storage and transplantation for capillary perfusion and leukocyte-vessel wall interactions.

\section{Materialas and Methods}

\section{Animals}

Male Lewis rats of 120-190 grams were used. The rats were housed in pairs on a 12:12 hour (light-dark) cycle and were provided a standard diet and water ad libitum. All animals received care in compliance with the European Convention guidelines. The local ethics committee approved all protocols. Rats were anesthetized with fentanyl-fluanisone (Hypnorm ${ }^{\mathrm{TM}}$, Janssen Pharmaceutica, Beerse, Belgium) at an intramuscular dose of $0.5 \mathrm{ml} / \mathrm{kg}$, and sodium pentobarbital (Nembutalrm, Sanofi Sante B.V. Maassluis, The Netherlands) at a subcutaneous dose of $15 \mathrm{mg} / \mathrm{kg}$. Additional injections were given when necessary. A blood pressure cannula (PE 50) was inserted into the left carotid artery to monitor systemic arterial pressure. During the experiment, and also during warm ischemia, body and cremaster temperatures were maintained at 36 to $37^{\circ} \mathrm{C}$ and at 33 to $34^{\circ} \mathrm{C}$, respectively, 
using heating lamps. At the end of the experiment, the animals were euthanized by an intracardial injection of an overdose of sodium pentobarbital.

\section{Surgical procedure}

Dissection of the cremaster muscle on its vascular pedicle was performed as previously described. 9,18 During dissection, the tissues were kept moist by irrigation using normal saline. The full thickness of the abdominal wall muscles was divided for $1 \mathrm{~cm}$ cranial and parallel to the inguinal ligament. Irrelevant branches of the iliac vessels were ligated. The muscle was isolated on the femoral artery and vein (external diameter of 400 and $600 \mu \mathrm{m}$, respectively) (Fig. 6.1 A). Anastomoses to the recipient vessels were performed at this level (Fig. 6.1B). For immediate transplantation, the muscle flap was not detached until the end of the preparation of the recipient site to ensure a short duration of ischemia.

In case of immediate transplantation, we chose the contralateral femoral artery and vein as the recipient site (Fig. 6.1B). A skin incision was made from the anterior iliac spine to the top of the scrotum. The femoral vessels were dissected and vascular clamps were placed. Before anastomoses were performed, the endings of the vessels were flushed with saline containing heparin. Anastomoses were performed using standard end-to-side technique with interrupted sutures under standard surgical microscopy (Fig. 6.1C). Anastomoses between the femoral veins were performed using ethilon 10/0; anastomoses between the femoral arteries were performed using ethilon $11 / 0$. The muscle was spread on a platform and covered with gas-impermeable plastic film (Saran Wrap ${ }^{\mathrm{TM}}$; presoaked for 24 hours in distilled water to remove chemical residues) and the clamp was released (Fig. 6.1D). The platform was then placed on the stage of the intravital microscope.

When the transplantation was performed after 8 or 24 hours of cold storage, the right femoral artery and vein of a recipient rat were dissected to connect the femoral vessels of the preserved cremaster. The distal part of the femoral artery and vein of the graft were anastomosed end-to-side to the femoral vessel of the recipient rat. One person performed all procedures.

\section{Cold storage}

The vascular isolated cremaster muscle was excised after ligation of the distal and proximal parts of the femoral vessels. The tissue was stored at $4^{\circ} \mathrm{C}$ for 8 or 24 hours in $15 \mathrm{ml}$ of storage solution: either $\mathbb{H T K}$ or saline. 

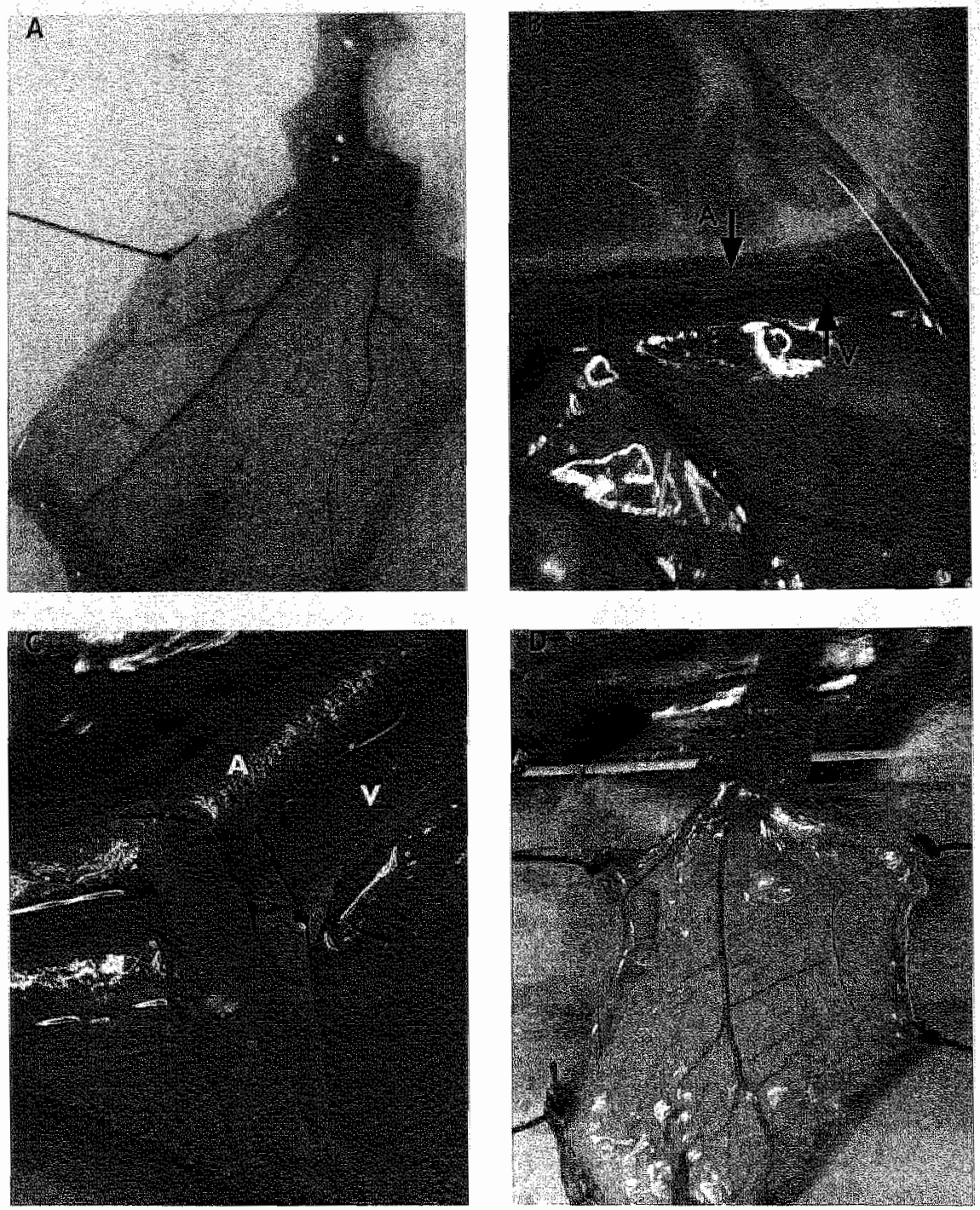

Fig. 6.1

Transplantation procedure of rat cremaster muscle.

A) The cremaster muscle was isolated on the femoral artery and wein.

B) The right femoral artery (A) and wein (V) (external diametter of 400 and $600 \mu m_{n}$ respectively) were the recipient vessels.

C) Anastomoses were performed using standard end-to-side technique with interrupted sutures. Anastomoses between the femoral veins $(V)$ were performed using ethilon $10 / 0 ;$ anastomoses between the femoral arteries (A) were performed using ethilon 11,10 .

D) After transplantation and spreading of the cremaster muscle, the muscle color changed within a few seconds after clamp release, indicating that flow had resumed. 


\section{Experimental groups}

Experimental groups of 6 animals each were studied. In the control group (control) the cremaster muscle was isolated on its vascular pedicle, but the tissue was not transplanted. In group 2 (CTX), immediate isograft transplantations were performed. This group served as control group to reveal the microcirculatory changes after surgical trauma of transplantation. In group 3 (HTK-CTX8) and group 4 (s-CTX8) transplantations were performed after 8 hours of cold storage at $4^{\circ} \mathrm{C}$ in HTK or saline, respectively. In group 5 (HTK-CTX24) and group 6 (s-CTX24), transplantations were performed after 24 hours of cold storage in HTK or saline, respectivelly.

The consequences of transplantation for the microcirculation were investigated by intravital microscopic assessment of capillary perfusion and leukocyte-endothelium interactions during an observation period of 3 hours. Measurements were performed at $0,1,2$, and 3 hours after transplantation. In the control group measurements were performed at corresponding time points.

\section{Intravital Microscopy and Microcirculation Parameters}

The microvasculature was observed using a Leitz intravital microscope equipped with a 2/3-inch Hitachi CCD camera coupled to a closed-circuit video system. Microvascular images were recorded on videotape using an S-VHS video recorder (Panasonic).

\section{Capillary Perfusion}

The number of perfused capillaries was quantified using a $4 x$ objective (numerical aperture 0.12) at three different locations in nine adjacent fields of view. One field of view measured 720*540 $\mu \mathrm{m}$. The same locations were measured throughout the experiment. Results are expressed as the average number of perfused capillaries per location (of 9 fields of view).

\section{Leukocyte-endothelium interactions}

Three pre-selected third-order venules (diameter 30-60 $\mu \mathrm{m}$ ), related to the locations observed for capillary perfusion, were examined to assess leukocyte-endothelium interactions using a $4 \mathrm{x}$ objective (numerical aperture 0.12 ). The number of leukocytes rolling along the vessel wall was counted for a period of 60 seconds. Leukocytes were defined as rolling if they moved along the endothelial wall at a velocity clearly lower than the velocity of other blood cells. ${ }^{19}$ The number of leukocytes adhering to the vascular endothelium was assessed in a segment of $100 \mu \mathrm{m}$ length. 
Adherent leukocytes remained stationary on the endothelial wall for at least 30 seconds.

In edematous tissue intravital microscopic observation of leukocytevessell wall interactions is severely hampered. We used this property as a marker of tissue edema development after transplantation

\section{Statistics}

Data are presented as means \pm SEM. Capillary perfusion data are presented as percentage of the average of the control group at baseline ( $T=0$ : first observation after preparation and spreading of the cremaster muscle) to reduce the covariance in the data set. Repeated-measures ANOVA was used to compare data groups, followed by a multiple comparison procedure for specific differences (using Bonferroni correction) in capillary perfusion. Because of non-normality of data, nonparametric tests (Mann Whitney and Wilcoxon tests) were used to test specific differences in leukocyte-vessel wall interactions. A p-value $<0.05$ was considered significant.

\section{RESULTS}

Mean carotid artery pressure ranged from 85 to $110 \mathrm{mmHg}$ and remained stable throughout the experiments. In the immediate transplantation group, ischemia time ranged from 50 to 65 minutes and the total operative time was 60-75 minutes. When the cremaster muscle was stored for 8 or 24 hours in HTK or in saline, the ischemic period was prolonged with 8 or 24 hours, respectively. After 24 hours of cold storage the cremaster muscles were edematous; analysis of leukocyte-vessel wall interactions appeared to be difficult. Macroscopic observation and tissue handling revealed that cremaster muscles preserved in saline were more contracted than muscles preserved in HTK, especially when storage lasted 24 hours.

After transplantation and spreading of the cremaster muscle, the vascular clamp was released and the muscle color changed within a few seconds (macroscopic observation), indicating that flow had resumed (Fig. 6.1D). Intravital microscopic observations showed that this reperfusion occurred in the whole transplanted cremaster muscle, including its distal part, both after immediate transplantation and after 8 hours of cold storage, although flow was lower than in the control situation (qualitative observation). After 24 hours of cold storage in saline, however, flow was very low in 3 out of 6 animals; in parts of the cremaster, capillary perfusion did not 
resume. After 24 hours of cold storage in HTK, tissue perfusion resumed throughout the muscle in all 6 animals.

\section{Capillary perfusion}

In the control group, an average number of $88 \pm 1.5$ capillaries was perfused per location. Capillary perfusion did not change during 3 hours of observation. After immediate transplantation (CTX), capillary perfusion was slightly lower than in the control group ( $90 \%$ at $\mathrm{T}=0 ; \mathrm{p}<0.01)$ and remained at that level during the observation period (Fig. 6.2A).

Cremaster muscle transplantation performed after 8 hours of cold storage in HTK (HTK-CTX8) resulted in a mean capillary perfiusion of $112 \%$ of control values at $\mathrm{T}=0(\mathrm{p}<0.01)$ and did not significantly alter thereafter. Transplantation after 8 hours of cold storage in saline (s-CTX8) resulted in an initial capillary perfusion of $106 \%$ of control values, slightly decreasing to $89 \%$ after 3 hours of observation; values were not significantly different from the HTK-CTX8 group (Fig. 6.2B).

A Capillary perfusion
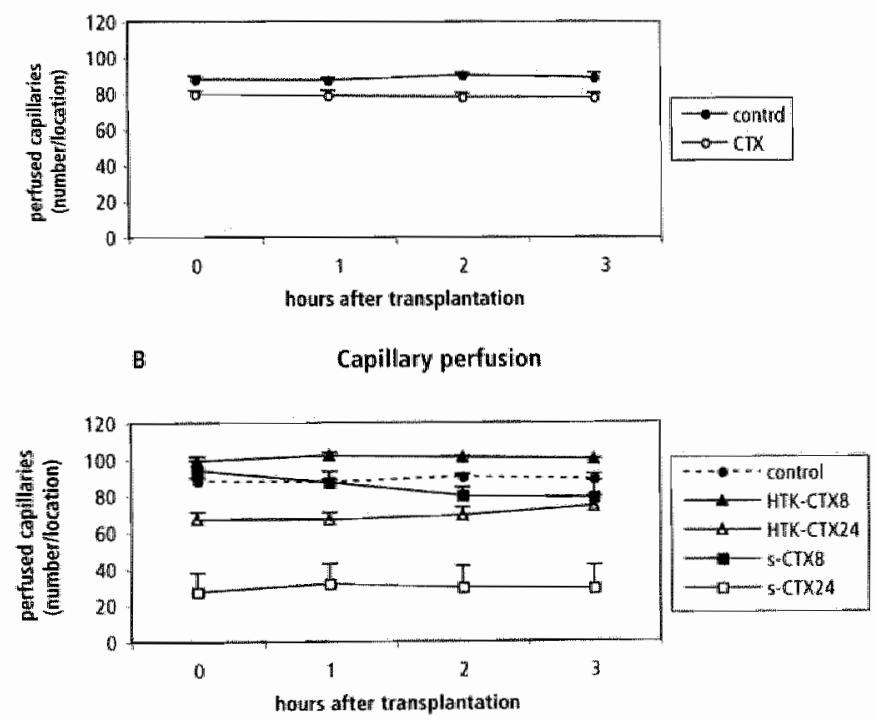

Fig. 6.2

Effect of immediate transplantation (A) or of transplantation after 8 or 24 hours of cold storage in HTK or saline (B) on capillary perfiusion in rat cremaster muscle.

Significant differences, with levels of significance, are indicated in the text.

in contirol group: baseline measurements performed at $T=0$ hours.

$\mathrm{CTX}=$ mmediate isograft transplantation; HTK-CTX8 and 24: transplantation after 8 or 24 hours of cold storage in HTK; 5-CTX8 and 24: transplantation after 8 or 24 hours of cold storage in saline. 
After 24 hours of cold storage in HTK (HTK-CTX24), initial capillary perfusion after transplantation was $76 \%$ of control $(\mathrm{p}<0.01)$, and it remained stable during the subsequent 3 hours $(84 \%$ of control at end of the observation period). After $24 \mathrm{~h}$ of cold storage in saline (s-CTX24), capillary perfusion immediately after transplantation was only $31 \%$ of control values; it remained at this low level during the observation period (p<0.01 vs. HTK-CTX24; Fig. 6.2B).

\section{Leukocyte-endothelium interactions}

In the control group, the number of rolling leukocytes in the selected venules was $8 \pm 1$ per minute at start of observation. This number increased to $22 \pm 5$ per minute during the subsequent 3 hours ( $p<0.05$ vs. $T=0$ ). After immediate transplantation (CTX) the number of rolling leukocytes was $11 \pm 4$ per minute at $T=0$, and did not significantly change during the observation period. As a result, after 3 hours of observation, the level of rolling leukocytes after immediate transplantation was lower than in the control group ( $<<0.01$; Fig. 6.3A).

A

Rolling Leukocyte
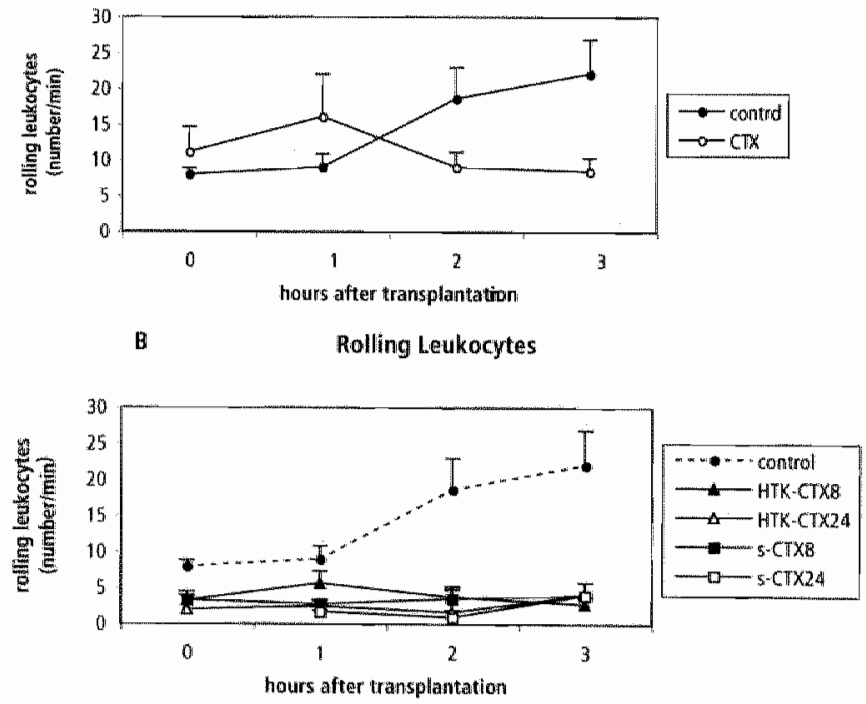

Fig. 6.3

Effect of immediate transplantation (A) or of transplantation after 8 or 24 hours of cold storage in HTK or saline $(B)$ on the level of letkocyte rolling in rat cremaster muscle venules.

Significant differences, with levels of significance, are indicated in the text.

In control group: baseline measurements performed at $T=0$ hours.

CTX = immediate isograft transplantation; HTK-CTX8 and 24: transplantation after 8 or 24 hours of cold storage in HTK: $\mathrm{s-CTX8}$ and 24: transplantation after 8 or 24 hours of cold storage in saline. 
When transplantation was performed after 8 hours of cold storage in HTK (HTK-CTX8) or saline (s-CTX8), low levels of leukocyte rolling were observed (ranging from $3 \pm 1$ to $6 \pm 2$ per minute) during the whole observation period; levels did not differ between the two groups (Fig: 6.3B).

After 24 hours of cold storage in either HTK (HTK-CTX24) or saline (s-CTX24), the cremaster muscles were edematous, which hampered quantification of leukocyte rolling. Blood flow was so low, that rolling leukocytes could not always be identified between the individually visible red blood cells. Only occasionally a rolling leukocyte could be identified. In the venules of all groups, levels of leukocyte adhesion were low. In the control group, the number of adhering leukocytes ranged from $0.7 \pm 0.1$ to $1.4 \pm 0.1$ per $100 \mu \mathrm{m}$ during the observation period. After immediate transplantation (CTX), the level of leukocyte adhesion was higher, ranging from $2.6 \pm 0.8$ to $2.9 \pm 0.6$ cells per $100 \mu \mathrm{m}$ ( $\mathrm{p}<0.05$ versus control; Fig. 6.4A).

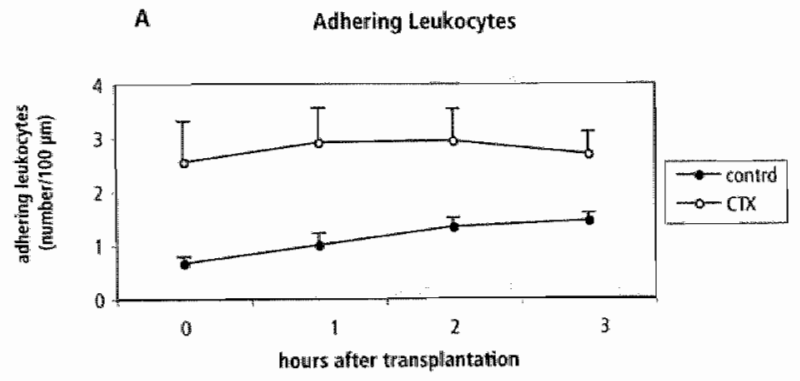

B

Adhering Leukocytes

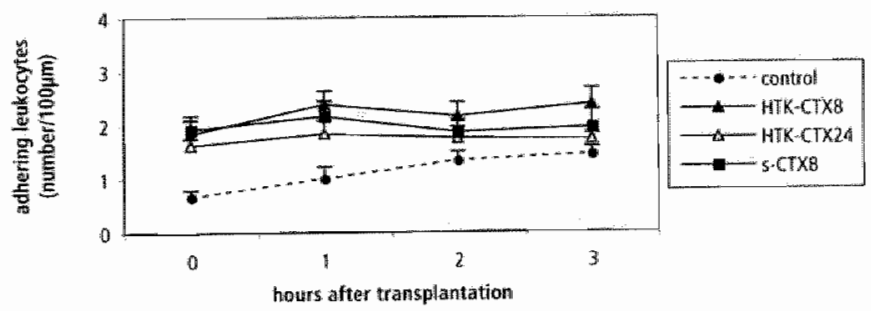

Fig. 6.4

Effect of immediate transplantation (A) or of transplantation after 8 or 24 hours of cold storage in HTK or saline (B) on the level of leukocyte adhesion in rat cremaster muscle wenules.

Significant differences, with levels of significance, are indicated in the text.

In control group: baseline measurements performed at $\mathrm{T}=0$ hours.

CTX $=$ immediate isograft transplantation; HTK-CTX8 and 24: transplantation after 8 or 24 hours of cold storage in HTK: 5 -CTX8: transplantation after 8 hours of cold storage in saline. After 24 hours of cold storage in saline, adhering leukocytes could nol be discriminated due to edema formation. 
No significant differences were observed between leukocyte adhesion levels in cremaster muscles preserved for 8 hours in HTK (HTK-CTX8) or saline ( $\mathrm{s}-\mathrm{CTX} 8$; values ranging from $1.8 \pm 0.2$ to $2.4 \pm 0.3$ cells per $100 \mu \mathrm{m}$ ). In addition, the level of leukocyte adhesion after 24 hours of cold storage in HTK (HTK-CTX24) was similar to the one observed after 8 hours in HTK (HTK-CTX8; Fig. 6.4B). After 24 hours of cold storage in saline, adhering leukacytes could not be discriminated due to edema formation.

\section{DISCUSSION}

Transplantation of rat cremaster muscle after 8 or 24 hours of cold storage in the preservation solution HTK proved to be successful, with good capillary perfusion. In contrast, 24 hours of cold storage in saline resulted in impaired capillary perfusion in the transplanted muscle. No or only slight increases in venular leukocyte-vessel wall interactions were observed after cold storage during 8 or 24 hours, independent of the solution used. These data suggest that the use of the preservation solution HTK adds to the success of preservation of muscle microcirculation in case of cold storage during 24 hours.

When an organ or tissue is transplanted, prolonged periods of ischemia may occur. During such periods, the tissue needs to be preserved to achieve optimal (functional) results after transplantation. At present, storage of tissues and organs at low temperatures $\left(4-6^{\circ} \mathrm{C}\right)$ and in preservation solutions has become standard in clinical practice. ${ }^{20}$ Preservation solutions are designed to minimize both hypothermia-induced cell swelling and ischemiareperfusion induced cell damage. ${ }^{21}$ The storage solutions most commonly used are Euro-Collins (EC), University of Wisconsin solution (UW), HTKBretschneider solution (HTK) and revised St. Thomas'Hospital solution. HTK is often used in heart preservation ${ }^{22}$ and also yields good results in preservation of other organs, like liver and kidney. ${ }^{23}$ In previous studies, isolated rat skeletal muscles were preserved during 8 and 16 hours in various preservations solutions. Contractility of these muscles was best preserved by immersion in HTK at $4^{\circ} \mathrm{C}$. ${ }^{17.24}$ Therefore, we decided to use HTK for storage of isolated cremaster muscle in the present study as well.

Our results show that a relatively short warm ischemic period of 50-65 minutes combined with the surgical trauma involved in transplantation is not very harmful to the rat cremaster muscle microcirculation; this procedure did not induce a relevant decrease in capillary perfusion. Ozer and colleagues performed cremaster transplantations with comparable 
short ischemic periods in mice and found good results for capillary perfusion as well: $70 \%$ of control immediately after transplantation, followed by a slight increase during the subsequent 3 hours of observation. ${ }^{7}$ Previously, we showed that even 4 hours of warm $\left(33-34^{\circ} \mathrm{C}\right)$ ischemia of the cremaster muscle pedicle causes only a transient decrease (to $50 \%$ ) in capillary perfusion, after which it recovers almost to baseline levels. ${ }^{10}$ The present data indicate that prolonged storage of isolated rat cremaster muscle, during 8 or 24 hours, in HTK at $4^{\circ} \mathrm{C}$ and subsequent transplantation does not result in a considerable alteration in capillary perfusion. Cold storage in saline yielded good results as well, provided that the storage period was confined to 8 hours. The relatively good perfusion after immediate cremaster muscle transplantation, and after transplantation following 8 hours of cold storage may be explained by the denervation caused by the transplantation procedure: denervated cremaster muscle pedicles were shown to have $27 \%$ more perfused capillaries than cremaster muscles with intact neurovascular pedicles. ${ }^{25}$ After 24 hours of cold storage in saline, however, capillary perfusion was significantly deteriorated; after transplantation perfusion resumed in only $30 \%$ of the capillaries, and no further improvement was noted during the subsequent 3 -hour observation period. These data indicate that the use of the preservation solution HTK is beneficial for the cremaster muscle microcirculation during prolonged periods ( $>8$ hours) of cold storage. Our data comply with the results of Corner et al. ${ }^{26}$ who showed that cold preservation of vascular (aortic) segments in HTK during 24 hours preserves smooth muscle cell contraction and endothelium-dependent relaxation. In addition, Yang et al. showed that HTK maximally preserves endothelium-derived hyperpolarizing factor-mediated dilatation in small coronary arteries, whereas UW was found to be less successful. ${ }^{27}$

Ischemia/reperfusion injury in skeletal muscle is not only characterized by reduced capillary perfusion. It also induces an acute inflammatory reaction in which activated leukocytes play a key role. 2,28 Although restoration of flow is essential in reducing ischemic injury, reperfusion initiates a cascade of reactions that lead to leukocyte accumulation, enhanced microvascular endothelial permeability, and edema formation. In several organs, it has been shown that such microvascular consequences of ischemia/ reperfusion worsen with prolongation of the (warm) ischemic period. In the present study, we find that immediate transplantation of the cremaster muscle, with a relatively short warm ischemic period of 50-65 minutes induces a small, significant increase in leukocyte adhesion, while no increase in leukocyte rolling was observed. In their mouse model, Ozer et al. ${ }^{7}$ observed a small, but significant increase in leukocyte rolling and adhesion after 
immediate transplantation of the cremaster muscle, with an ischemic period of 75 minutes. These limited inflammatory reactions may at least partly be due to a decrease in venular flow velocity after immediate transplantation? (and qualitative observation in the present study). As a result, leukocyte delivery to the venules may have been restricted. ${ }^{29}$ This explanation probably also holds for the low levels of leukocyte-vessel wall interactions observed when transplantation was performed after cold storage for 8 or 24 hours; in these situations venular flow seemed to be even lower than after immediate transplantation. Moreover, after 24 hours of cold preservation the rat cremaster muscle was edematous, which severely hampered the quantification of leukocyte-vessel wall interactions. As a result, we are -at present- not able to draw reliable conclusions on the effects of prolonged periods of cold storage on leukocyte-vessel wall interactions in transplanted cremaster muscle. Future investigation of the effects of intermediate periods ( 12 or 16 hours) of cold storage may elucidate whether HTK offers additional protection by reducing the inflammatory response after transplantation, provided that tissue perfusion is not influenced.

In clinical practice, organs are flushed with a solution to remove blood cells before cold storage and transplantation. In the study of Ozer et al., the mouse cremaster muscle was perfused with heparinized Ringer's solution prior to transplantation of the muscle. ${ }^{7}$ However, it was also shown previously that pre-storage perfusion with HTK did not improve muscle function or cytoarchitecture of rat skeletal muscles after 16 hours cold storage. ${ }^{30}$ Furthermore, pre-ischemic perfusion of rat cremaster muscle with HTK did not improve capillary perfusion after 4 and 6 hours of warm ischemia. ${ }^{10}$ Therefore, in the present study the cremaster muscles were not perfused with a preservation solution prior to cold storage and transplantation. Although pre-ischemic or pre-storage perfusion with a preservation solution has no beneficial effects for preservation of contractility and microvasculature in isolated (small) rat muscles, perfusion may be necessary when larger (human) muscles are subjected to a prolonged ischemic period. Under those circumstances, cold storage by immersion in a preservation sollution at $4^{\circ} \mathrm{C}$ may not be sufficient, because diffusion distances are too large. The use of larger animal models may elucidate whether pre-ischemic perfusion with a preservation solution is beneficial for the microcirculation, when larger muscles are transplanted after prolonged periods of ischemia.

In conclusion, the present study shows that even after 8 or 24 hours of cold storage in the preservation solution HTK, transplantation of rat cremaster muscle was successful with good capillary perfusion. Capillary perfusion was better preserved in HTK than in saline. 


\section{REFERENCES}

1. Menger MD, Vollmar B. Role of microcirculation in transplantation. Microcinculation. 2000;7:291-306.

2. Siemionow M, Arslan E. Ischemia/reperfusion injury: A review in nelation to free tissue iransfers. Microsurgery. 2004:24:468-475.

3. Pober JS. Activation and injury of endothelial cells by cytokines. Pathol Biol (Panis). $1998 ; 46: 159-63$.

4. Carroll WR. Esclamado RM. Ischemia/reperfusion injury in microvascular surgery. Head Neck. 2000;22:700-13.

5. Blaisdell FW. The pathophysiology of skeletal muscle ischemia and the reperfusion syndrome: a rewiew. Cardiowasc Surg. 2002;10:620-30.

6. Gudemez E, Turegun M Zins I, Siemionow M. Microvascular permeability following composite tissue ransplantation. Amn Plast Surg. 1998;41:519-29.

7. Ozer K, Zielinski M, Unsal M. Siemionow M. Development of mouse cremaster ransplantation model for intravital microscopic evaluation. Microciatcularon. 2002:9:487-95.

8. Ozer K. Zielinski M, Siemionow M. New composite tissue allograft transplantation model in mouse with intravitall microscopic evaluation of microcirculation. J Recomst Microsurg. 2003; 19:323-30.

9. Franken RJ, Peter FW, Anderson GL, Wang WZ, Werker PM, Schuschke DA, Kon $\mathrm{M}$, Barker JH. Anatomy of the feeding blood vessels of the cremaster muscle in the rat. Microsurgery. 1996;17:402 8.

10. Bastiaanse J, Anderson GL, Franken RJ, van der Heijden EPA, oude Egbrink MG, Slaaf DW, Kon M. Effect of HTK on the microcirculation in the rat cremaster muscle during warm ischemia and reperfusion. Microsurgery. 2005;25:174-80.

11. Siemionow M, Romanowski L, Lister G. Leukocyte-depleting effect of hypothermia on muscle flap microcirculation following ischemia-reperfusion injury. J Hand Surg $|A m| .1993: 18: 963-7 \mid$.

12. Siemionow M, Andreasen T, Lister G. Microcirculatory response to surgical trama in composite-tissue transfer. I Recofstm Microsurg. 1995;11:7-13.

13. Siemionow M, Manikowski W, Gawronski M. Histopathology of mascle llap microcirculation following prolonged ischemia. Microsurgery 1995;16:515-21.

14. Siemionow $M$, Kimon $K$, Lister $G$. Microciculatory hemodynamics dung the alute phase of free vaseularized muscle allogr at rejection. Ann Plast Surg. 1998:41:275-82.

15. Beris AE Soucacos PN, Seaber AV, Urbaniak JR. Effects of cold ischemia on reflow pattems in the rat cremaster muscle microcinculation. Int Angiot. 1995;14:248-52.

16. van der Heijden EP, Kroese AB. Werker PM, Grabietz PD, de Jong MB, Bar PR, Kon M. Function of rat skeletal muscles after storage at 10 degrees $C$ in various preservation solutions. Clin Sci (Lond). 1998:94:271-8. 
17. van der Hejden EP. Kroese AB. Werker PM, de With MC, de Smet M, Kon M, Bar DP. Improving the preservation of isolated rat skeletal muscles stored for 16 hours at 4 degress C. Transplantation. 2000,69:1310-22.

18. Anderson GL. Acland RD, Siemionow M, McCabe SJ. Vascular isolation of the rat cremaster musele. Microvasc Res. 1988:36:56-63.

19. oude Egbrink MG. Tangelder GJ, Slaaf DW, Reneman RS. Influence of platelet vessel wall interactons on leukocyte rolling in vivo. Cinc Res. 1992;70:355-63.

20. St Peter $\mathrm{SD}$, Imber Cl, Friend PJ. Liver and kidney preservation by perfusion. Lancer. 2002;359:604-13.

21. Belzer FO, Southard JH. Principles of sollidorgan preservation by cold storage. Transplanation. 1988;45:673-6.

22. Muhlbacher F, Langer $F$. Mittermayer $C$. Preservation solutions for transplantation. Transplant Proc. 1999;31:2069-70.

23. Spiegel HU, Schleimer K, Freise H, Diller R, Drews G, Kranz D. Organ preservation with $\mathrm{EC}, \mathrm{HTK}$, and UW, solution in orthotopic rat liver transplantation. Part $\mathrm{H}$. Momphological study. J Inwest Surg. 1999:12:195-203.

24. van der Hejiden EP, Kroese AB, Stremel RW, Bar PR, Kon M, Werker PM. Contrachle properties of rat skeletal muscles following storage at 4 degrees $\mathrm{C}$. Clin Scd (Lond). $1999 ; 97: 45-57$.

25. Siemionow M, Andreasen T, Chick L, Lister G. Effect of muscle flap denervation on flow hemodynamics: a new model for chronic in vivo studies. Microsurgery. $1994,15: 891-4$.

26. Comer JA, Berwanger CS, Stansby G. Preservation of vascular tissue unde. hypothermic conditions. J Surg Res. 2003;113:21-5.

27. Yang Q, Zhang RZ, Yim AP, He GW. Histidine-tryptophan-katoglutarate solution maximally preserves endothelium derived hyperpolarizing factor-mediated function during heart preservation: comparison with University of Wasconsin solution. I How Lnig Transplan. 2004:23:352-9.

28. Gute DC, Ishida T, Yamiza K, Korhuis $\mathbb{R I}$. Inflammatory responses to ischemia and reperfusion in skeletal muscle. Mol Cell Biochem. 1908:179:169-87.

29. Lawrence MB, Kansas GS, Kunkel EJ, Ley K. Thresllold levels of lluid shear promote lenkocyte adhesion through selectins (CD62L,P,E). I Cell Biol. 1997;136:717-27.

30. van der Heijden EP, Kroese AB, Werker PM, Kon M. de With MC, Bar DP. Preservation of rat skeletal musele function during storage for $16 \mathrm{~h}$ at 4 degrees $\mathrm{C}$ is nol improwed by pre-storage pertusion. Chim Sici (Lond). 2003;105:29-37. 



\section{CHAPTER 7 \\ General discussion}

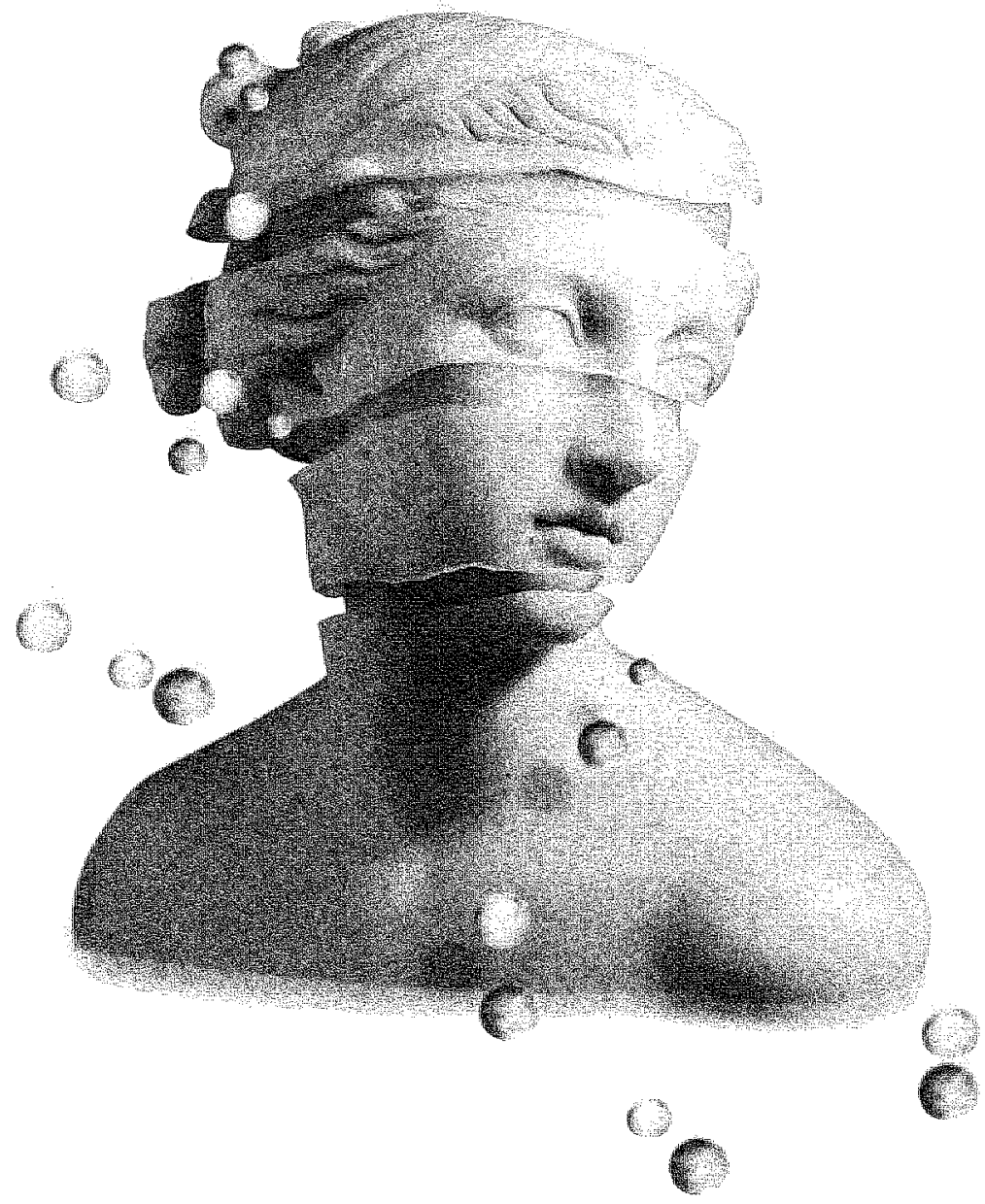


The ultimate aim of tissue and organ preservation is to provide a recipient with a viable graft, which will exhibit primary function. Although the survival rate of free flaps used in clinical practice for reconstruction of complex tissue defects is $95-98 \% \%^{1,2}$ frequently loss of function is seen ${ }^{3.4}$ as well as morbidity of the donor site ${ }^{5}$ Use of analogue cadaver tissue, socalled Composite Tissue Allografts (CTAs), may result in reconstruction of complex defects with good functional results. ${ }^{6}$ In spite of progress in operative technique $7-9$ and immunosuppresion $7,8,10$ development of preservation strategies for CTAs has not been extended. Transplantation of a (composite) tissue or organ involves an obligatory period of ischemia during surgery, preservation, and revascularization. Restoration of blood flow and oxygenation of the tissue (reperfusion) is a prerequisite for recovery of the ischemic tissue. Nevertheless, both ischemia and reperfusion are potentially damaging to the transplanted tissue. Of all tissues present in CTAs, muscle is most sensitive to ischemia ${ }^{11}$. Therefore, the aim of this thesis was to develop a strategy for the preservation of muscle tissue during ischemia and reperfusion or during prolonged storage and transplantation, in order to contribute to the development of a preservation strategy for CTAs.

While tissue injury due to ischemia and reperfusion may vary between tissues, it is generally accepted that microvascular dysfunction is a key component of this pathologic process. ${ }^{12}$ The cellular element within the microcirculation that appears to be most affected is the endothelial cell. This cell, at the interface between blood and tissue, experiences an oxidant stress during reperfusion that is initiated by biochemical and molecular changes occurring during ischemia. Ultimately, endothelial cells swell inducing an increase in resistance to flow in the capillaries (capillary noreflow"), 13 while at the same time endothelial adhesion molecules are upregulated initiating leukocyte-vessel wall interactions. ${ }^{12}$ Migrated leukocytes induce parenchymal cell injury viat release of reactive oxygen species and proteolytic enzymes, and disrupt the microvascular barrier during diapedesis. As a consequence, microvascular permeability increases, transcapillary fluid filtration enhances, and edema resulits. The increase in interstitial tissue pressure may result in decreased capillary diameters, thereby hampering microvascular perfusion and promoting the no-reflow phenomenon. It was the more specific aim of the present thesis to investigate the effects of several preservation methods on the microcirculation in muscle tissue during ischemia/reperfusion and transplantation. Special focus was on capillary perfusion of the tissue and on venular leukocytevessel wall interactions. 
The model used in the present study was the rat cremaster muscle. This muscle can be isolated on its vascular pedicle ${ }^{14}$ and perfused with a preservation solution. ${ }^{15}$ In addition, the cremaster muscle of young rats is thin and transparent, allowing clear visualization of microvessels and quantification of various microvascular parameters. Ischemia can be induced by placing a wascular clamp on the femoral artery (after isolation of the pedicle) and clinical conditions of transplantation can be simulated:16-18 the muscle can be harvested, stored in a preservation solution, and transplanted.

\section{Tissue cooling during ischemia and reperfusion}

The current basis of preservation for transplantation is cold storage using specific preservation solutions. The success of preservation depends on the temperature during storage and the choice of an appropriate preservation solution. Most organs are presently stored at a low temperature (hypothermia). In chapter 4 we assessed the effects of hypothermia $\left(4^{\circ} \mathrm{C}\right.$ ) during 4 or 6 hours of ischemia on the cremaster muscle microcirculation. This period was based on the findlings of several other groups. Belkin and colleagues ${ }^{19}$ showed that significant muscle injury occurred after 3 hours of ischemia, while after 6 hours only $3 \%$ of control functional activity remained, while Labbe and co-workers ${ }^{20}$ observed $90 \%$ necrosis in muscle tissue after 6 hours of ischemia. Other investigators have confirmed that 4-6 hours of ischemia induces irreversible changes in muscle tissue ${ }^{21-23}$ In our studies, we observed that 4-6 hours of warm ischemia was damaging to the cremaster muscle microcirculation as well. Four or 6 hours of warm ischemia transiently or permanently reduced the number of perfused capillaries to $<50 \%$, respectively. Cooling of the muscle to $4^{\circ} \mathrm{C}$ during ischemia appeared to preserve the cremaster muscle microcirculation. After the cold ischemic period, capillary perfusion resumed at about the same level as before ischemia. Moreover, hypothermia attenuated the increase in venular leukocyte-vessel wall interactions observed after 4 hours of warm ischemia.

Up to now there is no consensus in literature with regard to the effect of local cooling on microvascular hemodynamics. Tissue metabolic rate and oxygen consumption are inversely related to local temperature. ${ }^{24} \mathrm{At}$ temperatures of $0-4^{\circ} \mathrm{C}$, tissues remain viable in the absence of circulation ten or more times longer than at body temperature. The simple method of hypothermia proved useful in preserving skin, cornea, ${ }^{25,26}$ kidney, ${ }^{27}$ liver, heart, ${ }^{28,29}$ pancreas $^{30}$ and blood. ${ }^{31}$ However, one should be aware that hypothermia can be a risk factor as well. ${ }^{32}$ Increasing cold ischemia time appears to be associated with functional problems in transplanted 
organs. ${ }^{33}$ At a temperature lower than $10^{\circ} \mathrm{C}$ hemoglobin loses its ability to bind oxygen and tissue oxygenation is impaired. ${ }^{34,35}$ Hypothermia can directly induce tissue damage through physical alterations in cellular membranes and calcium influx into endothelial cells, while it also has indirect effects. Because anaerobic metabolism continues at a slow rate, end-products accumulate; and during reperfusion these end-products contribute to the generation of oxygen free radicals that are damaging to the tissue. ${ }^{33}$ Such damaging effects can be tolerated for short periods, but eventually they cause irreversible damage. In our experiments, we did not observe any detrimental effects of 4-6 hours of hypothermia in the cremaster muscle microcirculation. In contrast, hypothermia preserved capillary perfusion and prevented an increase in leukocyte-vessel wall interactions after ischemia.

Literature on the effects of cooling on the microcirculation in muscle is scarce and usually describes the situation during cooling. In our experiments the microcirculation was not observed during the cooling (and ischemic) period; instead, the hypothermia effects were studied during reperfusion. During the cooling period, the muscle was not perfused and, therefore, transmural pressures were low. As a result, hydrostatic pressure in the venular section of the microcirculation was low, preventing edema formation. This condition parallels that described by Vanhoutte ${ }^{35}$ and $\mathrm{Smith}^{37}$ who reported venodilation and suggested that this condition favors fluid reabsorption and attenuates edema formation. Other studies performed during hypothermia report arteriolar constriction ${ }^{38}$ and reduced flow. ${ }^{24}$ Such effects may also have occurred in our preparation, but were not visualized due to complete interruption of flow by the clamp. The finding of Beris ${ }^{39}$ that hypothermia protects arteries from excessive spasm during ischemia and lessens reactive hyperemia, may explain the prompt return to normal perfusion after cold ischemia of our preparation.

Cooling during the ischemic period reduced the inflammatory reaction to ischemia and reperfusion. This may be due to downregulation of endothelial adhesion molecules. Recent studies suggest that moderate hypothermia $\left(32-33^{\circ} \mathrm{C}\right)$ is associated with reduced expression of the endothelial adhesion molecule ICAM-1 and, hence, decreased leukocyte infiltration during acute tissue injury or after ischemia and reperfusion in organs like brain ${ }^{40}$ lung $^{41}$ and intestine. ${ }^{42}$ In vitro studies suggest that the endothelial transcription and expression of E-selectin is inhibited by hypothermia as well..$^{43,44}$ The effect of several hours of cooling to $4^{\circ} \mathrm{C}$ on adhesion molecule expression in venules in vivo remains to be elucidated. 
Altogether, it can be concluded that during relatively short periods (4-6 hours) of ischemia cooling of the tissue to $4^{\circ} \mathrm{C}$ is effective in preserving the microcirculation in muscle tissue.

\section{Choice of preservation sollution during ischemia and reperfusion}

Besides storage temperature, use of an appropriate preservation solution is also important for preservation of tissues or organs during transplantation. The appropriate preservation solution should provide a physical and biochemical environment that maintains viability of the structural components of transplanted tissue during hypothermic metabolic arrest, and minimize the effects of reperfusion injury. ${ }^{45}$ The storage solutions most commonly used are Euro-Col]ins (EC), University of Wisconsin solution (UW), HTK-Bretschneider solution (HTK) and revised St. Thomas" Hospital solution. UW can be considered the current golden standard solution; it is the preservation solution most often used for livers, kidneys, and pancreases with excellent clinical and experimental preservation data. However, disadvantages are its high viscosity and its high price ${ }^{32}$ HTK has been introduced as a physiologic cardioplegic solution with a low viscosity and is particularly used for cardiac preservation. ${ }^{32}$ It also yields good results in preservation of other organs, like liver and kidney. 46 In previous studies in our \aboratory, isolated rat skeletal muscles were preserved during 8 and 16 hours in various preservations solutions. ${ }^{47,48}$ At $4^{\circ} \mathrm{C}$ the preservation potential of the intracellular-like solutions UW and HTK was found to be greater than that of the extracellular-like Krebs-Henseleit solution. ${ }^{49}$ Contractility of isolated rat muscles was best preserved in HTK at $4^{\circ} \mathrm{C} .47$ This is why we first investigated the effects of pre-ischemic perfusion with HTK on cremaster muscle microcirculation after 4 and 6 hours of warm and cold ischemia (chapters 3 and 4). Flushing of the tissue with HTK of $4^{\circ} \mathrm{C}$ was preferred over surface cooling, because of the smaller diffusion distances and because it provides rapid cooling, within seconds, to temperatures that by surface cooling are achieved only after several minutes. and at the expense of loss of viability. In clinical practice, organs are also flushed with a solution to remove blood cells before cold storage and transplantation. In several studies it has been demonstrated that use of physiological washout solutions improves tissue tolerance to ischemia with a delay in onset of vascular hyperpermeability. $50,5 \|$ Therefore, we hypothesized that in our model pre-ischemic perfusion with HTK, which removes blood cells from the microvasculature prior to ischemia and exposes the microvasculature to HTK during ischemia, would reduce the adverse microvascular effects of ischemia and reperfusion. However, 
capillary perfusion after either warm or cold ischemia was not improved by HTK perfusion, irrespective of duration of the ischemic period. In contrast, the inflammatory response observed after warm ischemia was attenuated by pre-ischemic perfusion with cold $\left(4^{\circ} \mathrm{C}\right)$ HTK. Furthermore, pre-ischemic HTK perfusion did not add to the protective effects of tissue cooling to $4^{\circ} \mathrm{C}$ during ischemia (chapter 4).

Exposure of the vascular compartment to HTK for 10 minutes, without subsequent ischemia and reperfusion, had no adverse effects on microcirculatory parameters like arteriolar diameters, capillary perfusion and numbers of rolling and adhering leukocytes (chapter 3 ), which suggests that HTK by itself is not detrimental to the endothelium. In this respect, HTK differs from UW and lactated Ringer's solutions that were shown to be harmful to the microcirculation in the same preparation. ${ }^{18}$ Capillary no-reflow occurred in 6 of 8 rats in which UW was used as perfusion solution, while diameters of A 1 arterioles decreased after perfusion with lactated Ringer's solution. These effects have been attributed to the high potassium content of UW (124 mmol/l), which may have an injurious impact on vascular endothelium or vascular smooth muscle leading to an impaired vascular relaxation after extended preservation periods. HTK contains only small amounts of potassium $(9 \mathrm{mmol} / \mathrm{l})$ and this may account for the fact that we did not find any major alteration in vascular perfusion characteristics. ${ }^{52}$

In literature, the suggested protective efficacy of HTK in transplantation is attributed to the high buffering capacity provided by histicline/histidinehydrochloride, which is claimed to suppress ischemia-induced tissue acidosis. The high buffering capacity of histidine, combined with membraneprotecting effects of tryptophan and ketoglutarate may also protect the endothelial membrane against free-radicals during reperfusion. ${ }^{53}$ In our cremaster muscle model, however, these HTK characteristics were not able to prevent the decrease in tissue perfusion after 4 or 6 hours of warm ischemia. Therefore, we decided to investigate the protective potential of another preservation solution, Celsior, which contains free-radical scavengers (chapter 5). Celsior is an extra-cellular preservation solution, specifically designed for cardiac preservation. It combines the general principles of preservation solutions with properties specific of the heart such as prevention of development of ischemic contracture and dysfunction due to edema. ${ }^{54}$ Because of the high amount of free-radical scavengers in Celsior, we hypothesized that pre-ischemic perfusion with Celsior would have more beneficial effects in preserving the cremaster muscle microvasculature than HTK. However, pre-ischemic perfusion of 
rut cremaster muscle with Celsior did not improve tissue perfusion during reperfusion; instead, it had an adverse effect. Without pretreatment with a preservation solution, capillary perfusion transiently decreased to $50 \%$ of baseline during reperfusion after 4 hours of warm ischemia and remained lower than $50 \%$ after 6 hours of warm ischemia. With Cellsior pretreatment capillary perfusion remained lower than $50 \%$ after 4 hours of ischemia and decreased even further after 6 hours of ischemia. Hence, unlike HTK, Celsior deteriorates cremaster muscle perfusion after a period of warm ischemia. This unexpected finding suggests that the protective effects, if any, of the antioxidants in Celsior are overruled by detrimental effects of other components of this preservation fluid. The fact that tissue perfusion is better preserved when HTK is used as preservation solution compared to Celsior may be due to better preservation of endothelial function during ischemia, as suggested in a study by Wilson et al. ${ }^{55}$ Although the underlying mechanism has not yet been elucidated, Wilson and colleagues suggest that the large amount of the potent $\mathrm{pH}$ buffer histidine in HTK, and not in other solutions like Celsior, may be an explanation for the relatively good preservation of endothelial function with HTK. ${ }^{55}$ Another possible explanation may be that Celsior contributes to increased endothelin- 1 gene expression, with elevated endothelin-1 plasma levels. ${ }^{56}$ Upregulation of the endothelin-1 system leads to vasoconstriction and may contribute to decreased tissue perfusion.

In contrast to the adverse effect of pretreatment with Celsior on tissue perfusion, it had a favorable effect on the initial inflammatory reaction to warm ischemia and reperfusion, just like HTK. The increase in both leukocyte rolling and adhesion during reperfusion after 4 hours of warm ischemia was prevented by pre-ischemic perfusion with either solution at $4^{\circ} \mathrm{C}$. The protective effect of both Celsior and HTK is likely to be due to an effect on the endothelial cells inside the cremaster muscle, since blood cells were removed from the muscle during pre-ischemic perfusion.

The protective capacity of Celsior as a preservation solution appears to depend on the tissue or organ in which it is used. This may be related to the fact that the microcirculation in various tissues reacts differently to ischemia and reperfusion: critical ischemia time varies between tissue types. ${ }^{57}$ In addition, the degree of tissue injury caused by ischemia and reperfusion depends on the duration of ischemia. 58 Only a few minutes of hypoxia can be deleterious in the brain, whereas heart muscle can sustain some 45-60 minutes of ischemia before irreversible injury develops. Skeletal muscle is even more tolerant to ischemia and can survive up to 
3-4 hours of total ischemia. ${ }^{11}$ Irreversible muscle cell damage starts after 3 hours of ischemia and is nearly complete after 6 hours of ischemia. These muscle changes are paralleled by progressive microvascular damage (chapters 3 and 4) ${ }^{59}$ Skin and bone seem to be more resistant to ischemia than other tissues. ${ }^{60}$ Such tissue differences may underlie the fact that the reaction to Celsior in a situation of ischemia and reperfusion is different in skeletal muscle than in other organs. In heart transplantation, the use of Celsior as preservation solution yielded good results and was found to be superior to HTK and UW. ${ }^{61}$ Celsior allowed for better posttransplantation heart recovery and accounted for a lower incidence of vasculopathy in the midterm follow-up compared to UW and HTK. ${ }^{61}$ As in cremaster muscle, Celsior appears to be detrimental for reperfusion of pancreatic tissue. Uhlmann and coworkers ${ }^{62}$ reported capillary perfusion failure and enhanced tissue edema after porcine pancreas preservation in Celsior. Their data suggest that Celsior is not as effective as UW in preventing pancreatic ischemia/reperfusion injury. ${ }^{62}$

In summary, Celsior does not appear to be the preservation solution of choice to reduce ischemia/reperfusion injury in skeletal muscle. HTK may be more suitable than Celsior, especially when the protective effects of HTK on muscle function ${ }^{47}$ are taken into account.

\section{Preservation during prolonged storage and transplantation}

In transplantation surgery a relatively long time delay may occur between the moment a donor organ becomes available and the moment transplantation in the recipient can actually be performed. Damage to the organ or tissue due to such a prolonged ischemic period has to be minimized. In clinical practice, cold storage $\left(4-6^{\circ} \mathrm{C}\right)$ of organs or tissues is used, which protects arteries from excessive spasm during ischemia and also decreases reactive hyperemia. ${ }^{39}$ In larger muscle tissue parts, however, cold storage may not be sufficient to prevent damage; submersion in or even pre-ischemic perfusion with specific preservation solutions may be required.

In previous studies it was shown that prolonged storage in HTK (during 8 or 16 hours) was more effective for preservation of contractility of isolated rat skeletal muscles than storage in other preservation solutions (Krebs-Henseleit, Euro Collins, St. Thomas' Hospital solution). ${ }^{47,49}$ In addition, we showed that the microcirculation of muscle was better preserved during ischemia and reperfusion by HTK than by an extracellular-type preservation solution like Celsior (see above, chapter 5). Therefore, in our transplantation study (chapter 6) we used HTK as preservation solution. Instead of perfusing the cremaster muscle with 
HTK, we decided to submerge the tissue in the solution, because it was shown before that pre-ischemic perfusion with a preservation solution did not improve preservation of contractility in isolated (small) rat muscles during prolonged cold storage $\left(16\right.$ hours at $\left.4^{\circ} \mathrm{C}\right) .^{63}$ Cremaster muscle transplantations were performed immediately, or after 8 or 24 hours of cold storage $\left(4^{\circ} \mathrm{C}\right)$ in HTK or saline. After direct transplantation capillary perfusion was $90 \%$ of control. Transplantation after 8 or 24 hours of cold storage in the preservation solution HTK proved to be successful, with good capillary perfusion $(>75 \%)$ as compared to preservation in saline, which resulted in only $30 \%$ capillary reperfusion after 24 hours of cold storage. These data comply with the results of Corner et al. ${ }^{64}$ who showed that cold preservation of vascular (aortic) segments in HTK during 24 hours preserves smooth muscle cell contraction and endothelium-dependent relaxation. In addition, Yang et al. showed that HTK maximally preserves endothelium-derived hyperpolarizing factor-mediated dilatation in small coronary arteries, whereas UW was found to be less successful. ${ }^{52}$

Altogether, our data and those of others suggest that the use of the preservation solution HTK adds to the success of preservation of muscle microcirculation in case of cold storage during 24 hours.

\section{Monitoring the microcirculation during transplantation in clinical practice}

One of the microvascular parameters that is most crucial for survival of tissue during ischemia and reperfusion or transplantation is capillary perfusion. Capillary perfusion is a prerequisite for the transport of oxygen and nutrients to and metabolites from tissue cells. The nutritive perfusion of tissue depends on number and anatomical distribution of capillaries and on blood flow within these condluits. Postoperative monitoring of tissue perfusion in free flaps has proven to be crucial in enhancing flap salvage rate in case of vascular compromise (e.g., thrombosis of the anastomosed vessels). ${ }^{65}$ Changes in perfusion need to be recognized quickly in order to solve problems. Disruption of perfusion in a flap may result in partial or complete flap loss. Failure to establish reperfusion of ischemic tissue after performing anastomoses is known as the no-reflow phenomenon, and the severity of this phenomenon is related to ischemia time. Monitoring and quick recognition of ischemia reduces the chance of a no-reflow phenomenon and flap failure.

The signs that are usually monitored to describe tissue perfusion in a clinical setting are color, texture (turgor), capillary refill and temperature. ${ }^{66}$ Various methods have been employed to improve clinical monitoring of 
free flaps, ${ }^{67}$ such as (acoustic) surface or implantable Doppler probes, $65,67,68$ laser doppler probes, ${ }^{69}$ temperature probes, ${ }^{70}$ quantitative fluorimetry, ${ }^{67}$ laser-induced fluorescence angiography, ${ }^{68}$ and capillaroscopy. ${ }^{71}$ of these techniques, the latter enables investigation of capillaries in patients in a way that is similar to the intravital microscopy technique used in the studies described in this thesis. Employment of the noninvasive orthogonal polarization spectral (OPS) imaging technique allows direct visualization of all types of hemoglobin-carrying microvessels, without the need for fluorescent dyes for contrast enhancement; quantitative analysis of the microcirculation is possible as well. ${ }^{72,73}$ Clinical application of this OPS technique during and after transplantation would allow monitoring of tissue perfusion and quick recognition of microvascular problems.

\section{Conclusions and recommendations}

Our study indicates that in case of a relatively short ischemic period (4-6 hours) the microcirculation in rat cremaster muscle is best preserved by hypothermia (cooling of the tissue to $4^{\circ} \mathrm{C}$ during ischemia). Both a decrease in capillary perfusion and an increase in leukocyte-vessel wall interactions is prevented during reperfusion. Pre-ischemic perfusion with the preservation solution HTK does not add to the protective effects of tissue cooling, while the antioxidant-containing preservation solution Celsior has adverse effects. On the contrary, in case of prolonged cold storage ( 24 hours) the preservation solution HTK does add to the succes of preservation of muscle microcirculation.

In conclusion, the best strategy to preserve the microcirculation in muscle tissue is dependent on the duration of the ischemic period. In case of short ischemic periods (few hours), hypothermia can be applied to protect the microvascular compartment from damaging effects during reperfusion; the use of a preservation solution has no additional effect. When the muscle tissue has to be stored for longer periods ( 24 hours), the use of the preservation solution HTK at $4^{\circ} \mathrm{C}$ is recommended to preserve the microcirculation, and also the function of the muscle ${ }^{47}$ Considering the fact that -of all tissues present in CTAs-muscle is most vulnerable to the damaging effects of ischemia and reperfusion, cold storage in HTK may also be the method of choice in case of prolonged ischemia times before CT allografting. However, the sensitivity of the other CTA-tissues for the effects of such long periods of cold ischemia, in the presence of HTK, should be investigated as well, especially in view of the heterogeneous reactions in different tissues (and their microcirculation) to different preservation solutions and to ischemia and reperfusion. 


\section{Future research}

The present experiments have shown that the rat cremaster muscle model can be used to mimick human free flap transplantation and to investigate effects of preservation solutions and hypothermia in case of ischemia and reperfusion or transplantation. However, when human muscles are transplanted, the size of the muscle often exceeds the dimensions of the rat cremaster muscle. Larger animal models will have to be used to find out whether pre-ischemic perfusion with a preservation solution is beneficial for the microcirculation of larger muscles that are transplanted after prolonged periods of ischemia.

The ongoing development of novel preservation solutions may result in further reduction of ischemia/reperfusion injury and allow for prolonged preservation times. Addition of chemical compounds, such as calcium channel blockers, ${ }^{74}$ anti-apoptosis agents ${ }^{33,75}$ and superoxide dismutase ${ }^{76}$ may help to achieve this aim. ${ }^{33}$ Furthermore, pre-ischemic tissue perfusion with blood substitutes or solutions containing oxygen may lead to improved tissue preservation. ${ }^{77,78}$

An alternative way to reduce ischemia/reperfusion injury, which can be applied in microvascular tissue transfer, is preconditioning. Ischemic preconditioning (IP) is defined as a brief period of ischemia ("preclamping") followed by tissue reperfusion, which increases ischemic tolerance for a subsequent longer ischemic period. ${ }^{79}$ Ischemic preconditioning has already been found to be effective in decreasing muscle functional impairment after prolonged ischemia. ${ }^{80,81}$ It increases functional capillary perfusion and reduces leukocyte-mediated inflammation during reperfusion. ${ }^{17,82,83}$ Several studies showed the effectiveness of local ischemic preconditioning in microvascular tissue transfer by preclamping the flap pedicle. ${ }^{84-88}$ Preconditioning of skeletal muscle $89-91$ may be used for myocutaneous flaps during reconstructive surgery. ${ }^{92}$ Ischemic preconditioning can also be achieved by induction of an ischemia/reperfusion event in a body area distant from the flap ("remote ischemic preconditioning"). 93 Another general adaptational response to a variety of cellular or tissue stresses, including ischemia/reperfusion and heat stress, is the upregulation of the synthesis of heat shock proteins (HSPs). ${ }^{94,95}$ The cytoprotective effects of HSPs have been attributed to their ability to alter cellular metabolism and protect the structure and function of critical proteins during stress, which increases the tolerance of cells and tissues to such endangering situations as ischemia and reperfusion. ${ }^{94-97}$ Heat stress preconditioning was already shown to improve survival and functioning of transplanted rat kidneys, 98,99 as well as skin flap survival in mice ${ }^{100}$ and rats. 101 
The ultimate goal of organ preservation research is to provide preservation of unlimited duration. Methods of hypothermic preservation have limits; however, it is unlikely that those limits have been reached. The ability to preserve tissues or organs for at least one week would make organ banks a reality. Organs of the best immunologic match could than be transplanted and conveniently shipped. Long-term preservation will require a better understanding of the mechanisms of tissue damage caused by hypothermic preservation, and ischemia and reperfusion. When these mechanisms are understood, a rational approach to the therapeutic intervention can be defined and long-term organ and tissue preservation will become reality. 


\section{REFERENCES}

1. Genden EM, Rinaldo A, Suarez C, Wei WI. Bradley PJ, Ferlito A. Contiplications of free flap transfers for head and neck reconstruction following cancer resection. Orall Oncol. 2004:40:979-84.

2. Chen $\mathrm{CH}$, Lin GT, Fu YC, Wu CF, Shieh TY, Huang $\mathbb{1 Y}$, Shen YS, Chen CM. Comparison of celtopectoralis flap and free radial forearm ftap in reconstruction after oral cancer ablation. Oral Oncol. 2005;41:602:6.

3. Nakatsuka T, Harii K, Asato H, Takushima A, Ebilhara S, Kinata Y. Yamada A, Ueda $\mathbb{K}$, Ichioka $S$. Analytic review of 2372 free flap transfers for head and neck reconstruction following cancer resection. I Reconstr Microsurg. 2003;19:363-8; discussion 369.

4. Chien W, Varvares MA, Hadlock T, Cheney M, Deschler DG. Effects of aspirin and low-dose heparin in head and neck reconstruction using microvascular free flaps. Laryngoscope. 2005:115:973-6.

5. Lipa JE, Nowak CB, Binhammer PA. Patient-reponted donor-site morbidity following anterolateral thigh free flaps. $J$ Reconst Microsurg. 2005:21:365-70.

6. Lluli R. An open proposal for clinical composite tissue al lotransplantation. Transplant Proc. 1998;30:2692-6; discussion 2697-703.

7. Siemionow M, Ozer K. Advances in composite tissue allograft transplantation as related to the hand and upper extremity. J Hand Surg [AM]. 2002;27:565-80.

8. Petit $\mathbb{F}$, Minns $A B$, Dubernard JM, Hettiaratcly $S_{x}$ Lee WP. Composite tissue allotransplantation and reconstructive surgery: first clinical applications. Anm Surg. $2003: 237: 19-25$

9. Hettiaratchy S, Randolph MA, Petit F, Lee WP, Butler PE. Composite tissue allotransplantation-a new era in plastic surgery? Br J Plast Surg. 2004;57:381-91.

10. Jones NF. Concerns about human thand transplantation in the 21 st century. I Hand Surg (Am). 2002:27:771-87.

11. Blaisdell FW. The pathophysiology of skeletal muscle ischemia and the reperfusion syndrome: a review. Cardionase Surg. 2002;10:620-30.

12. Granger DN. Ischemia-reperfusion: mechanisms of microvascular dystunction and the influence of risk factors for cardiovascular disease. Microcincuditions. 1999;6:167.78.

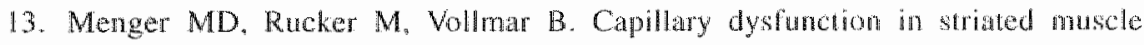
ischemia/meperfusion: on the mechanisms of capillary "no-fellow", Shrok. 1997:8:2-7.

14. Anderson GL, Acland RD, Siemionow M. MeCabe SJ. Vascular isolation of the rat cremaster muscle. Microvasc Res. 1988:36:56-63.

15. Franken RJ, Werker PM, Peter FW. Overgoor ML, Wang WZ, Anderson GL. Schuschke DA, Banis JC, Jr. Kon M, Baker JH. Microcirculatory changes folllowing different temperature washouts in a free flap model. Micmsargery. 1999.19:2/4-22. 


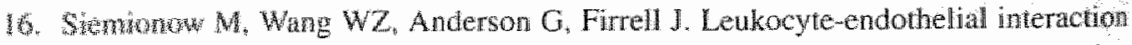

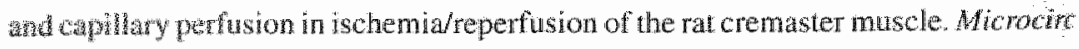

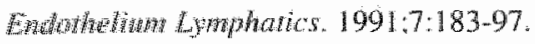

17. Wast W2, Anderson $O$, Maldonado $C$, Barker J. Attenuation of vasospasm and

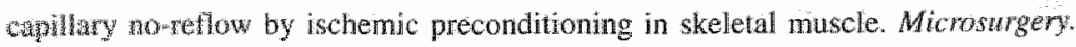
$90 ; 17: 39.9$

18. Amet M, Orek C. Erdem O, Denk M, Colen LB, Prewit R. Effects of University of Wroconom and lactated Ringer's solutions to ischemia-reperfusion injury in isolated cremester flap. Microsurgery. 2002:22:69-73.

25. Bekin M, Brown RD, Wright JG, LaMorte WW, Hobson RW, 2nd. A new quantitative spectrophotometric assay of ischemia-reperfusion injury in skeletal muscle. Am I Surg. $1988 ; 156: 83-6$.

20. Labbe R, Lindsay T, Waker PM. The extent and distribution of skeletal muscle necrosis after graded periods of complete ischemia. J Vasc Surg. 1987;6:152-7.

23. Hickey MJ, Hurley JV, Angel MF, O'Brien BM. The response of the rabbit rectus femoris muscle to ischemia and reperfusion. I Surg Res. 1992;53:369-77.

22. Wolff KD, Stiller D. Ischemia tolerance of free-muscle flaps: an NMR-spectroscopic study in the rat. Plast Reconstr Swg. 1993;91:485-91.

23. Sabido F, Milazzo VJ, Hobson RW, 2nd, Duran WN. Skeletal muscle ischemiareperfusion injury: a review of endothelial cell leukocye interactions. I Iwest Swg. $1994 ; 7: 39-47$.

24. Thorlacius H., Vol'mar B, Westermann S, Torkvist L, Menger MD. Effects of local cooling on microvascular hemodynamics and leukocyte adhesion in the striated muscle of hamsters. I Trawna. 1998;45:715-9.

25. Lindstron RL. Advances in comeal preservation. Trans Am Ophthalmol Soc. 1990;88:555-648.

26. Boume WM. Comeal preservation: past present, and future. Refract Comeal Sarg. $1991 ; 7: 60-1$.

27. Belzer FO, Southand JH. The future of kidney preservation. Transplamation. $1980 ; 30: 161-5$

28. Takathashi T, Morishita Y, Ichikawa H, Sato Y, Suzuki M, Ohya T, Tomisawa N. Multiple organ harvesting from in single donor for transplantation. A comparison of simple cooling texhnique and bypass technique. I Cardiovase Surg (Torino). $1999 ; 40: 347-53$.

29. Rivard Al. Gallegos RP, Bianco RW, Liao $\mathrm{K}$. The basic science aspect of donor heart preservation: a review. I Exna Conpor Technol. 2004;36:269-74.

30. Southard JH. Belzer FO. Organ preservation. Anmu Rev Med. 1995;46:235-47.

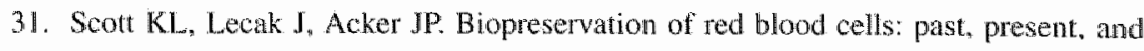
future. Tromsfiss Med Rev. 2005; 19:127-42. 
32. Muhbacher F, Langer F, Mittermayer C. Preservation solutions for transplantation. Thansplant Proc. 1999;31:2069-70.

33. McLaren AJ, Friend PI. Trends in organ preservation. Thaspl Int. 2003;16:701-8.

34. Nollent $G$, Mohnle $P$, Tassami-Prell $P$. Reichart B. Determinants of cerelyal oxygenation during cardiac surgery. Circulation. 1995;92:11327-33.

35. Menasche P. Blood candioplegia: do we still need to dilute? An Thomac Surg. $1996 ; 62: 957-60$

36. Vanhoutte PM, Miller VM. Alpha 2-adrenoceptors and endothelium-derived relaxing factor. Am J Med. 1989;87:1S-5S.

37. Smith TL, Curl WW, Smith BP, Holden MB. Wise T, Marr A, Koman LA. New skeletal muscle model for the longitudinal study of alterations in microcirculation following contusion and cryotherapy. Microsurgery. 1993;14:487-93.

38. Olson JE, Stravino VD. A review of cryotherapy. Phys Ther. 1972:52:840-53.

39. Beris AE, Soncacos PN, Seaber AV, Urbaniak JR. Effects of cold ischemia on reflow patterns in the rat cremaster muscle microcirculation. In Angiol. 1995; 14:248 52 .

40. Luan X, Li J, McAllister JP, 2nd, Diaz FG, Clark JC, Fessler RD, Ding Y. Regional brain cooling induced by vascular saline infusion into ischemic territory reduces brain inflammation in stroke. Acta Neuropathol (Berl). 2004;107:227-34.

41. Kura S, Daa T, Kashima K, Mori M, Noguchi T, Yokoyama S. Mild hypothermia reduces expression of intercellular adhesion molecule-1 (ICAM-1) and the accumulation of neutrophils after acid-induced lung injury in the rat. Acra: Anaesthesiol Scand. 2005;49:351-9.

42. Vejchapipat $P$, Leawhiran N, Poomsawat S, Theamboonlers A, Chitmittrapap S, Poovorawan Y. Anelioration of Intestinal Reperfusion Injury by Moderate Hypothermia Is Associated with Serum sICAM-1 Levels. I Surg Res. 2005.

43. Johnson M, Haddix T, Pohlman T, Verrier ED. Hyporhermia rewersibly inhibits endothelial cell expression of E-selectin and tissue factor I Card Surg. 1995;10:428-35.

44. Haddix TL Pohlman TH, Noel RF, Sato TT, Boyle EM, J Verrie ED. Hypothermia inhibits human E-selection transcription. I Surg Res. 1996:64:176-83,

45. Belzer FO, Southard JH. Principtes of solid-organ preservation by cold storage. Transplawnation. 1988:45:673-6.

46. Spiegel HU, Schleimer K. Freise H, Diller R, Drews G, Kranz D. Organ preservation with EC, HTK, and UW, solution in orthotopic rat liver transplantation. Part II. Morphological study. J Imest Surg. 1999;12:195-203.

47. van der Heijden EP, Kroese AB, Stremel RW, Bar PR, Kon M. Werker PM Contractile properties of rat skeletul muscles following stonage at 4 degrees C. Chin Sci (Lond). $1999 ; 97: 45-57$.

48. Wan der Hejden EP, Kroese AB. Werker PM, de With MC, de Smet M, Kon M, Bar DP. Improving the preservation of isolated rat skeletal muscles stored for 16 hours at 4 degrees C. Transplantation. 2000;69:1310-22. 
49. wan ater Hejón EP, Kroese AB, Weker PM, Grabiatz PD, de Jong MB, Bar PR, Kon M. Function of rat skeletal muscles after storage at 10 degrees $C$ in various preservation solutions. Chin Ser (Lond). 1998:94:271-8.

50. Rosen HM, Slivak MI, McBrearty FX. Delayed microchchlatory hyperpemeability following perfusion washout. Plose Reconstr Surg. 1987:79:102-7.

51. Gordon L. Levinsohn DG, Borowsky CD, Manojlonic RD, Sessler DI, Weiner MW. Baker AJ. Improved preservation of skeletal ruscle in amputated limbs using pulsatale thypothermic perfusion with University of Wisconsin solution. A preliminary study. I Bone Join Surg Am. 1992:74:1358-66.

52. Yang Q. Zhang RZ, Yim AP. He GW. Histidine-tryptophan-ketoglutarate solution maximally preserves endothellum-derived hyperpolarizing factor-mediated function during beart preservation: comparison with University of Wisconsin solution. J Hear Lung Treinsplant. 2004:23:352-9.

53. Saitoh Y, Hashimoto M, Ku K, Kin S. Nosaka S, Masumura S, Nakayama K. Heart preservation in HTK solution: role of coronary vasculature in recovery of cardiac function. Am Thorac Surg. 2000;69:107-12.

54. Mendsche P, Termignon $\mathrm{IL}$, Pradier F, Grousset C. Monas C, Alberici G, Weiss M, Piwnica A, Bloch G. Experimental evaluation of Celsion, a new heart preserwation solution. Eur J Candiothorac Surg. 1994;8:207-13.

55. Wilson CH, Stansby G, Haswell M, Cunningham AC. Talbot D. Evaluation of eight preservation solutions for endothelial in situ preservation. Transplantation. 2004:78:1008-13.

56. Wildhint SM. Weis M. Schulze C, Conrad N, Rieder G, Enders G, lhnken K, von Scheidt W, Reichart B. Effects of Celsior and University of Wisconsin preservation solutions on hemodynamics and endothelial function after cardiac transplantation in humans: single-center, prospective, randonized trial. Transp/ hat 2000:13 Suppl $\|: \$ 203-\| 1$

57. Sumionow M. Arshan E. Ischenia/repetfusion injury: a review in relation to frea tissue trans lers. Michosugery. 2004:24:468-75.

58. Morris SF, Pang CY, Zhong A, Boyd B, Forrest CR. Assessment of ischemiamduced reperfusion injury in the pig latissimus dorsi myocutaneous flap model. Plast Reconst Surg. 1993;92:1162-72.

59. Haris AG, Leiderer R, Peer F, Messmer K Skeletal muscle microwascullar and issue injury ater varying durations of ischemia. Am J Physol. 1996:271:H2388-98.

60. Simionow $M$. Ulusal $B G$, Ozmen S. Ulusal AE, Ozer $K$. Composite vascularized skin/bone graft model: a viable source for vascularized bone marow transplanation. Michowrery. 2004:24:200-6.

61. Garticki M. May preserwation solution affect the incidence of graft velsculopathy in transplanted heart? Anm Transplant 2003;8:19-24. 
62. Uhlmann D, Amam B, Ludwig S, Escher E, Pietsch UC, Tannapel A, Teupser D. Hauss J, Witzigmann $H$. Comparison of Celsion and $U$ W solution in expentmental pancreas preservation. I Surg Res. 2002;105:173-80.

63. van der Heijden EP. Kroese AB, Werker PM, Kon M. de With MC Bar DP. Preservation of rat skeletal muscle function during storage for $16 \mathrm{~h}$ at 4 degrees $\mathrm{C}$ is not improved by pre-storage perfusion. Cin Sci (Lond). $2003 \cdot 10529$-37.

64. Corner JA. Berwanger CS, Stansby G. Preservation of vascular tiscue under bypothemic conditions. I Surg Res. 2003:113:21-5.

65. Yuen JC. Techniques of extemal monitoring of buried free faps. Am Plast Sum. 2005:55:460-5.

66. Cotter CJ, Devine JC. Spatula bruises and monitoring of free flaps. Br I Oral Maxillofac Sug. 2005;43:343-4.

67. Payetle JR, Kohlenberg E, Leonardi L, Pabbies A, Kert P. Liu KZ, Sowa MG. Assessment of skin flaps using optically bused methods for measuring blood flow and oxygenation. Plost Reconsur Surg. 2005;115:539-46.

68. Mothes H, Donicke T, Friedel R, Simon M. Markgraf E, Bach O. Indocyaninengreen fluorescence video angiography used clinically to evaluate tissue perfusion in microsurgery I Trauma. 2004;57:1018-24.

69. Khan MS, Kainos N, Cadier M. The use of laser Doppler in determining timing for division of cross leg liree llaps. Br J Plast Surg. 2005;58:120-1.

70. Busic V, Das-Gupta R. Temperature monitoring in free flap surgery. Br J Plast Swg. $2004 ; 57: 588$.

71. Hern S, Mortimer PS. Visualization of dermal blood vessels-capillaroscopy. Clin Exp Derwatal. 1999;24:473-8.

72. Groner W, Winkelman JW, Harris AG, Ince C, Bouma GJ, Messmer K, Nadea RG. Orthogonal polarization spectral imaging: a new nethod for study of the michocitculation Nat Med 1999:5:1209-12.

73. Langer S. Born Fin Hat R. Biberthater P. Messmer K. Orthogonal polarization spectral innging versus intravial fluorescen microsopy for microvascular sudies in wounds. Ann Plast Sug. 2002:48:646-53.

74. Jassem W, Fuggle SV. Reh M, Koo DD. Heaton WD. The role of mitochondria in ischemia/reperfusion injury. Transp/antation. 2002:73:493-9.

75. Bums AT. Davies DR. Mclaren A. Cerundolo L. Morris PJ Fuggle SV. Apoptosis in ischemiafreperfusion injury of human renal allografs. Thmoplanomion. $1998,66.872-6$.

76. Land W. Schneeberger H. Schleibner S. Hiner WD, Abendroth D. Ruili G, Arfors KE. Messmer $K$. The beneficial effect of human recombinam superoxide dismulase on acute and chronic rejection events in recipients of cadaveric renal transplants. Tramsplanation. 1994:57:211-7. 
77. Winslow RM. Blood substitutes a review of the literature 1997-1998. IDmgr. $1999,2 \cdot 340.54$

78. Thyes $\mathrm{C}$, Span DR. Current status of artifcial $\mathrm{O} 2$ carriers. Aneshesiol Clin North Amevica. 2005,23:373-89, vin.

79. Kuntscher $M \mathrm{~V}$, Hartmani $\mathrm{B}$, German $\mathrm{G}$. Remote ischemic preconditioning of flaps: a reviev. Microsurgery. 2005,25:346-52.

80. Schroeder CA, Jr, Lee HT, Shah PM, Babu SC, Thompson Cl, Belloni $\mathrm{FL}$. Preconditioning with ischemia or adenosine protects skeletal muscle from ischemic tissue reperfusion injury. J Surg Res. 1996;63:29-34.

81. Gurke L, Marx. A, Sutter PM, Frentzel A, Salm T, Harder F, Seelig J, Heberer M. Ischemic preconditioning improves post-ischemic skeletal muscle function. Am Sty $\mathrm{g}$. 1996,$62 ; 391-4$.

82. Akimitsu T, Gute DC, Konthuis RJ. Ischemic preconditioning attenuates postischemic leukocyte adhesion and emigration. Am I Physiol. 1996;27 :H2052-9.

83. Adanali $\mathrm{G}$, Ozer $\mathrm{K}$, Siemionow $\mathrm{M}$. Early and late effects of ischemic preconditioning on microcirculation of skeletal muscle flaps. Plast Reconwt Surg. 2002; 109:1344-51.

84. Carroll CM, Carroll SM, Overgoor ML, Tobin G, Barker JH. Acute ischemic preconditioning of skeletal muscle prior to flap elevation augments muscle-flap survival. Plast Reconstr Surg. 1997;100:58-65.

85. Wang WZ, Anderson $G$, Firrell JC, Tsall TM. Ischemic preconditioning versus intermittent reperfusion to inprove blood flow to a vascular isolated skeletal muscle frap of rats. I Tromma. 1998;45:953-9.

86. Zahir KS. Syed SA, Zink JR, Restifo RJ, Thomson JG. Ischemic preconditioning improwes the survival of skin and myocutaneous faps in a rat model. Plast Reconsir Surg. 1998;102:140-50; discussion 151-2.

87. Kuntscher MV, Juran S, Altmann J, Menke H, Gebhard MM, Germann G. Role of nitric oxide in the mechanism of preclamping and remote ischemic preconditioning of adpocutaneous flaps in a rat model. J Reconsir Microsurg. 2003; 19:55-60.

88. Marian CF, Jiga LP, Lonac M. Ischemic preconditioning of free muscle flaps: An experimental study. Microsurgery 2005:25:524-31.

89. Mounsey RA, Pang CY, Forrest C. Preconditioning: a new technique for improved muscle flap surviwal. Otolanngol Head Neck Surg. 1992;107:549-52.

90. Hopper RA. Forrest CR, Xu H, Zhong A, He W, Rutka J, Neligan P, Pang CY. Role and mechanism of $\mathrm{PKC}$ in ischemic preconditioning of pig skeletal muscle agains infurction. Am J Physhol Regul lntegr Comp Physiol. 2000;279:R666-76.

91. Satia Y, Yokoyama K, Nakamura K, Itoman M. Protective effect of ischaemic preconditioning against ischaemia-induced reperfusion injury of skeletal muscle: how many preconditioning cycles are appropriate? Br.J Plast Surg. 2002;55:241-5. 
92. Tsai BM, Wang M, March KL. Turrentine MW, Brown IW, Meldrum DR. Preconditioning: evolution of basic mechanisms to potential therapeutic strategies. Shock. 2004:21:195-209.

93. Kuntscher MV, Kastell T, Sauebier M, Nobiling R, Gebhard MM, German G. Acute remote ischemic preconditioning on at rat cremasteric muscle tap model. Micusurgery. 2002;22:221-6.

94. Carden DL, Granger DN. Pathophysiology of ischaemia-reperfusion injury. J Pathol. $2000 ; 190255-66$

95. Snoeckx LH, Comelussen RN, Van Nienwenhoven FA, Reneman RS. Van Den Vusse GJ. Heat shock proteins and candiovascular pathophysiology. Phosiol Rev. $2001: 81: 1461-97$

96. Cray CC, Amrani M, Yacoub MH. Heat stress proteins and myocardial protaction: experimental model or potential climical tool? for J Biochen Cell Biol 1999; 31:559-73.

97. Joyeux-Faure M, Arnaud C. Godin-Ribuot D, Ribuot C. Heat stress preconditioning and delayed myocandial protection: what is new? Cardiovasc Res. 2003;60;469-77.

98. Redaelli CA. Wagner M, Kulli C, Tian YH, Kubulus D, Mázzuchelli L, Wagner AC. Schilling MK. Hyperthermia-induced HSP expression correlates with improved rat renal isograft viability and surviwal in kidneys harvested from non-heart-beating donors. Transpl Int. 2001;14:351-60.

99. Wagner M, Cadetg P, Rur R, Mazzucchelli L, Ferrari P, Redaelli CA. Heme oxygenase- attenuates ischemia/reperfusion-induced apoptosis and improwes survival in rat renal allografts. Kidney $/ n t .2003 ; 63: 1564-73$.

100. Mirh TC, Ichioka S, Nakatsuka T, Kawai J, Shibata M. Ando J, Hari K. Effect of hyperthemic preconditioning on the survival of ischemiamepentused skin flaps: a new skin flap model in the mouse. J Reconst Microswrg. 2002;18:115-9.

101. Ghavami A. Nutt MP, Hardy SP. Heat shock protein and high-dose aspinin: effects on fandom skin fap survival in at rat model. Ann Plast Surg. 2002;48:60-7. 



\section{CHAPTER 8 Summary}

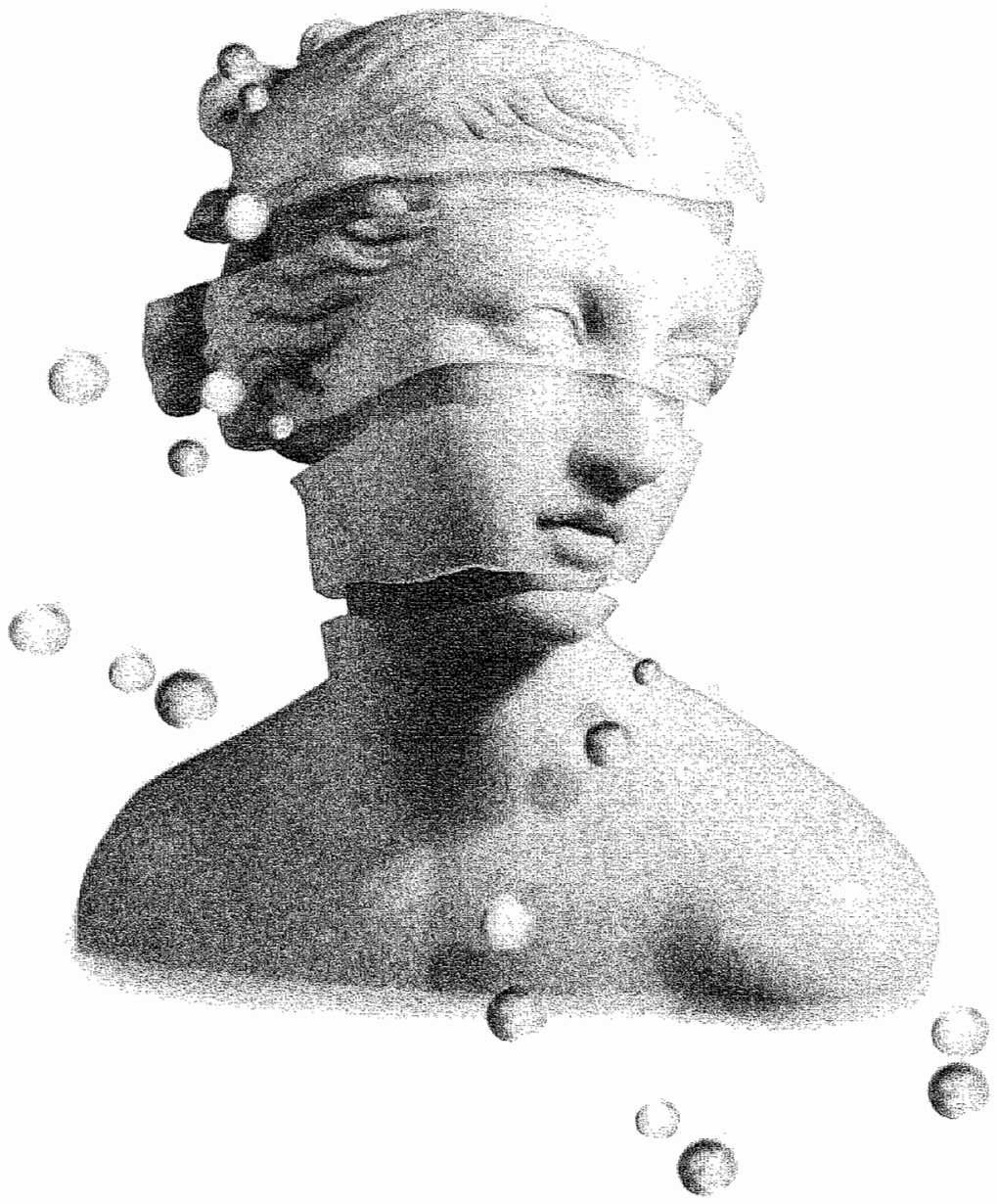




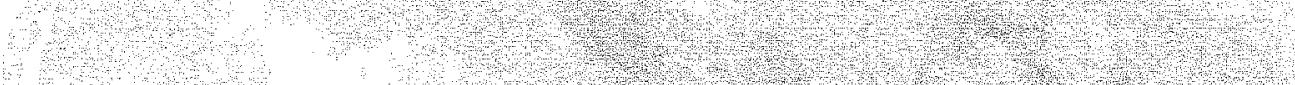

\begin{tabular}{llll}
\hline \\
3
\end{tabular}

(स)

(a)

(4)

\begin{tabular}{llll} 
& \\
\hline & \\
\hline
\end{tabular}

$+3$

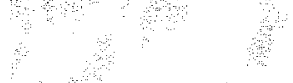

se
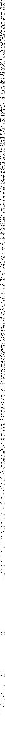
In plastic surgery, complex defects are usually reconstructed wih free flaps. Common indications include reconstruction after tumor ablation or trauma and reconstruction of congenital defects and chronic wounds. The survival rate of these flaps is high $(95-98 \%)$. The functional outcome, however, can be suboptimal. Furthermore, donorsite morbidity can be quite substantial.

The use of composite tissue allografts (CTAs) may improve the results of free tissue transfer, because of reduced functional loss and absence of donorsite morbidity. Transplantation of an organ or (composite) tissue involves an obligatory period of ischemia, followed by reperfusion; together, this can induce tissue injury (see below). Of all tissues present in CTAs, muscle is most sensitive to ischemia. Therefore, the aim of this thesis was to investigate various preservation strategies for muscle tissue in order to contribute to the development of an optimal preservation strategy for CTAs. At present, cooling is the best preservation strategy for CTAs. In previous studies, it was found that cold storage of isolated skeletal rat muscles in Histidine-Tryptophan-Ketoglutarate-Bretschneider solution (HTK) solution at $4^{\circ} \mathrm{C}$ was beneficial for preservation of contractility of these muscles. This preservation strategy was based on diffusion. In larger (human) muscles this may be not sufficient due to large diffusion distances; perfusion of the tissue with a preservation solution may be required. Moreover, preservation of the vascular bed is of major importance for tissue survival. In this thesis, we assessed the effects of hypothermia and pre-ischemic perfusion with various preservation solutions on the consequences of ischemia and reperfusion, or transplantation for the microcirculation in vivo, in rat cremaster muscle. This muscle can be isolated on its vascular pedicle and perfused with a preservation solution; in addition, it allows in vivo examination of various microcirculatory parameters with the use of intravital microscopy (Chapter 1).

As an introduction to the experimental chapters, chapter 2 of this thesis provides an overview of literature on transplantation, ischemia/ reperfusion injury, preservations solutions, and relevant methods from microcirculation research.

Transplantation of an organ or (composite) tissue involves an unavoidable period of ischemia during surgery, preservation, and revascularization. During this ischemic period, blood supply to the tissue is interrupted, which initiates a sequence of cellular and biochemical events that can lead to cellular dysfunction and ultimately to cell death. Although restoration of blood flow and oxygenation of the tissue is a prerequisite for recovery of ischemic tissue, 
reperfusion itself may also result in an enhancement of tissue injury. Current methods of organ and tissue preservation are based on suppression of metabolism by hypothermia and on systems that support active metabolism. To render organs tolerant to hypothermia, blood is removed and replaced with an appropriate hypothermic preservation solution. The composition of the preservative appears to be a critical determinant of tolerance of the organ to hypothermic storage. The ideal preservation solution provides metabolites, substrates, and agents that enhance recovery of the organ on reperfusion, and suppresses unwanted reactions and breakdown of critically important metabolites. The biochemical factors (and their concentrations) necessary for high-quality, long-term organ preservation are not yet fully known; further research in this field is necessary. The combination of hypothermia and an optimal preservation fluid will help to minimize injury, when a tissue is reperfused with blood at the end of the transplantation procedure (chapter 2).

In our initial studies (chapters 3 and 4), we first established the microvascular consequences of 4 and 6 hours of total, warm ischemia of the rat cremaster muscle, without using any preservation strategy. After 4 hours of warm ischemia, capillary perfusion of the muscle resumed at $50 \%$ and recovered to $90 \%$ of baseline levels during the 2 hours of reperfusion (chapter 3). After 6 hours of warm ischemia, no recovery occurred: capillary perfusion remained at $45 \%$ of baseline levels (chapter 4 ). In addition to this decrease in tissue perfusion, a period of warm ischemia also induced an inflammatory reaction: a significant increase in the level of leukocyte-vessel wall interactions was observed in the venules during reperfusion after 4 hours of ischemia (chapter 3 ). No such increase occurred after 6 hours of warm ischemia, possibly due to reduced venular flow and, hence, decreased leukocyte delivery during reperfusion (chapter 4).

In the study described in chapter 4 we assessed the effects of hypothermia on the microvascular consequences of 4 and 6 hours of ischemia and 2 hours of reperfusion in the rat cremaster muscle. Coolling of the tissue to $4^{\circ} \mathrm{C}$ during the ischemic period was clearly beneficial for the microcirculation. It completely prevented the $50 \%$ reduction in capillary perfusion after 4 hours of ischemia, while only a slight decrease $(<10 \%)$ in capillary perfusion was observed after 6 hours of cold ischemia. In addition, hypothermia attenuated the significant increase in venular leukocyte-vessel wall interactions after 4 hours of ischemia. In conclusion, hypothermia preserved capillary perfusion and prevented the inflammatory reaction during reperfusion after muscle tissue ischemia (chapter 4 ). 
In chapters 3,4 and 5 we investigated the protective potential of preischemic perfusion of the tissue with a preservation solution. In the first studies we focused on the effects of Histidine-Tryptophan-KetoglutarateBretschneider solution (HTK). HTK is an intracellular type preservation solution with a low viscosity. It was originally designed as a cardioplegic solution. The basic philosophy behind the development of this solution is the introduction of a very potent buffer system (histidin, along with the two substrates tryptophan and ketogutarate).

Pre-ischemic perfusion with HTK had no beneficial effect on capillary perfusion after 4 and 6 hours of warm or cold ischemia, irrespective of the temperature of the HTK solution (chapters 3 and 4 ). In addition, preischemic perfusion with $\mathrm{HTK}$ at $22^{\circ} \mathrm{C}$ had no effects on venular leukocyteendothelium interactions (chapter 3 ). In contrast, pre-ischemic perfusion with HTK at $4^{\circ} \mathrm{C}$ attenuated the inflammatory response after 4 hours of warm ischemia (chapter 3 ). In conclusion, pre-ischemic perfusion of the vasculature with HTK did not improve the beneficial effects of hypothermia on tissue perfusion, but attenuated the inflammatory response when applied at $4^{\circ} \mathrm{C}$.

We also evaluated the effects of Celsior, an extracellular preservation solution specifically designed for cardiac preservation (chapter 5). Celsior combines the general principles of preservation solutions with properties specific of the heart such as prevention of the development of ischemic contracture and dysfunction due to edema. Because of the high amount of free-radical scavengers in Celsior, we hypothesized that pre-ischemic perfusion with Celsior would show more beneficial effects on the preservation of the muscular microvasculature than HTK. It turned out that -like HTK-Celsior did not improve capillary perfusion after 4 or 6 hours of warm ischemia (chapter 5). Celsior pre-treatment actually deteriorated capillary perfusion: it remained low during the entire reperfusion period after 4 hours of ischemia, and decreased even further after 6 hours of ischemia. However, Celsior eliminated the increase in leukocyte-vessel wall interactions observed after 4 or 6 hours of warm ischemia, which is similar to the effect of HTK. These data suggest that HTK is more suited as a preservation solution for muscular tissue than Celsior, especially when the known protective effects of HTK on muscle function are taken into account.

The rat cremaster model was used to simulate clinical conditions of transplantation. In case of prolonged periods of ischemia, the cremaster had to be harvested, stored in a preservation solution, and transplanted. 
In the study described in chapter 6 , we examined the effects of transplantation and ischemia/reperfusion on the microcirculation after prolonged cold storage in HTK ( $4^{\circ} \mathrm{C}$ ). Cremaster muscle transplantations were performed immediately, or after 8 or 24 hours of cold storage in HTK or saline. After direct transplantation capillary perfusion was $90 \%$ of control. Transplantation after 8 hours of cold storage in either HTK or saline did not deteriorate capillary perfusion. When the tissue was stored for 24 hours, HTK was superior to saline in preserving capillary perfusion. After 24 hours of preservation in $\mathrm{HTK}\left(4^{\circ} \mathrm{C}\right)$, capillary perfusion was about $80 \%$ of control as compared to preservation in saline, which resulted in only $30 \%$ capillary reperfusion after 24 hours of cold storage. Immediate transplantation induced a small increase in leukocyte adhesion. Prolonged cold storage in either fluid resulted in reduced flow velocities (qualitative observations) and edema formation, which hampered quantification of leukocyteendothelium interactions. In conclusion, even after 8 or 24 hours of cold storage in HTK, transplantation of rat cremaster muscle was successful with good capillary perfusion. Preservation of capillary perfusion was significantly better in HTK than in saline.

In conclusion, the best strategy to preserve the microcirculation in muscle tissue is dependent on the duration of the ischemic period. In case of short ischemic periods (few hours), hypothermia can be applied to protect the microvascular compartment from damaging effects during reperfusion; the use of a preservation solution has no additional effect. When the muscle tissue has to be stored for longer periods ( 24 hours), the use of the preservation solution HTK at $4^{\circ} \mathrm{C}$ is recommended to preserve the microcirculation, and also the function of the muscle. Considering the fact that -of all tissues present in CTAs- muscle is most vulnerable to the damaging effects of ischemia and reperfusion, cold storage in HTK may also be the method of choice in case of prolonged ischemia times before $\mathrm{CT}$ allografting.

The ultimate goal of organ preservation research is to provide preservation of unlimited duration. The ability to preserve tissues or organs for at least one week would make organ banks a reality. Long-term preservation will require a better understanding of the mechanisms of tissue damage caused by ischemia and reperfusion. When these mechanisms are understood, a rational approach to the therapeutic intervention can be defined and long-term organ and tissue preservation will become reality. 


\section{CHAPTER 9 Samenvatting}

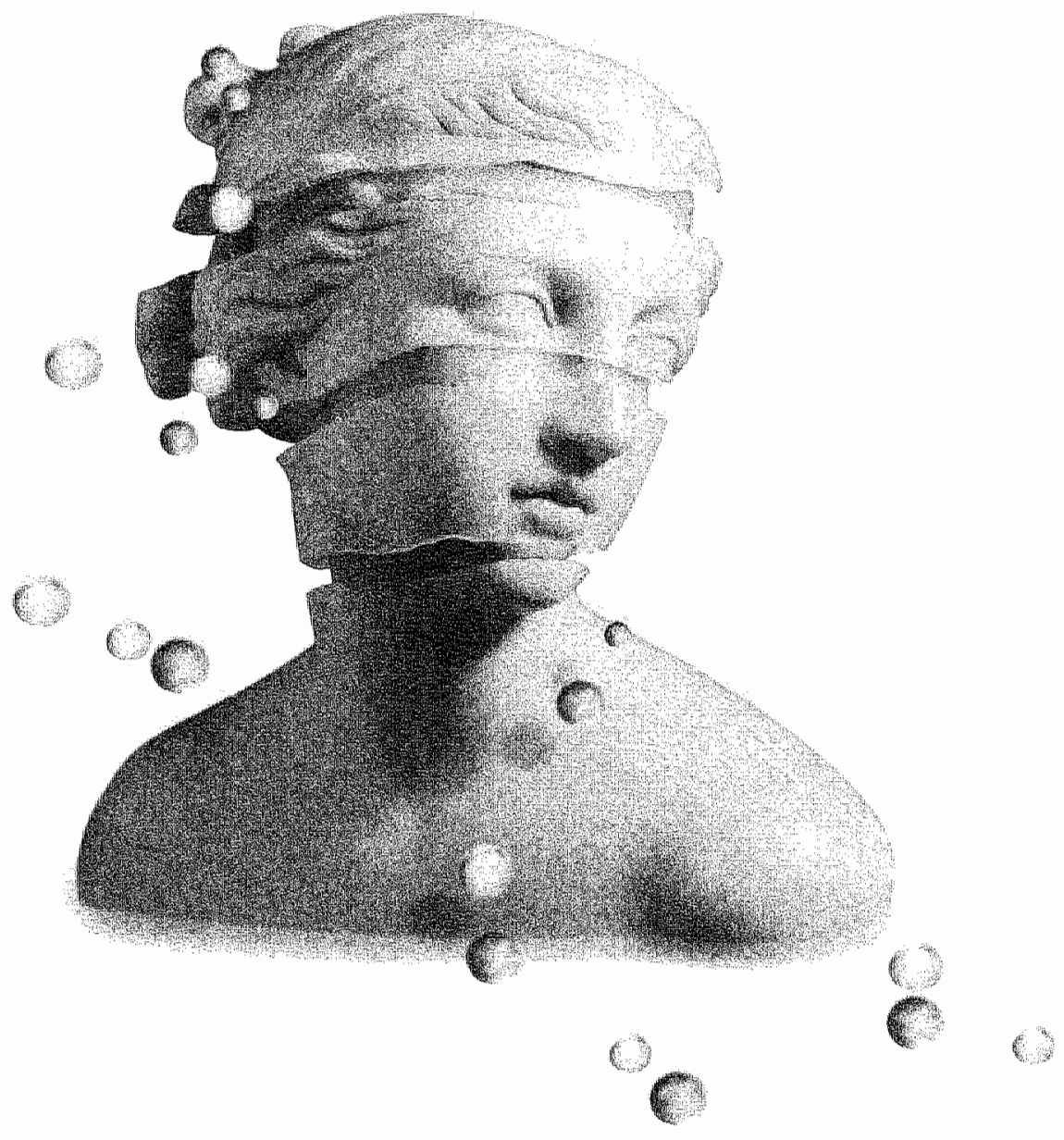


. म.
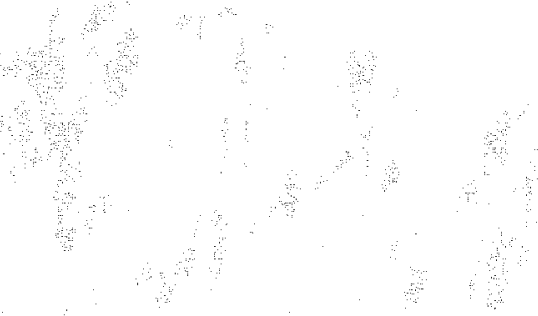

...

\section{$\sqrt{3+}$}

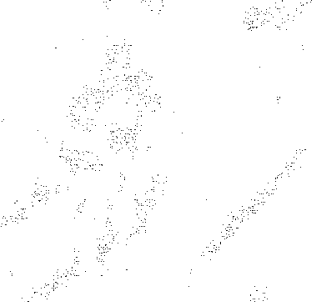

152 
Complexe weefseldefecten kunnen ontstaan na traumatische verwondingen, amputatie van vingers of ledematen, of na het verwijderen wan tumoren. Ook kan er sprake zijn van congenitale defecten of chronische wonden. Deze defecten worden gereconstrueerd met behulp van weefsel gelegen in de nabijheid wan het defect. Indien dit niet mogelijk is, bijvoorbeeld in geval van zeer grote defecten, wordt er weefsel dat niet essentieel is voor het lichaam, getransplanteerd naar een andere plaats van het lichaam, zodat vorm en functie hersteld kunnen worden. Dit zijn zogenoemde microvasculaire transplantaten (vrije lappen of weefsel transplantaties). De aan- en afvoerende vaten van een dergelijke "vrije lap" worden met behulp van een operatiemicroscoop aangesloten (geanastomoseerd) in het te reconstrueren gebied en hierna kan de bloedstroom weer hersteld worden. Tijdens het uitnemen van het weefsel en het anastomoseren van de vaten wordt het weefsel tijdelijk niet van bloed voorzien (ischemie; deze periode wordt aangeduid als ischemische periode). Het overlevingspercentage (of succespercentage) van deze vrije lappen is hoog: 95-98\%. Het functionele resultaat is echter vaak suboptimaal. Ook kan er sprake zijn van aanzienlijke defecten op de plaats waar het getransplanteerde weefsel is verwijderd (donorsite).

De resultaten van de microvasculaire transplantaten of vrije lappen zouden verbeterd kunnen worden, wanneer men in de kliniek gebruik zou kunnen maken van identiek donorweefsel, de zogenaamde Composite Tissue Allografts (CTAs). Deze transplantaten kunnen bestaan uit verschillende soorten weefsels, zoals spierweefsel, bloedvaten, zenuwweet'sel, huid, bot en kraakbeen. Op deze wijze zou weefsel of een lichaamsdeel vervangen kunnen worden door identiek weefsel, zoals bijvoorbeel bij een handtransplantatie. Bovendien wordt er geen nieuw defect gecreëerd bij de patiënt. Van alle weefsels die kunnen voorkomen in CTAs is spierweefsel het meest gevoelig voor een gebrek aan zuurstof ten gevolge van ischemie. Het doel van dit proefschrift was het onderzoeken van verscheidene preservatie strategieën voor spierweefsel (methodes om weefsel te bewaren of preserveren zonder functieverlies), om zo bij te dragen aan de ontwikkeling van een optimale preservatie methode voor CTAs. Experimenteel onderzoek heeft al aangetoond, dat het transplanteren van CTAs technisch mogelijk is, indien er gebruik gemaakt wordt van de benodigde immunosuppressiva. Handtransplantaties zijn reeds klinisch uitgevoerd en recent is ook een eerste (partiële) gezichtstransplantatie uitgevoerd.

Op dit moment bestaat er geen betere methode voor weefsel preservatie dan (oppervlakte) koeling: uitgenomen of geïsoleerde organen en weefsels worden gekoeld $\left(4-15^{\circ} \mathrm{C}\right)$ in de periode tot transplantatie. In eerdere studies werd aangetoond, dat de functie (contractiliteit) van geïsoleerde rattenspieren 
het best bewaard bleef in Histidine-Tryptophaan-Ketoglutaraat-Bretschneider vloeistof (HTK) bij een temperatuur van $4^{\circ} \mathrm{C}$. Deze bewaarmethode was gebaseerd op diffusie; de gedachte hierbij is, dat de werkzame stoffen in HTK via diffusie alle cellen in de spier bereiken. In grotere (humane) spieren is dit waarschijnlijk niet voldoende, aangezien de diffusie afstanden groot zijn. Mogelijk is dan perfusie van het weefsel met een preservatie vloeistof noodzakelijk, waardoor alle cellen in het weefsel in contact kunnen komen met bestanddelen uit de vloeistof. Behalve het spierweefsel zelf dient ook het vaatbed gepreserveerd te worden om de overleving van het weefsel te garanderen. In de studies beschreven in dit proefschrift zijn de effecten van hypothermie (koeling) en verschillende preservatie vloeistoffen op de microcirculatoire consequenties na ischemie/reperfusie of transplantatie van spierweefsel onderzocht. De studies werden in vivo uitgevoerd met behulp van intravitaal microscopie in een cremaster spier model in de rat. Deze spier kan geïsoleerd worden met behoud van de vaaten zenuwwoorziening. Hierdoor kan een ischemische periode geïnduceerd worden en bovendien kan de spier geperfundeerd worden met verschillende preservatie vloeistoffen. Met behulp van dit model kunnen verschillende parameters in de microcirculatie onderzocht worden (hoofdstuk 1).

Als introductie op de experimentele hoofdstukken wordt in hoofdstuk 2 een overzicht van de literatuur gegeven op het gebied van transplantatie, ischemie/reperfusie, preservatie vloeistoffen en methoden voor microcirculatie onderzoek.

Bij transplantatie van organen en weefsels is er altijd sprake van een ischemische periode, waarin het weefsel (of orgaan) niet wordt voorzien van bloed. Hierdoor worden biochemische (en cellulaire) processen geïnduceerd die kunnen leiden tot celdysfunctie of zelfs celdood. Het herstel van de bloedstroom na een ischemische periode (reperfusie) is essentieel voor de overleving van weefsel. Toch kan de reperfusie zelf ook tot extra weefselschade leiden, resulterend in verminderde functie en overleving van het weefsel. Hierbij spelen witte bloedcellen (leukocyten) een belangrijke rol. Bij de start van de reperfusie-fase treedt een cascade aan reacties op. Leukocyten worden geactiveerd en er is sprake van een toename van leukocyt-vaatwand interacties; de leukocyten die normaal gesproken vrij in de bloedstroom voorkomen, rollen langs de vaatwand en vertonen adhesie. Vervolgens verplaatsen ze zich cloor de vaatwand naar het weefsel. Hierdoor onstaat lekkage van vaatwanden en oedeemvorming, hetgeen leidt tot verminderde capillaire perfusie ("no-reflow"), terwijl de leukocyten bovendien direct schade kunnen toebrengen aan het weefsel. Op dit moment is koeling (hypothermie) de belangrijkste methode voor 
het preserveren van organen en weefsels. Bloed wordt uit organen en weefsels gespoeld en wordt vervangen door een preservatie vloeistof. De samenstelling van preservatievloeistoffen is van cruciaal belang voor orgaanpreservatie tijdens koeling. Het is op dit moment nog niet bekend wat de samenstelling van de ideale preservatievloeistof zou moeten zijn. De combinatie van hypothermie en een optimale preservatievloeistof zal de reperfusieschade, die optreedt aan het einde van de transplantatieprocedure, (wanneer het weefsel weer van bloed wordt voorzien), verminderen (hoofdstuk 2).

In onze studies beschreven in hoofdstuk 3 en 4 werden allereerst de effecten een ischemische periode ( 4 en 6 uur) zonder preservatiestrategie op de microcirculatie in de cremaster spier van de rat onderzocht. Na 4 uur warme ischemie hervatte de capillaire perfusie op $50 \%$ van het uitgangsniveau en herstelde vervolgens tot $90 \%$ van dit niveau gedurende de 2 uur durende reperfsusie fase (hoofdstuk 3). Na 6 uur warme ischemie trad geen herstel van de weefselperfusie op: de capillaire perfusie was $45 \%$ van het uitgangsniveau en bleef gedurende de gehele reperfusie periode op dit lage niveau (hoofdstuk 4). Warme ischemie induceerde niet alleen een vermindering van capillaire perfusie, maar ook een ontstekingsreactie. Na 4 uur warme ischemie werd gedurende de reperfusie fase een significante toename van het aantal leukocyt-vaatwandinteracties waargenomen in de venulen (hoofdstuk 3). Deze toename werd niet waargenomen na 6 uur warme ischemie, wat mogelijk te verklaren is door de verminderde doorbloeding in het weefsel (hoofdstuk 4).

In hoofdstuk 4 werden de effecten van hypothermie (koeling) op de microvasculaire gevolgen van 4 en 6 uur ischemie en 2 uur reperfusie onderzocht in de cremasterspier van de rat. Na 4 uur koude $\left(4^{\circ} \mathrm{C}\right)$ ischemie werd er geen reductie in capillaire perfusie waargenomen; het aantal geperfundeerde capillairen was gelijk aan de controle situatie zonder ischemie. Na 6 uur koude ischemie werd slechts een geringe reductie $(<10 \%)$ van het aantal geperfundeerde capillairen waargenomen. Bovendien werd door de hypothermie de ontstekingsreactie tijdens de reperfusiefase na 4 uur ischemie onderdrukt. Deze data tonen aan, dat koeling van spierweefsel gedurende de ischemische periode zowel de capillaire perfusie in stand houdt als een ontstekingsreactie voorkomt.

In de studies beschreven in hoofdstuk 3,4 en 5 zijn de effecten van preischemische perfusie van het spierweefsel met een preservatievloeistof onderzocht. In de eerste studie (hoofdstukken 3 en 4) werd de aandacht gericht 
op de effecten van Histidine-Tryptophaan-Ketoglutaraat-Bretschneider vloeistof (HTK) op de microcirculatie na een ischemische periode van 4 en 6 wur. HTK is een preservatie vloeistof met een lage viscositeit, die oorspronkelijk als een cardioplegie vloeistof werd gebruikt. HTK bevat een sterk buffersysteen (histidine met de substraten tryptophaan en ketoglutaraat).

Het effect van pre-ischemische HTK perfusie op leukocyt-vaatwand interacties tijdens de reperfusie was afhankelijk van de HTK temperatuur. HTK van van $22^{\circ} \mathrm{C}$ had geen effect, terwijl HTK van $4^{\circ} \mathrm{C}$ de ontstekingsreactie na 4 uur warme ischemie significant verminderde (hoofdstuk 3 ). Perfusie met $\mathrm{HTK}$ ( 4 of $22^{\circ} \mathrm{C}$ ) voorafgaand aan de ischemische periode had geen effect op de capillaire perfusie (hoofdstuk 3 ).

Concluderend, pre-ischemische perfusie met HTK leidde niet tot verbetering van capillaire perfusie, maar onderdrukt wel de ontstekingsreactie mits gekoelde HTK wordt gebruikt.

Daarna werden ook de effecten van de preservatie vloeisof Celsior onderzocht (hoofdstuk 5). Aangezien de concentratie anti-oxidanten in Celsior hoger is dan in HTK, verwachtten we meer gunstige effecten op preservatie van de microcirculatie in spierweefsel met deze vloeistof. Preischemische perfusie met Celsior leidde echter niet tot een verbetering van de capillaire perfusie na 4 of 6 uur ischemie. Integendeel, Celsior perfusie induceerde zelfs een verslechtering van de capillaire perfusie na de ischemische periode: de perfusie bleef laag tijdens de gehele reperfusie periode na 4 uur ischemie en verslechterde verder na 6 uur ischemie. Net als HTK had perfusie met Celsior wel een gunstig effect op de ontstekingsreactie na warme ischemie. Op grond van deze data lijkt HTK beter geschikt als preservatievloeistof voor spierweefsel dan Celsior, vooral wanneer het gunstige effect van HTK op de spierfunctie in overweging wordt meegenomen.

De cremasterspier van de rat werd in onze studies gebruikt als een model om de klinische transplantaties te simuleren. In geval van lange ischemie perioden (langer dan 6 uur), moet de spier echter daadwerkelijk uitgenomen, bewaard en getransplanteerd worden.

In de studie beschreven in hoofdstuk 6 werden de effecten van transplantatie en ischemie/reperfusie op de microcirculatie na langdurige preservatie in $\mathrm{HTK}\left(4^{\circ} \mathrm{C}\right)$ onderzocht. Cremaster spier transplantaties werden direct (zonder preservatie) uitgevoerd of na 8 of 24 uur preservatie in koude $\left(4^{\circ} \mathrm{C}\right)$ HTK of fysiologisch zout. Na directe transplantatie was de capillaire 
perfusie $90 \%$ van het controle niveau. Preservatie gedurende 8 uur in koude HTK of fysiologisch zout leidde niet tot een verminderde capillaire perfusie. $\mathrm{Na} 24$ uur preservatie in HTK $\left(4^{\circ} \mathrm{C}\right.$ ) was het aantal geperfundeerde capillairen nog steeds $80 \%$ van de controle waarden, terwijl dit niveau daalde tot $30 \%$ als de spieren 24 unr in fysiologisch zout bewaard werden. Als het weefsel echter 24 uur bewalard werd bij een temperatuur van $4^{\circ} \mathrm{C}$, was het aantal geperfundeerde capillairen hoger wanneer HTK als preservatie vloeistof werd gebruikt. Directe transplantatie leidde tot een geringe toename van leukocyt adhesie. Preservatie (gedurende 24 uur) in beide vloeistoffen leidde tot lagere bloedstroomsnelheden en oedeemvorming waardoor het meten van leukocytvaatwand interacties moeilijk en in veel gevallen onmogelijk was. Cremaster spier transplantaties waren succesvol en zelfs na preservatie gedurende 8 of 24 uur in koude HTK was er sprake van een goede capillaire perfusie.

Het veelvuldig gebruik van CTAs in de kliniek kan realiteit worden als het mogelijk is organen en weefsels gedurende een lange tijd te preserveren. Hiervoor is het noodzakelijk te weten welke mechanismen weefselschade veroorzaken, zodat een preservatie strategie ontwikkeld kan worden, waarmee genoemde weefselschade verminderd of voorkomen kan worden. Met het cremaster spier model (geïsoleerd op de vaatsteel) kan een transplantatie van een (humane) vrije lap nagebootst worden. Met behulp van dit model is het mogelijk om verschillende microvasculaire effecten van preservatie vloeistoffen en hypothermie bij ischemie/ reperfusie en transplantatie te onderzoeken.

Uit ons onderzoek kan geconcludeerd worden, dat de beste strategie om de microcirculatie in spierweefsel te preserveren afhangt van de duur van de ischemische periode. In geval van korte ischemie tijden (enkele uren) kan koeling voldoende protectie bieden tegen schadelijke effecten van reperfusie na transplantatie. Als er sprake is van langere ischemie tijd ( 24 uur) wordt het gebruik van koude HTK als preservatievloeistof angeraden, om de microcirculatie te preseveren en ook de functie van het weefsel in stand te houden. Aangezien spierweefsel -van alle weefsels die voorkomen in CTAshet meest gevoelig is voor de schadelijke effecten van ischemie en reperfusie, zou preservatie in koude HTK ook aangeraden kunnen worden voor CTAs preservatie wanneer sprake is van een lange ischemieduur.

Verder onderzoek naar effecten van preservatie vloeistoffen op de microcirculatie en de functie van grotere (humane) spieren na langere ischemische perioden kan in de toekomst mogelijk leiden tot frequenter toepassen van CTAs in de kliniek. 



\section{Dankwoord}

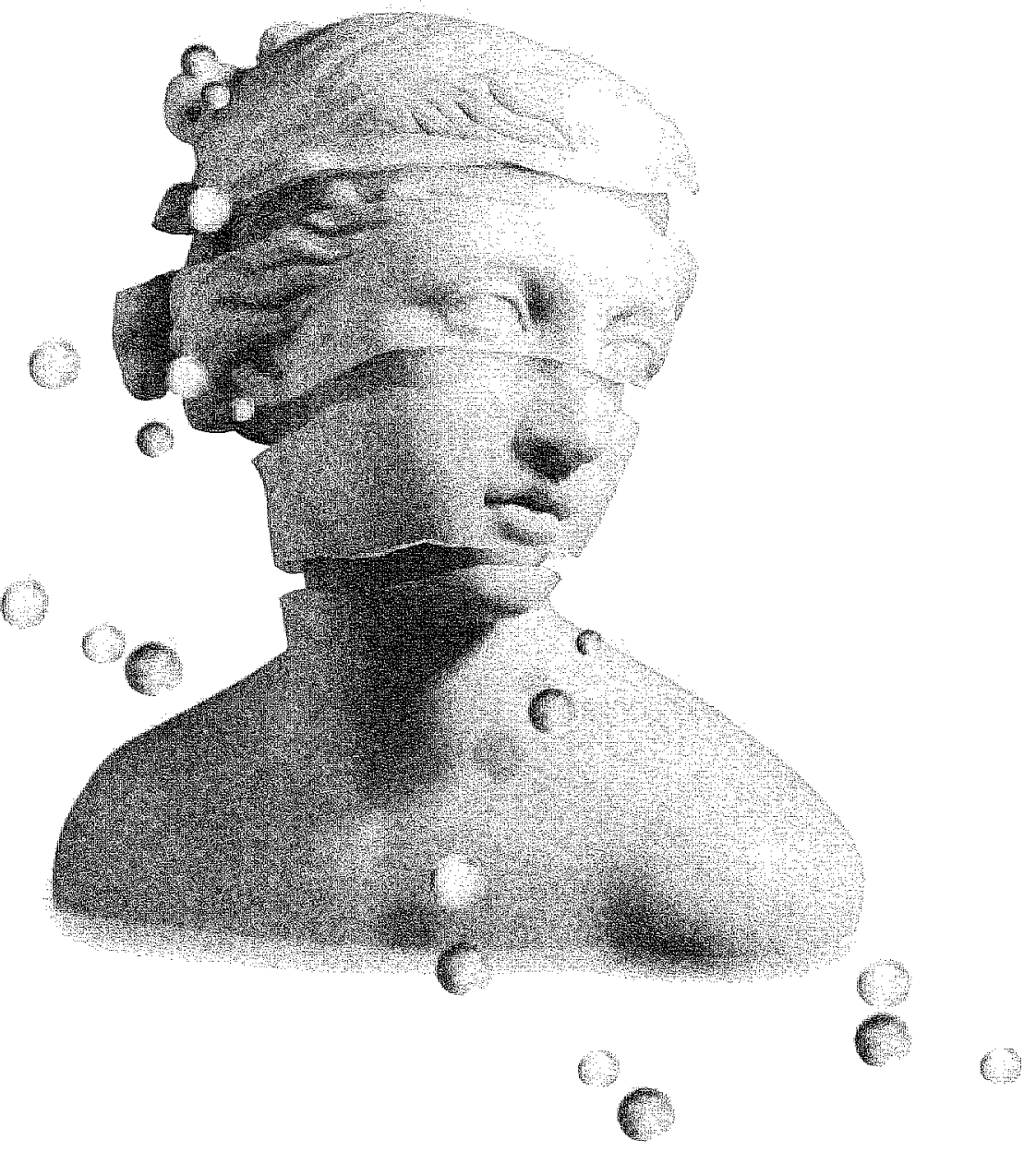


Vele mensen hebben bijgedragen aan de totstandkoming van dit proefschrift. Hiervoor wil ik iedereen hartelijk bedanken en ik wil een aantal mensen met name noemen. Na mijn afstuderen was ik werkzaam aan de afdelingen Thoraxchirurgie en Experimentele Cardiologie van het Hart Long Instituut (HLI) te Utrecht. Prof. J.J. Bredée en Prof.dr. C. Borst hebben ervoor gezorgd dat mijn wetenschappelijke interesse toenam en reeds in deze periode stond de microvasculaire anastomose centraal.

Prof.dr. M. Kon, promotor. Hartelijk dank dat u mij de mogelijkheid heeft geboden een microcirculatie lab in Utrecht op te zetten. Dankzij de samenwerking met microcirculatie laboratoria in Amsterdam (AMC), Louisville en Maastricht is dit gelukt en heeft het onderzoek geleid tot dit proefschrift.

Prof.dr. W.D. Boeckx, promotor. Ik heb in de kliniek erg veel van u geleerd met betrekking tot wondbehandeling en operatieve technieken. Ook was $\mathrm{u}$ altijd zeer enthousiast over onderzoek dat uitgevoerd werd in het microcirculatie laboratorium van de afdeling Fysiologie. Door u is mijn interesse in de microchirurgie nog verder toegenomen. Bedankt voor alles en ik hoop, dat er in de toekomst nog vele microchirurgie cursussen georganiseerd worden in Maastricht.

Prof.dr. D.W. Slaaf, promotor, beste Dick. Bij onze eerste ontmoeting in Orlando (Experimental Biology meeting) hebben we uitgebreid gesproken over methoden van het uitvoeren en weergeven van microcirculatie metingen. Ik wil je hartelijk bedanken voor alle begeleiding en adviezen voor het onderzoek uitgevoerd in Maastricht en Utrecht. Je was betrokken bij het uitvoeren van experimenten, data verwerking en analyse en ook nog de beschrijving van dit alles. We hebben veel discussies gevoerd en net als vele anderen zeg ik nu ook: hij heeft altijd gelijk.

Dr. M.G.A. oude Egbrink, co-promotor, beste Mirjam. Zonder jou was dit proefschrift er niet gekomen. Toen ik net in Maastricht was heb je me uitgenodigd om ook microcirculatie experimenten in het lab in Maastricht uit te voeren. Verder heb je ook direct aangeboden om naar de data van eerdere experimenten te kijken. Bij de eerste bespreking opperde je dat Dick waarschijnlijk interesse had in het bespreken/verklaren van de experimenten en zo is het eigenlijk begonnen. Ik ken niemand die zo grondig alle manuscripten leest en verbetert. Jouw deur stond altijd open, je had altijd tijd (zelfs 's avonds). Ik wil je hartelijk danken voor alles wat je gedaan hebt.

Dr. H.Vink, beste Hans. Jij bent degene met wie ik altijd alle data kon bespreken. Als ik het weer niet zag zitten, omdat bijvoorbeeld de 
leukocyten data een grote spreiding vertoonden, wees jij me erop dat de data consistent waren en "het dus klopte". Door deze besprekingen vond ik altijd weer de motivatie om toch verder te gaan met het onderzoek. Je komst naar Maastricht zorgt wellicht voor een voortzetting van de wetenschappelijke samenwerking...

Dr. G.L. Anderson, dear Gary. I would like to thank you for your advices and sharing your expertise regarding microcirculatory experiments in Louisville and Utrecht. It was a pleasure to work with you and it is a great honor that you are willing to visit Maastricht.

Alle experimenten beschreven in dit proefschrift zouden niet mogelijk zijn geweest zonder de uitstekende verzorging van de proefdieren door alle medewerkers van het GDL in Utrecht en het CPV in Maastricht.

Ik wil met name Merel Schurink, Cees Verlaan, Maringa Emons, Herman Koning, André Verheem, Hans Vosmeer, Jannie Visser-de Heus, Nico Attevelt, Kees Brandt, Anja vd Sar en Helma Avezaat van het GDL hartelijk danken. Verder wil ik Richard Frijnts en Peter Kelderman, Nadine Doorn en Marianne Prein van het CPV bedanken voor de samenwerking, ook als alles op het laatste moment weer geregeld moest worden.

Rik Mansvelt Beck, beste Rik. Ik wil je hartelijk danken voor alles wat je gedaan hebt. Bij ieder probleem waarvan ik niet wist hoe ik het moest oplossen, of wanneer ik dacht dat er nu echt geen andere mogelijkheden meer waren, zei jij: "ooooh, dat doe je gewoon zo!". Het "custom made cooling device" heeft uitstekend gefunctioneerd bij alle experimenten met hypotherme ischemie. Niet alleen je praktische vaardigheden worden gewaardeerd; ik denk ook met veel plezier terug aan alle persoonlijke gesprekken die we gevoerd hebben.

Met name mijn collega's hebben er altijd voor gezorgd dat ik met veel plezier naar mijn werk ging. Allereerst wil ik alle arts-assistenten en stafleden van de afdeling Thoraxchirurgie van het AZU (nu UMCU) en de collega's van de Experimentele Cardiologie hartelijk bedanken.

Mijn promotie onderzoek is gestart aan de afdeling Plastische Chirurgie te Utrecht. Ik wil Paul Werker hartelijk bedanken voor de begeleiding en het opzetten van het lab van de plastische chirurgie. Je was over veel zaken enthousiast en je hebt vanaf het begin gestimuleerd dat ik zo snell mogelijk natar Louisville zou gaan. Ik bewonder je wetenschappelijke interesse en je werk in de kliniek. Mijn eerste microvasculaire anastomose met afzonderlijke 
hechtingen heb ik samen met jou in "ons lab" gemaakt. Helaas was het leiden van het lab niet te combineren met de talrijke klinische activiteiten en heb je besloten hoofdzakelijk voor de kliniek te kiezen door naar Zwolle te gaan. Ik wil je heel veel succes wensen in Groningen, een logische volgende stap.

Ralph Franken heeft me de eerste cremasterpreparatie getoond. Beste Ralph, jouw enthousiasme werkt erg aanstekelijk (er is zoveel te doen in deze wereld...). Jij en Max Overgoor waren de eerste Dutch research fellows in Louisville en jullie waren allebei betrokken bij alle voorbereidingen. Bedankt voor alle waardevolle tips, de leuke gesprekken en de gezelligheid.

Ook alle andere collega's in de kliniek: Duco van den Broecke, Edwin Wijburg, Erik Borg en Erik Zonnevylle wil ik bedanken voor de gezelligheid in de kliniek. Hierdoor heb ik de uren alleen in het lab met een rat kunnen relativeren en zag dat de afstand tusssen lab en kliniek te overbruggen was. Beste Brigitte, ook al hebben we maar een korte periode samen in de kliniek gewerkt, je was altijd betrokken bij het onderzoek. In plaats van spierfunctie werd nu microcirculatie in het lab bestudeerd, maar ook hiervoor toonde je veel interesse. Miriam heeft het onderzoek verder voortgezet en ik vind het erg leuk dat nu microcirculatie en functionele studies gecombineerd worden. Miriam, ik wil je heel veel succes wensen bij de voortzetting van je onderzoek.

Ook de stafleden: Pascal Schellekens, Aveline Ackermans, Yvette Jonasse, Arnold Schuurman, Wilco Deenstra, Menso Carpentier Alting, Pien Schwencke en iedereen van het secretariaat: Bea Sopacua, Margreet Blokland en Angelique van Dijk, en Phil Buckley van de IT-afdeling wil ik hartelijk danken voor de prettige samenwerking.

Mijn collega's uit Maastricht hebben ervoor gezorgd, dat ik me in korte tijd helemaal thuis voelde in deze stad. Roel, Marleen, Lloyd, René, John, Harm, Gabriel, Rose, Marjoes, Iris, Howard, Darren, Stefania, Alice, Tom, Kim en Kim, Ewald, An, Edith allemaal heel erg bedankt voor de geweldige tijd in en buiten de kliniek. Ook José, Petra en Titia van het secretariaat en de dames van de polikliniek: Claudia, Debbie, Lilian en Kim hebben hieraan bijgedragen.

Toen ik net in Maastricht was, heeft Mirjam oude Egbrink me tijdens een Microcirculatiecongres uitgenodigd voor een bezoek aan het microcirculatie lab in Maastricht en zij heeft me ook direct in contact gebracht met Dick Slaaf. Hierdoor werd ik al snel opgenomen in het microcirculatie lab en kreeg ook een plekje in de AIO kamer. Hier heb ik 
het grootste deel van de tijd doorgebracht met Anita. Het was erg leuk om met een collega onderzoeker alles te kunnen bespreken. Ook nu we geen kamergenoten meer zijn, gaan de gesprekken gewoon verder. Verder wil ik alle andere kamergenoten, Miriam, Bram, Marc, Alex, Bianca, Bernhard en ook de "buren" Ward en Kevin bedanken en succes toewensen met het onderzoek. Dit geldt natuurlijk ook voor de andere collega's van de Fysiologie: Andries, Pascal, Richard, Tammo, Viviane, Geertje, Arne, Jos, Vivian en Sander. Sander, hartelijk dank dat je als Apple service point hebt opgetreden. Bij ieder probleem met computers of beeldvorming stond je direct klaar en was altijd bereid om iedereen direct te helpen. Nogmaals hartelijk dank hiervoor.

Verder wil ik iedereen van de afdelling Biofysica en Biochemie: Remco, Kim, Sietze, Marc, Wim, Marijke en Imke bedanken voor de prettige samenwerking, net als mijn collega's van de kliniek in Aken: Isabella, Paul, Timm, Dietmar, Natascha, Silvester, Marta, Thomas, Erhan, Andrzej, Thies, Kai, Dan, Andreas, Ahmet, Karsten en Seth, OK verpleging: Miranda, Mona, Pedro, Truus, Danny, Petra, Gerd, Marion \& Marion, verpleging van PC08 en PCUC (PC01), de pollikliniek: Monica, Ilse, Ingeborg, Sabine en Gerda, Werner en last but not least: Susanna. Vielen Dank!

De leden van beoordelingscommissie: Prof.dr. P.J.E.H.M. Kitslaar, Prof.dr. M.P. van Dieijen-Visser, Prof.dr. G. Kootstra, Prof.dr.dr. N. Pallua en Prof.dr. G.J. "Tangeller wil ik hartelijk bedanken voor de interesse en de tijd voor het kritisch doorlezen en beoordelen van dit proefschrift.

Beste Eric en John, hartelijk dank voor alle tijd en moeite die jullie gestoken hebben in dit proefschrift. Ook als ik op het laatste moment weer veranderingen wilde aanbrengen, bleven jullie positief en waren erwan overtuigd dat alles zou lukken en op tijd af zou zijn.

Speciale dank wil ik richten aan mijn wrienden en vriendinnen. Jullie waren er altijd en hadden overal begrip voor. Lieve Lilian, Carla, Fellery en Merel, we zijn begonnen als collega's en dit is uitgegroeid tot hechte vriendschap. Patricia, Marcelle, Vanessa, Mireille, Irma, Alina en Henry, hopelijk worden de tijden rustiger en kunnen we elkaar vaker zien. Marijke, jij was al ver voor de aanvang van het onderzoek beschreven in dit proefschrift overal bij betrokken en gelukkig hebben we elkaar in Maastricht weer ontmoet, alles gast gewoon verder. Bedankt voor alles. Cara Isabella, Mazzo. Come "Il Fiume" capisci tutto senza parole. Grazie mille. 
Beste Pascal en Ward, we hebben veel tijd samen doorgebracht tijdens onderzoek en daarnaast zijn jullie echte vrienden. Ik ben blij dat jullie mijn paranimfen willen zijn.

Tenslotte wil ik mijn familie, in het bijzonder Yvonne, hartelijk danken voor alle steun. Aan hen zeg ik het met woorden. 



\section{Curriculum Vitae}

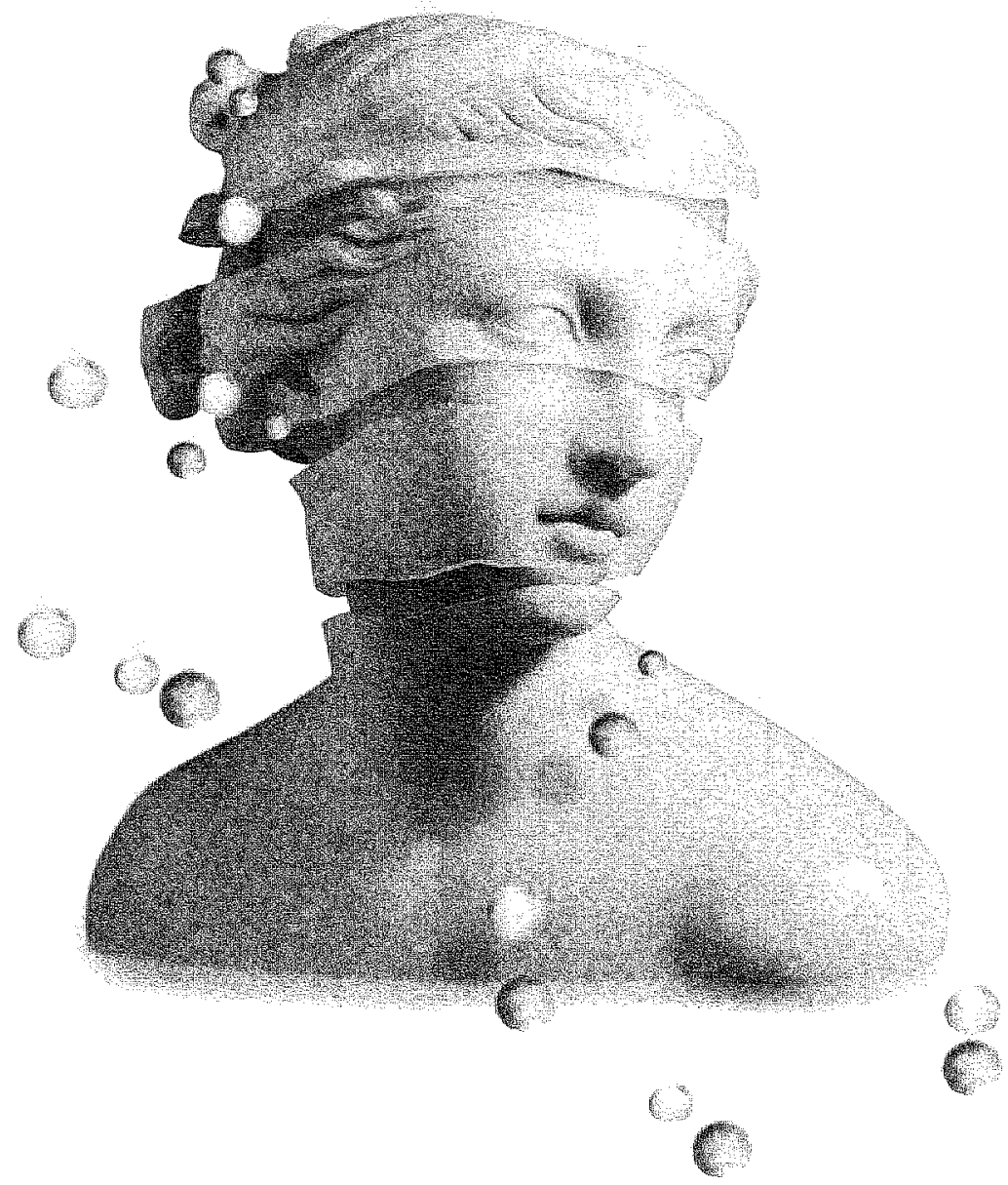




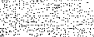

$+2$

$1+1$ मे

W

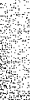

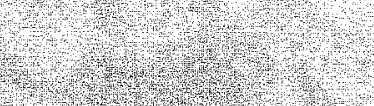

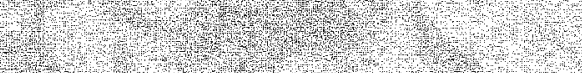

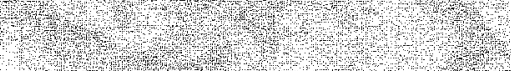

I.

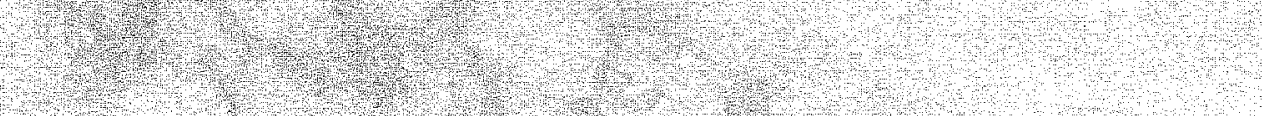

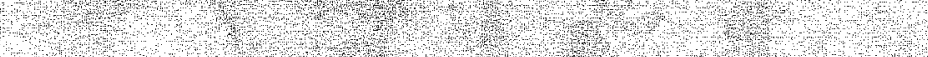

\begin{tabular}{lll}
1 \\
\hline
\end{tabular}

\begin{tabular}{lll}
\hline \\
\hline
\end{tabular}

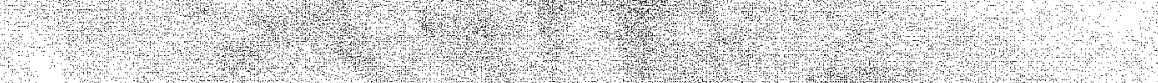

:

\&

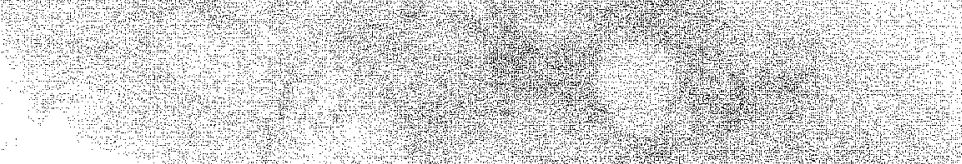

४ \begin{tabular}{lllllllll}
\hline \\
\hline
\end{tabular}

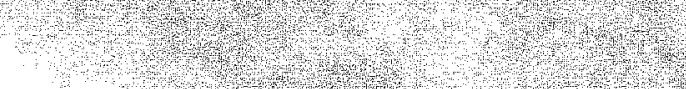

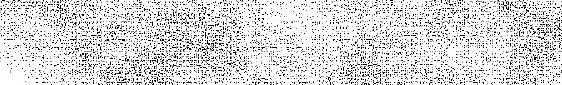

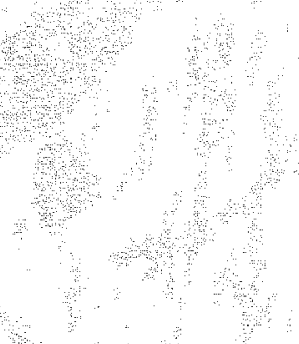

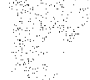

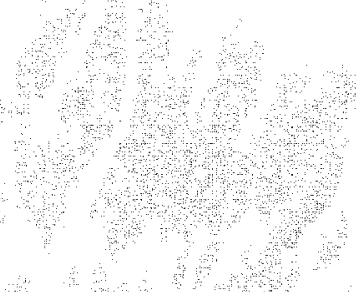
-1.2. +4. I. 
Jacqueline Bastiaanse was born on March 20,1971 in Weent, the Netherlands. In 1989 she graduated from highschool (Gymnasium B) at the Bisschoppelijk College in Weert. In 1990 she received her propaedeutic degree Biomedical Sciences and started Medical School at the University of Leiden. She graduated as medical doctor in 1997. In 1997 and 1998 she combined clinical work and research at the departments of Cardiac Surgery (head Prof.dr. J.J. Bredeé) and Experimental Cardiology (head Prof.dr. C. Borst) of the Heart Lung Institute at the Utrecht University Medical Center.

From 1.999 to 2002 she worked as a research fellow at the department of Plastic, Reconstructive and Hand Surgery at the Utrecht University Medical Center (head Prof.dr. M. Kon). She continued her research in the Laboratory for Microcirculation of the department of Physiology (Dr. M.G.A. oude Egbrink; in collaboration with Prof.dr. D.W. Slaaf, department of Biophysics). In august 2002 she started her clinical work at the department of Plastic, Reconstructive and Hand Surgery at the Maastricht University Hospital (head Prof.dr. W.D. Boeckx). Here she started her residency for Plastic Surgery. In 2005 the training program was continued at the University Hospital Aachen (head Prof.dr.dr. N. Pallua). 



\section{Publications}

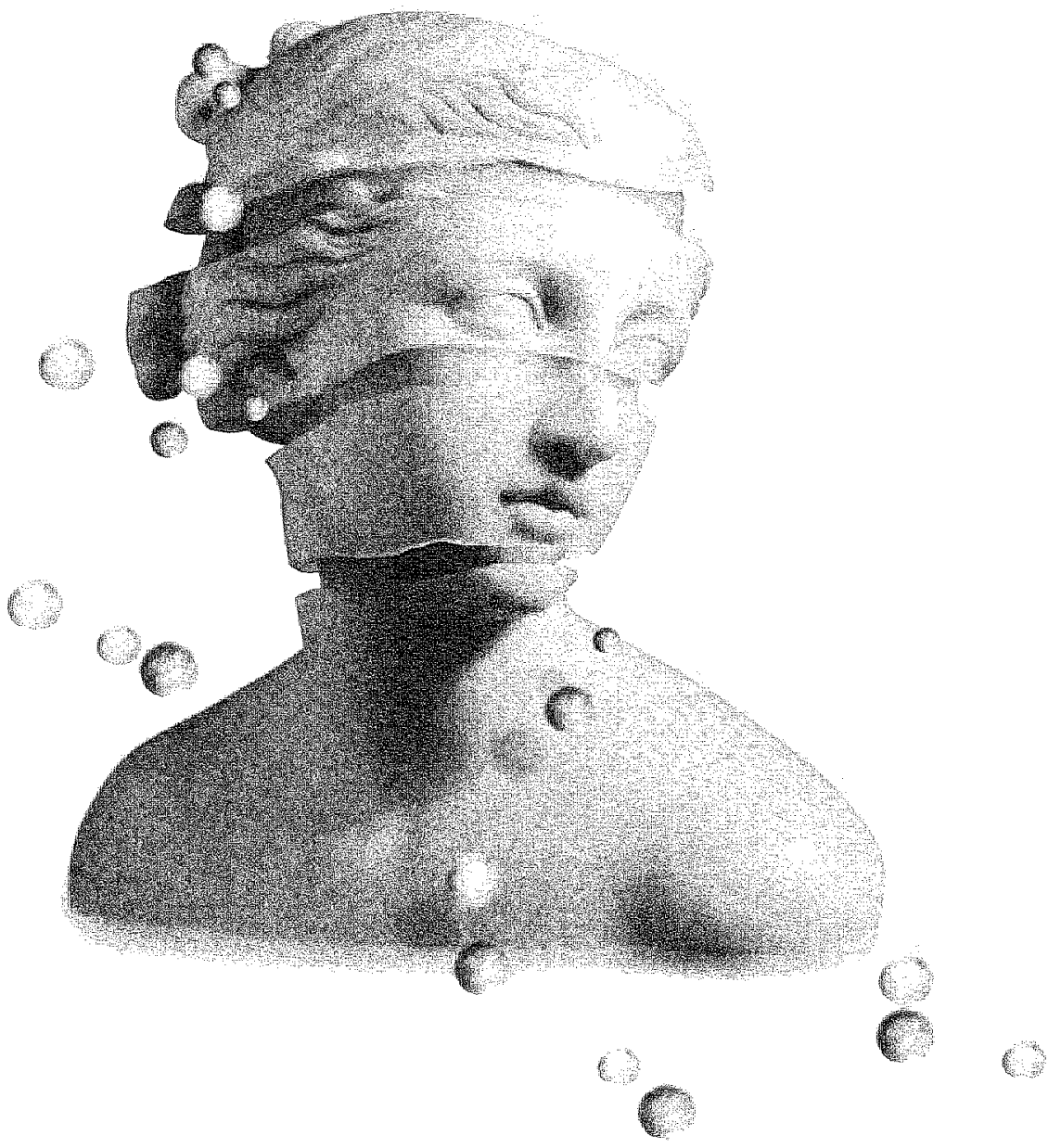





\section{PAPERS}

Bollen E, Wan Exel E, van der Velde EA, Buytels P, Bastanse J, van Dijk Jo. Saccadic eye movements in idopathic blepharospasm Mon Dison. 1996:11:678-32.

Bastianse J, Borst C, van der Helm YJ Loo KH, Gmudeman PF Arterotony closture by glued patch in the porcine carotid artery. Am Thorac Surg. $2000: 70: 1384-8$.

Bastianse J, Anderson GL. Franken RJ, wan der Heijden BE, oude Egbrink MO. Slat DW, Kon M. Effect of HTK on the microcinculation in the rat cremaster muscle during warm ischemia and repertusion. Microsugery. 2005;25:174-80.

Bastianse J, Slaaf DW, oude Egbrink MG, Anderson GL, Vink H, wan der Hejden BE, Kon M. Effect of bypothermia and HTK on the microcirculation in the rat cremaster muscle after ischaemia. Clin Sci (Lond). 2005;109:117-23.

Bastianse J, Slad DW, oude Egbrink MG. Boeckx WD, Kon M. Do preservation solutions protect rat cremaster nicrocinculation dung ischemiand andepertusion? J Sung Res. 2005:125:182-8.

Bastatnse J, Nanhekhan LV. Slad DW, Boeckx WD, oude Egbrink MG. Preserwtion of at cremaster muscle microcirculation after prolonged cold storage and transplantation. $\checkmark$ Sing Res. 2006:131:41-8.

\section{Abstracts}

Scheltes $\sharp$. Bastianse J, Pistecky $P$, Grindeman PF, Borst C: Technical considerations when using adhesives to repiace endoscopic suturing of arteries. Enopean Association for Endoscopic Sndgery, Linc. Austria 25-26 juni 1999: Abstreter vol. 1: 51 .

Bastiaanse I, Van der Heijden EPA, Franken RJPM, Anderson GL, Kon M. Perfusion of isolated cremaster muscle flap with preservation solutions in a modified model for intravial microscopy. Eur J Plast Surg. $2001: 24: 209$

Bastianse $₫$, Franken RJPM, Van der Hejon EPA. Anderson GL, Kon M: Perfusie van de geisoleerde cremasterspier in een gemodiliceerd model voo intravitale microscopie.

SEOHS, 17 November 2000 , Utrech: The Nether hands

Bastianse J, Van der Hejden EPA, Franken RJPM. Anderson GL, Kon M: Perfusion of isolated crentaster muscle haps with preservation solutions.

Nederlandse Verenging voor Microcirculatie ten Vasulaire Biologic. 2 Februaly 2001. Mastricht. The Netherinds 
Bastiaunse 1. Van der Heijden EPA, Franken RJPM, Anderson GL, Kon M: Microcirculatory responses to perfusion of isolated cremaster muscle flaps with preservation solutions.

FASEB, American Microcirculatory Sociefy, 30 March-1 April 2004, Orlando, FL, USA

Bastiaanse J, Van der Heijden EPA, Franken RJPM, Anderson GL, Kon M. Microcirculatory responses to perfusion of isolared cremaster muscle flaps with preservation solutions.

Eur Surtg Res. 2001.33 suppl 1

Bastiaanse J, Van der Heijden EPA, Anderson GL, Kon M. Effect of temperature and HTK on the microcirculation in the rat cremaster muscle.

IV Vasc Res. 2002;39 suppl I

Bastiaanse J, Van der Heijden EPA, Kon M, Boeckx WD: Effect of HTK and Celsior preservation solution on the microcirculation in the rat cremaster muscle. ECSAPS, 27-28 September 2002, Vienna, Austria

Bastiaanse I, Van der Heijden EPA, Kon M, Boeckx WD: Microcirculatory dysfunction following perfusion with preservation solutions.

FASEB, American Physiological Society, 11-15 April 2003, San Diego, CA, USA

Bastiannse J, Nanhekhan LV, Slaaf DW, Boeckx WD, oude Egbrink MGA Development of rat cremaster transplantation model for microscopic evaluation oll ischentia and a preservation solution on the microcirculation. Eir Surg Res. 2004;36 Suppl I

Bastiannse J, Slaaf DW, Nanhekhan LV, Boeckx WD, oude Egbrink MGA Rat cremaster muscle transplantation after cold storage: evaluation of capillary perfusion. I Vars Res 2004:41 suppl 2

Bastiamse J, Nanhakhan LV, Slaaf DW, oude Egbrink MGA, Boeckx WD. The ral cremuster free flap.

Angiogenesis\& microcimculation in flap surgery 12-13 November 2004. Homburg. Germatry.

Bastiaanse J, Nanhekhan LV, Slaaf DW, Boeckx WD, oude Egbrink MGA: Preservation of yat cremaster muscle microcirculation after prolonged cold storage and trimsplantation.

Experimental Biology 2005 with the XXXV fnternational Congress of Physisolengical Sciences. March 31-April 6 2005. Sin Diego, CA, USA

Bastianse J, Nanhekhar LV, Slaaf DW, Boeckx WD, oude Egbrink MGA: Transplantation of rat cremaster after prolonged cold storage: preservation of microcirculation.

ECSAPS, 16-17 September 2005. Leuven, Belgium 
Om vissen te vangen gebruiki men aas.

Heeft men de vis gevangen, dan kan men het aas vergeten.

Om konijnen te vangen gebruikt men een strik.

Heeft men komijnen gevangen darn kan men de strik vergeten.

Men gebruikt woorden om hun betekenis uit te drukken.

Wordt de betekenis verstaan, dan kunnen de woorden vergeten worden.

Warar wind ik een mens die woorden vergeet, opdat ik met hem praten kan"?

Tjoeang-Tje 